\title{
A Steady-state and Generational Evolutionary Algorithm for Dynamic Multiobjective Optimization
}

\author{
Shouyong Jiang and Shengxiang Yang, Senior Member, IEEE
}

\begin{abstract}
This paper presents a new algorithm, called steadystate and generational evolutionary algorithm, which combines the fast and steadily tracking ability of steady-state algorithms and good diversity preservation of generational algorithms, for handling dynamic multiobjective optimization. Unlike most existing approaches for dynamic multiobjective optimization, the proposed algorithm detects environmental changes and responds to them in a steady-state manner. If a change is detected, it reuses a portion of outdated solutions with good distribution and relocates a number of solutions close to the new Pareto front based on the information collected from previous environments and the new environment. This way, the algorithm can quickly adapt to changing environments and thus is expected to provide a good tracking ability. The proposed algorithm is tested on a number of bi- and three-objective benchmark problems with different dynamic characteristics and difficulties. Experimental results show that the proposed algorithm is very competitive for dynamic multiobjective optimization in comparison with stateof-the-art methods.
\end{abstract}

Index Terms-Steady-state and generational evolutionary algorithm, dynamic multiobjective optimization, change detection, change response.

\section{INTRODUCTION}

$\mathbf{M}$ ANY real-world multiobjective optimization problems (MOPs) are dynamic in nature, whose objective functions, constraints, and/or parameters may change over time. Due to the presence of dynamisms, dynamic MOPs (DMOPs) pose big challenges to evolutionary algorithms (EAs) since any environmental change may affect the objective vector, constraints, and/or parameters. As a result, the Pareto-optimal set (POS), which is a set of mathematical solutions to MOPs, and/or the Pareto-optimal front (POF) that is the image of POS in the objective space, may change over time. Then, the optimization goal is to track the moving POF and/or POS and obtain a sequence of approximations over time.

DMOPs can be defined in different ways, according to the nature of dynamisms [15], [41], [54]. In this paper, we mainly

Manuscript received November 13, 2015; revised March 7, 2016 and May 3, 2016; accepted May 10, 2016. This work was supported by the Engineering and Physical Sciences Research Council (EPSRC) of UK under Grant EP/K001310/1 (Corresponding author: Shengxiang Yang).

The authors are with the Centre for Computational Intelligence (CCI), School of Computer Science and Informatics, De Montfort University, Leicester LE1 9BH, U.K. (email: shouyong.jiang@email.dmu.ac.uk, syang@dmu.ac.uk).

This paper has supplementary downloadable material provided by the authors, which is available at http://ieeexplore.org. This supplementary material provides the formulation of the test problems used in the paper and some supplementary experimental results. This material is $102 \mathrm{~KB}$ in size.

Copyright (c) 2012 IEEE. Personal use of this material is permitted. However, permission to use this material for any other purposes must be obtained from the IEEE by sending a request to pubs-permissions@ieee.org. consider the following kind of DMOPs:

$$
\begin{array}{ll}
\min & F(x, t)=\left(f_{1}(x, t), \ldots, f_{M}(x, t)\right)^{T} \\
\text { s.t. } & \left\{\begin{array}{l}
h_{i}(x, t)=0, \quad i=1, \ldots, n_{h} \\
g_{i}(x, t) \geq 0, \quad i=1, \ldots, n_{g} \\
x \in \Omega_{x}, \quad t \in \Omega_{t}
\end{array}\right.
\end{array}
$$

where $M$ is the number of objectives, $n_{h}$ and $n_{g}$ are the number of equality and inequality constraints, respectively, $\Omega_{x} \subseteq R^{n}$ is the decision space, $t$ is the discrete time instance, $\Omega_{t} \subseteq R$ is the time space, and $F(x, t): \Omega_{x} \times \Omega_{t} \rightarrow R^{M}$ is the objective function vector that evaluates solution $x$ at time $t$.

In the past few years, there has been an increasing amount of research interest in the field of evolutionary multiobjective optimization (EMO) as many real-world applications, like thermal scheduling [42] and circular antenna design [3], have at least two objectives that conflict with each other, i.e., they are MOPs. Due to multiobjectivity, the goal of solving MOPs is not to find a single optimal solution but to find a set of trade-off solutions. When an MOP involves time-dependent components, it can be regarded as a DMOP. Many reallife problems in nature are DMOPs, such as planning [8], scheduling [12], [35], and control [15], [50]. There have been a number of contributions made to several important aspects of this field, including dynamism classification [15], [41], test problems [4], [15], [20], [23]-[26], performance metrics [9], [15], [17]-[19], [41], [55], and algorithm design [9], [12], [15], [18], [21], [28], [54], [55]. Among these, algorithm design is the most important issue as it is the problem-solving tool for DMOPs.

Due to the presence of dynamisms, the design of a dynamic multiobjective optimization EA (DMOEA) is different from that of a multiobjective optimization EA (MOEA) for static MOPs. Specifically, DMOEAs should not only have a fast convergence performance (which is crucial to their tracking ability), but also be able to address diversity loss whenever there is an environmental change in order to explore the new search space. Besides, if changes are not assumed to be knowable, DMOEAs should be able to detect them in order not to mislead the optimization process. This is because, when a change occurs, the previously discovered POS may not remain optimal for the new environment.

In principle, a change can be detected by re-evaluating dedicated detectors [12], [18], [47], [54], [55] or assessing algorithm behaviours [15], [32], [37]. The former is a easyto-use mechanism and allows "robust detection" [37] if a high enough number of detectors is used, but it may require additional cost since detectors have to be re-evaluated at every 
generation, and it may not be accurate when there is noise in function evaluations. The latter does not need additional function evaluations, but it may cause false positives and thus make algorithms overreacting when no change occurs. Both of them cannot guarantee that changes are detected [37].

On the other hand, whenever a change is detected, it is often inefficient to restart the optimization process from scratch, although the restart strategy may be a good choice if the environmental change is considerably severe [7]. In the literature, various approaches have been proposed to handle environmental changes, and they can be mainly categorized into diversity-based approaches and convergence-based approaches, according to their algorithm behaviours. Diversitybased approaches focus on maintaining population diversity whereas convergence-based ones aim to achieve a fast convergence performance so that algorithms' tracking ability are guaranteed. Generally, population diversity can be handled by increasing diversity using mutation of selected old solutions or random generation of some new solutions upon the detection of environmental changes [12], [18], [55], maintaining diversity throughout the optimization process [1], [2], [6], or employing multi-population schemes [18], [40]. Proper diversity is helpful for exploring promising search regions, but too much diversity may cause evolutionary stagnation [5].

Convergence-based approaches try to exploit past information for better tracking performance [7], especially when the new POS is somewhat similar to the previous one or environmental changes exhibit regular patterns. Accordingly, recording relevant past information to be reused at a later stage may be helpful for tracking the new POF as quickly as possible. The reuse of past information is closely related to the type of environmental change and hence can be helpful for different purposes [6]. If the environment changes periodically, relevant information of the current POS can be stored in a memory and can be directly re-introduced into the evolving population when needed. This kind of strategy is often called memory-based approaches and has been extensively studied in dynamic multiobjective optimization [7], [8], [18], [22], [52]. In contrast, if the environment change follows a regular pattern, past information can be collected and used to model the movement of the changing POF/POS. Hence, the location of the new POS can be predicted, helping the population quickly track the moving POF. Prediction-based approaches have received massive attention because most existing benchmark DMOPs (e.g., the FDA test suite [15]) involve predictable characteristics, and studies along this direction can be referred to [22], [28], [32], [33], [36], [47], [54], [55].

Aside from the above-mentioned approaches, some studies concentrate on finding an insensitive robust POF instead of closely tracking the moving POF [16], [27], [38]. Robustnessbased approaches assume that when the environment changes, the old obtained solution can still be used in the new environment as long as its quality is acceptable [27]. However, the criterion for an acceptable optimal solution is quite problemspecific, which may hinder the wide application of these approaches.

Although a number of approaches have been proposed for solving DMOPs, the development of DMOEAs is a relatively

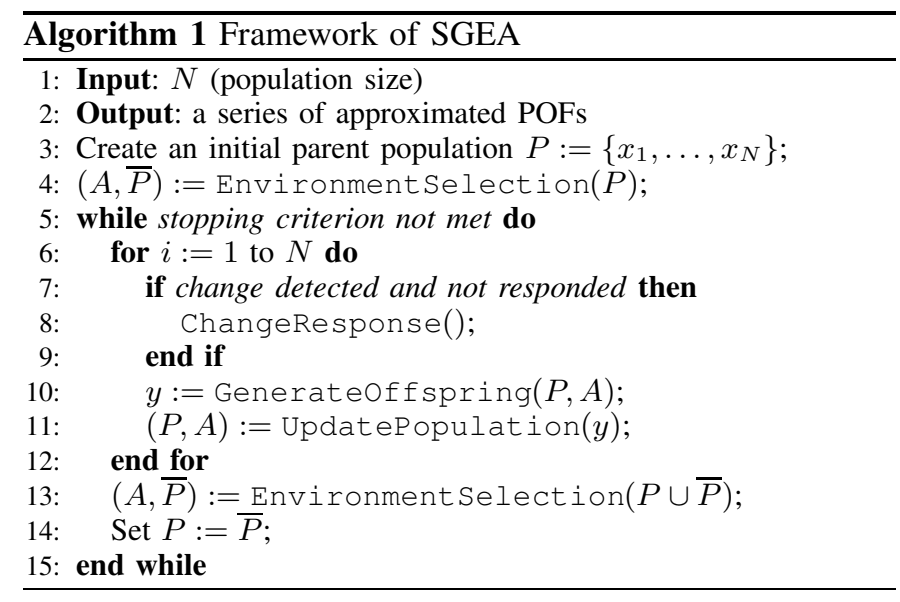

young field and more studies are greatly needed. In this paper, a new algorithm, called steady-state and generational EA (SGEA), is proposed for efficiently handling DMOPs. SGEA makes most of the advantages of steady-state EAs in dynamic environments [48] for environmental change detection and response. If a change is detected, SGEA reuses a portion of old solutions with good diversity and exploits information collected from both previous environments and the new environment to relocate a part of its evolving population. At the end of every generation, like conventional generational EAs [13], [56], SGEA performs environmental selection to preserve good individuals for the next generation. By mixing the steady-state and generational manners, SGEA can adapt to dynamic environments quickly whenever a change occurs, providing very promising tracking ability for DMOPs.

The rest of this paper is organized as follows. Section II describes the framework of the proposed SGEA, together with detailed descriptions of each component of the algorithm. Section III is devoted to presenting experimental settings for comparison. Section IV provides experimental results and comparison on tested algorithms. A further discussion of the algorithm is offered in Section V. Section VI concludes the paper with discussions on future work.

\section{PROPOSED SGEA}

The basic framework of the proposed SGEA is presented in Algorithm 1. SGEA starts with an initial population $P$ and the initialization of an elitist population $\bar{P}$ and an archive $A$ through environmental selection. In every generational cycle, SGEA detects possible environmental changes and evolves the population in a steady-state manner. For each population member, if a change is detected, then a change response mechanism is adopted to handle the detected change. After that, genetic operation is applied to produce one offspring solution for the population member, which is then used to update the parent population $P$ and archive $A$. At the end of each generation, $P$ and $\bar{P}$ are combined. Similar to generational EAs [13], [56] or speciation techniques used in niching [5], [29], a generational environmental selection is conducted on the combined population to preserve a population of good solutions for the next generation. This way, SGEA can be regarded as a steady-state and generational MOEA. In the 


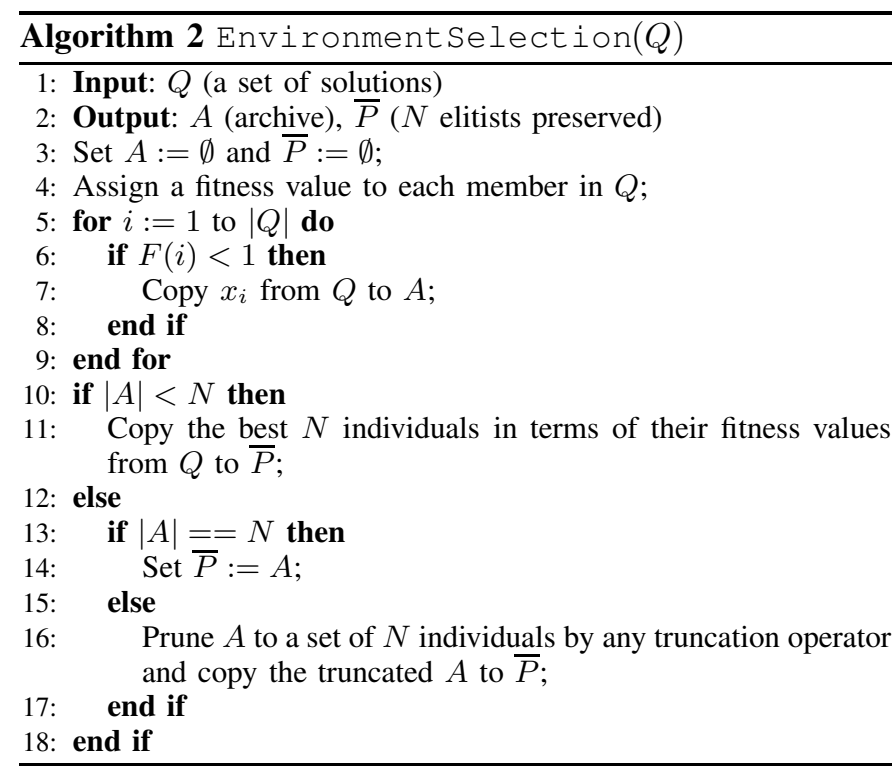

following subsections, the implementation of each component of SGEA will be detailed step by step.

\section{A. Environmental Selection}

The environmental selection procedure (Algorithm 2), which aims to preserve a fixed number of elitists from a solution set $Q$ after every generational cycle, starts with fitness assignment. Each individual $i$ of $Q$ is assigned a fitness value $F(i)$, which is defined as the number of individuals that dominate [56] it, as follows:

$$
F(i)=|\{j \in Q \mid j \prec i\}|
$$

where $|\cdot|$ denotes the cardinality of a set and $j \prec i$ indicates that $j$ dominates $i$. It should be noted that, various fine-grained methods proposed in the literature [14], [45], [56] can be used to assign fitness values for individuals. However, the fitness assignment method used in this paper is relatively simple and computationally efficient. Most importantly, when an external individual $e$ enters the set $Q$, the update of $F(i)$ needs only one dominance comparison between individuals $e$ and $i$. The easyto-update property of this method will be clearly embodied in the population update procedure (to be described in Section II-C).

Afterwards, individuals having a fitness value of zero are identified as nondominated solutions and then copied to an archive $A$. If $|A|$ is smaller than the population size $N$, the best $N$ individuals (including both dominated and nondominated ones) in terms of their fitness values are preserved in an elitist population $\bar{P}$. Otherwise, there can be two situations: either the number of nondominated solutions fits exactly the population size, or there are too many nondominated solutions. In the first case, all nondominated solutions are copied to $\bar{P}$. In the second case, a truncation technique is needed to reduce $A$ to a population of $N$ nondominated solutions such that the truncated $A$ have the best diversity possible. In SGEA, the $k$-th nearest neighbour truncation technique proposed in the strength Pareto EA 2 (SPEA2) [56] is used to perform the

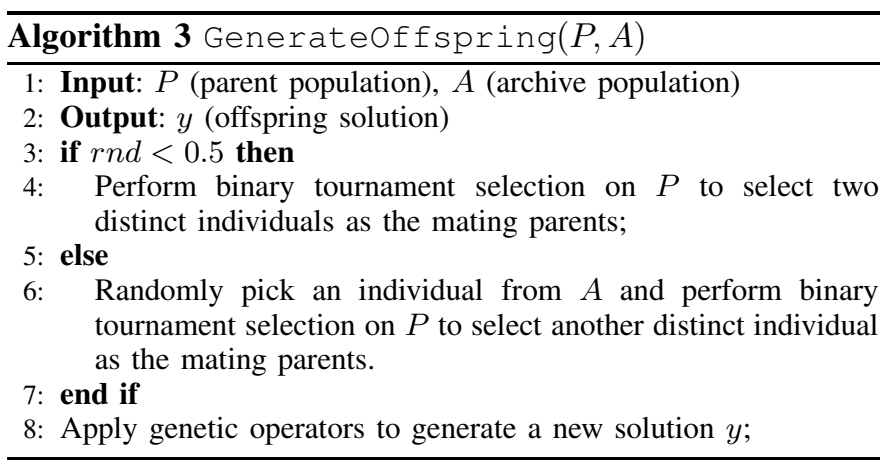

truncation operation, although we recognise there are other options, e.g., the farthest first method [10], [11], which can also serve this purpose. After that, solutions in the truncated $A$ are copied to $\bar{P}$.

Note that, like classical generational MOEAs, such as the nondominated sorting genetic algorithm II (NSGA-II) [13] and SPEA2 [56], SGEA performs environmental selection at the end of each generation. Thus, SGEA can be generally categorized into generational MOEAs.

\section{B. Mating Selection and Genetic Operators}

Mating selection is an important operation before the production of new offspring (line 10 of Algorithm 1). In this paper, mating parents can be selected either from the parent population $P$ or the archive population $A$. The benefit of such a mating selection method has been extensively investigated on static MOPs in a number of studies [30], [34], [44], [57]. While selecting mating parents from $P$ can maintain good population diversity, selecting parents from $A$ can significantly improve the convergence speed of the population, which is considerably desirable in fast-changing environments. If a mating parent is to be selected from $P$, SGEA performs a binary tournament selection according to individuals' fitness values. If not, the mating parent can be randomly selected from the archive population $A$.

Following the mating selection, genetic operators are applied on the mating parents to generate a new offspring solution. In SGEA, the simulation binary crossover and polynomial mutation are chosen as the recombination and mutation operators, respectively. The reproduction procedure is presented in Algorithm 3.

\section{Population Update}

In SGEA, population update (line 11 of Algorithm 1) is conducted on both the parent population $P$ and archive population $A$, which is detailed in Algorithm 4. The update operation on $P$ is in fact replacing the worst solution of $P$ with the newly generated solution $y$ while the update on $A$ is using $y$ to update the archived nondominated set. First, if $y$ is not a duplicate solution, it will be compared with each member $x_{i}$ of $P$ for the dominance relation (lines 4 to 14 of Algorithm 4). If $y$ dominates $x_{i}$ (denoted as $y \prec x_{i}$ ), the fitness value of $x_{i}$ is increased by one. If $y$ is dominated by $x_{i}$ (denoted as $y \succ x_{i}$ ), the fitness value of $y$ is increased by one. Then, the worst 


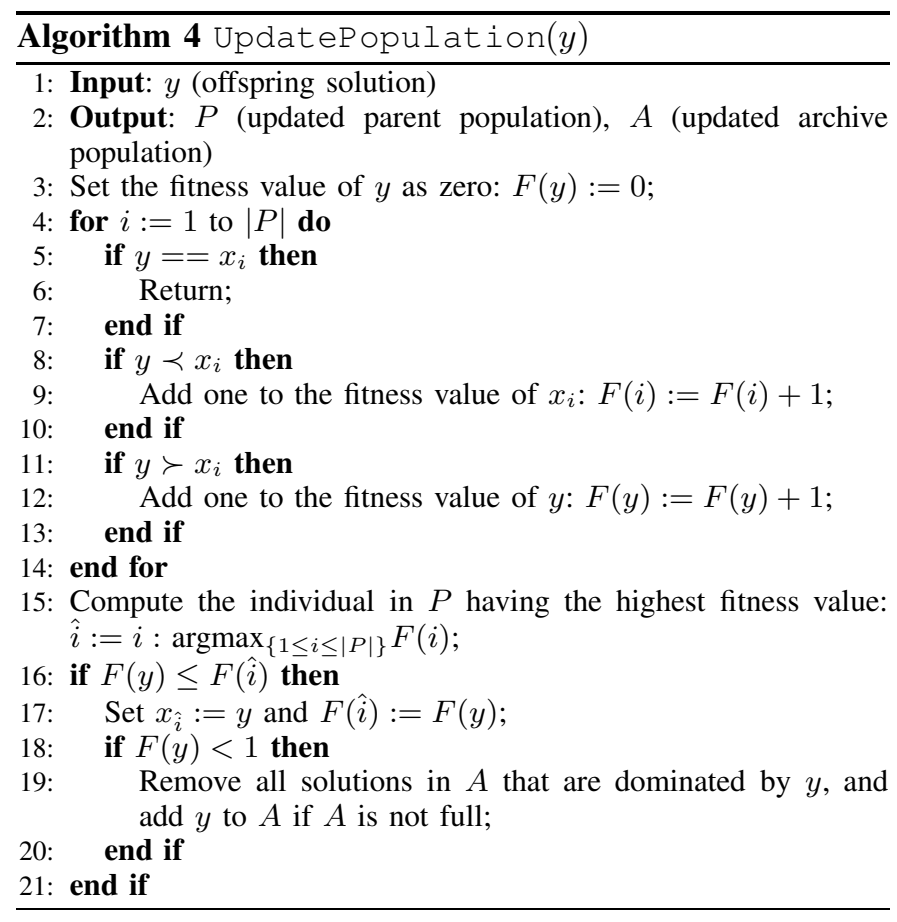

individual in $P$ with the highest fitness value is identified, and if there are two or more such individuals, a random one is selected. If $y$ is not worse than the identified individual $x_{\hat{i}}$ in terms of the fitness value, the solution replacement takes place, as shown in line 17 of Algorithm 4. Besides, if $y$ is not dominated by any member in $P$ (which means its fitness value is zero), it should be further considered to update the archive population $A$ if $A$ is not full. This means, the archive update occurs only when $y$ successfully enters the parent population. It can be observed that, the fitness assignment method used here is easy to update an individual's fitness value, which helps SGEA conduct solution replacement in the parent population and archive update in an efficient manner.

\section{Dynamism Handling}

This section discusses two main aspects of dynamism handling. One is change detection, a step to detect whether a change has occurs during the evolutionary process. The other is known as change response or change reaction, which takes actions to quickly react to environmental changes so that the population adapts to new environments rapidly.

1) Change Detection: Change detection can be performed by either re-evaluating a portion of existing solutions [12], [18], [47], [54], [55] or assessing some statistical information of some selected population members [15], [32], [37]. Since both methods choose a small proportion of population members as detectors, detection may fail if changes occur on nondetectors. On the contrary, it will be computationally expensive if the whole population members are chosen as detectors. Therefore, a good detection method should strike a balance between the detection ability and efficiency.

The proposed algorithm detects changes in a steady-state manner, as shown in line 7 of Algorithm 1. In every generation, population members (in random order) are checked one by one for discrepancy between their previous objective values and re-evaluated ones. If a discrepancy exists in a population member, we assume a change is successfully detected and there is no need to do further checks for the rest of population members. When a change is detected, SGEA immediately reacts to it in a steady-state manner. The detection method is beneficial to prompt and steady change reaction at the cost of high computational cost. For efficiency, the number of individuals re-evaluated for change detection is restricted to a small percentage of the population size. It is worth noting that, re-evaluation based change detection methods assume that there is no noise in function evaluations, i.e., they are not robust. Thus, the proposed method may not be suitable for detecting changes in noisy environments.

2) Change Response: If a change is successfully detected, some actions should be taken to react to the environmental change. A good change response mechanism must be able to maintain a good level of population diversity and relocate the population in promising areas that are close to the new POS. Simply discarding old solutions and randomly reinitializing the population is beneficial to population diversity but may be time-consuming for algorithms to converge. Likewise, fully reusing old solutions for the new environment might be misleading if the landscapes of two consecutive changes are significantly different. Also, this may cause the loss of population diversity. As a consequence, algorithms may get trapped into local minima or cannot find all POF regions for the new environment. For these reasons, in this paper the population for the new environment consists of half of old solutions and half of reinitialized solutions. The half old solutions are selected by the farthest first selection method [11], [43], which was originally proposed to reduce an approximation set to the maximum allowable size. The farthest first selection method has been reported to provide better approximation than NSGA-II's crowding distance [13] for unconstrained and constrained static MOPs [10], [11]. This method selects half of old solutions that maximize the diversity in the objective space (line 3 of Algorithm 5). The other half reinitialized solutions in the new population are produced by a guess of the new location of the changed POS. To make a correct or at least reasonable guess, one must know two things, i.e., moving direction and movement step-size. The following paragraphs contribute to how to compute them.

Let $C_{t}$ be the centroid of POS and $A_{t}$ be the obtained approximation set at time step $t$, then $C_{t}$ can be computed by:

$$
C_{t}=\frac{1}{\left|A_{t}\right|} \sum_{x \in A_{t}} x
$$

The movement step-size $S_{t}$ to the new location of the changed POS at time step $t+1$ can be estimated by:

$$
S_{t}=\left\|C_{t}-C_{t-1}\right\|
$$

where $S_{t}$ is actually the Euclidean distance between centroids $C_{t}$ and $C_{t-1}$.

The moving direction should be carefully elaborated to guide the population toward promising search regions. Otherwise, a completely wrong guess of the moving direction will 


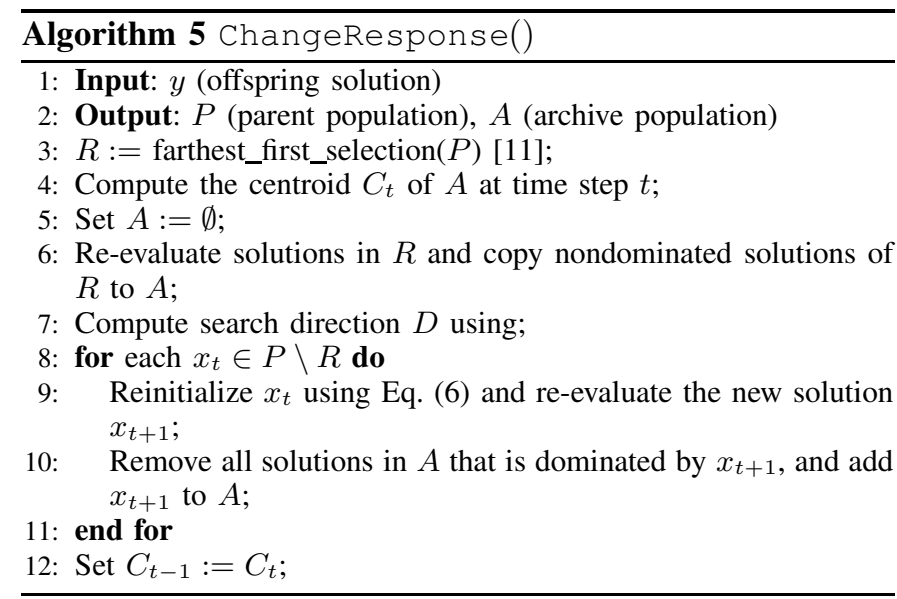

mislead the population and make it hard to converge. Bearing this in mind, we make use of half of the old solution set $R$ preselected by the farthest first selection [11] to compute the moving direction. First, The solutions in $R$ are re-evaluated, and nondominated solutions are saved in the pre-emptied archive $A$. Then, the moving direction can be calculated by:

$$
D=\frac{C_{A}-C_{R}}{\left\|C_{A}-C_{R}\right\|}
$$

where $C_{A}$ and $C_{R}$ are centroids of $A$ and $R$ in the decision space, respectively.

Having obtained the moving direction and movement stepsize, the other half population can be easily reinitialized. For each member $x_{t}$ in $P \backslash R$, its new location in the decision space is generated as follows:

$$
x_{t+1}=x_{t}+S_{t} D+\varepsilon_{t}
$$

where $\varepsilon_{t} \sim N\left(0, I \delta_{t}\right)$ is a Gaussian noise, added to increase the probability of the reinitialized population to cover the POS in the new environment. $I$ is an identity matrix and $\delta_{t}$ is the standard deviation in the Gaussian distribution. $\delta_{t}$ is defined by:

$$
\delta_{t}=\frac{S_{t}}{2 \sqrt{n}}
$$

where $S_{t}$ is the step-size defined in Eq. (4), and $n$ is the number of decision variables.

The overall change response procedure is presented in Algorithm 5. It is worthy noting that when the first environment change occurs, the computation of $C_{t-1}$ is not applicable. In this situation, randomly reinitialization is employed for the generation of solutions in $P \backslash R$. As long as the centroids of the approximation sets of two consecutive environments are available, the above reinitialization method can be adopted.

It should be mentioned that, our proposed reinitialization method is somewhat predictive but in some sense beyond prediction. Prediction approaches usually collect only history information to predict future events. However, our method exploits both the information of previous environments and that of the new environment to reinitialize a portion of solutions, which we would like to call "guided" solutions because their relocation are guided by an estimate of the performance of the reused old solutions in the new environment. Therefore, this method may be helpful for quickly tracking the changing environment if the estimate of the new environment is reliable. It is worth mentioning that, the guided reinitialization method implicitly assumes that a change does not affect too much the relative positions between solutions in the POS. It may fail in case of a notable violation of the assumption. In this situation, The proposed method may need to work with other population reinitialization techniques in order to produce good tracking performance.

\section{E. Computational Complexity of One Generation of SGEA}

In the for loop (lines 6 to 12 in Algorithm 1) of each generation, computational resources are mainly consumed by the offspring reproduction, population update and environmental selection procedures, and other procedures need less computational cost. The generation of an offspring solution (line 10 of Algorithm 1) requires $O(M)$ computations, where $M$ is the number of objectives. The population update procedure (line 11 of Algorithm 1) takes $O(M N)$, where $N$ is the population size. Thus, the whole steady-state evolution part takes $O\left(M N^{2}\right)$ computations. The environmental selection procedure (line 13 of Algorithm 1) spends $O\left(M N^{2}\right)$ computations on fitness assignment and on average $O\left(N^{2} \log N\right)$ computations [56] on elitist preservation. Therefore, the overall computational complexity of SGEA for one generational cycle is $O\left(M N^{2}\right)$ or $O\left(N^{2} \log N\right)$, whichever is larger. It should be noted that, in fast-changing environments, the run-time complexity of environmental selection might rarely reach $O\left(N^{2} \log N\right)$ as individuals usually are unlikely well-converged (obtaining excessive nondominated solutions) within very limited response time.

\section{EXPERIMENTAL DESIGN}

\section{A. Test Problems}

Twenty-one test problems, including five FDA [15] problems, three dMOP [18] problems, six ZJZ problems (F5F10) [54], and seven UDF [4] problems, are used to assess our proposed algorithm in comparison with other algorithms. The time instance $t$ involved in these problems is defined as $t=\frac{1}{n_{t}}\left\lfloor\frac{\tau}{\tau_{t}}\right\rfloor$ (where $n_{t}, \tau_{t}$, and $\tau$ represent the severity of change, the frequency of change, and the iteration counter, respectively). The definition of these problems can be found in the supplementary material of this paper. Note that, some problems have been modified to implement our experiments, and most of the test problems have periodical changes.

\section{B. Compared Algorithms}

Four popular DMOEAs are used for comparison in our empirical studies. They are the MOEA based on decomposition (MOEA/D) [51], dynamic version of NSGA-II (DNSGA-II) [12], dCOEA [18], and PPS [54], representing different classes of metaheuristics. The following gives a brief description of each compared algorithm.

1) MOEA/D: as a representative of decomposition-based algorithms, MOEA/D [51] converts a mutiobjective problem by aggregation functions into a number of 
single-objective subproblems and optimizes them simultaneously. MOEA/D maintains population diversity by the diversity of subproblems, and a fast convergence can be achieved by defining a neighbourhood for each subproblem and performing mating selection and solution update within this neighbourhood. Due to these features, MOEA/D has gained increasing popularity in recent years and has become a benchmark algorithm in static multiobjective optimization. In this paper, the modified version of the weighted Tchebycheff approach used in [49] is adopted as the aggregation function for MOEA/D because it has been recently proved to provide better distribution than its original version. Also, a limited number $n_{r}$ of solutions will be replaced by any new solution, as suggested in [31].

2) DNSGA-II: it is a dynamic version of the popular NSGA-II algorithm [13], which is a representative of Pareto-dominance based MOEAs. To make it suitable for handling dynamic optimization problems, Deb et al. [12] adapted NSGA-II by replacing some population members with either randomly created solutions or mutated solutions of existing solutions if a change occurs. While the former may perform better in environments with severe changes, the latter may work well on DMOPs with moderate changes. In our experiment, the latter method is adopted as it shows slightly better performance than the former in the study of [12].

3) dCOEA: it hybridizes competitive and cooperative mechanisms observed in nature to solve static MOPs and to track the changing POF in a dynamic environment [18]. dCOEA uses a fixed number of archived solutions to detect changes, and if detected, its competitive mechanism will be started to assess the potential of existing information of various subpopulations. To increase diversity after a change, dCOEA also introduces stochastic solutions into the competitive pool. Besides, dCOEA uses an additional external population to store useful but outdated archived solutions, hoping to help the evolving population quickly adapt to the new environment by exploiting these history information. It has been shown that dCOEA is very promising for handling dynamic environments [18], [24].

4) PPS: it is a representative of prediction-based methods that model the movement track of the POF or POS in dynamic environments and then use this model to predict the new location of POS. In PPS [54], the POS information is divided into two parts: the population centre and manifold. Based on the archived population centres over a number of continuous time steps, PPS employs a univariate autoregression model to predict the next population centre. Likewise, previous manifolds are used to predict the next manifold. When a change occurs, the initial population for the new environment is created from the predicted centre and manifold. PPS has been proved to be very competitive for dynamic optimization when it is incorporated with an estimation of distribution algorithm [53], and it outperforms other predictive models [54].

\section{Performance Metric}

In our experimental studies, we adopt the following performance metrics, as they can help deeply investigate algorithms' performance regarding convergence, distribution, and diversity.

1) Inverted Generational Distance (IGD): The IGD [49], [50], [54] measures both the convergence and diversity of found solutions by an algorithm. Let $P O F$ be a set of uniformly distributed points in the true $\mathrm{POF}$, and $P O F^{*}$ be an approximation of the POF. The IGD is calculated as follows:

$$
I G D=\frac{1}{n_{P O F}} \sum_{i=1}^{n_{P O F}} d_{i}
$$

where $n_{P O F}=|P O F|, d_{i}$ is the Euclidean distance between the $i$ th member in $P O F$ and its nearest member in $P O F^{*}$.

2) Schott's Spacing Metric (S): Schott [39] developed this kind of metric with regard to the distribution of the discovered Pareto front. $\mathrm{S}$ measures how evenly the members in $P O F^{*}$ are distributed, and is computed as:

$$
S=\sqrt{\frac{1}{n_{P O F^{*}}-1} \sum_{i=1}^{n_{P O F^{*}}}\left(D_{i}-\bar{D}\right)^{2}}
$$

where $D_{i}$ is the Euclidean distance between the $i$ th member in $P O F^{*}$ and its nearest member in $P O F^{*}$ and $\bar{D}$ is the average value of $D_{i}$.

3) Maximum Spread (MS): The MS [17] measures to what extent the obtained $\mathrm{POF}^{*}$ covers $P O F$ :

$$
M S=\sqrt{\frac{1}{M} \sum_{k=1}^{M}\left[\frac{\min \left[\overline{P O F_{k}}, \overline{P O F_{k}^{*}}\right]-\max \left[\underline{P O F_{k}}, \underline{P O F_{k}^{*}}\right]}{\overline{P O F_{k}}-\underline{P O F_{k}}}\right]_{(10)}^{2}}
$$

where $\overline{P O F_{k}}$ and $P O F_{k}$ are the maximum and minimum of the $k$ th objective in $\overline{P O F}$, respectively; Similarly, $\overline{P O F_{k}^{*}}$ and $P O F_{k}^{*}$ are the maximum and minimum of the $k$ th objective in $P O F^{*}$, respectively.

4) Hypervolume Difference (HVD): The HVD [55] measures the gap between the hypervolume of the obtained $P O F^{*}$ and that of the true $P O F$ :

$$
H V D=H V(P O F)-H V\left(P O F^{*}\right)
$$

where $H V(S)$ is the hypervolume of a set $S$. The reference point for the computation of hypervolume is $\left(z_{1}+0.5, z_{2}+\right.$ $\left.0.5, \cdots, z_{M}+0.5\right)$, where $z_{j}$ is the maximum value of the $j$-th objective of the true POF and $M$ is the number of objectives.

\section{Parameter Settings}

The parameters of the MOEAs considered in the experiment were referenced from their original papers. Some key parameters in these algorithms were set as follows:

1) Population size: The population size $(N)$ for all the test problems was set to 100 . To make MOEA/D have 100 subproblems for three-objective FDA4 and FDA5, we first uniformly generate around 1000 weight vectors using the simplex-lattice design [51], then prune them to 100 using the farthest first method [10], [11].

2) Parameter settings for SGEA: These parameters were set to the same values in all the compared algorithms. 
TABLE I

MEAN AND STANDARD DEVIATION VALUES OF SP METRIC OBTAINED B Y FIVE ALGORITHMS

\begin{tabular}{|c|c|c|c|c|c|c|}
\hline Prob. & $\left(\tau_{t}, n_{t}\right)$ & DNSGA-II & dCOEA & PPS & MOEA/D & SGEA \\
\hline \multirow{3}{*}{ FDA1 } & & $2.5421 \mathrm{E}-2(2.5497 \mathrm{E}-3)^{\ddagger}$ & $3.3966 \mathrm{E}-2(2.6330 \mathrm{E}-3)^{\ddagger}$ & $6.1386 \mathrm{E}-2(1.6514 \mathrm{E}-2)^{\ddagger}$ & $4.6542 \mathrm{E}-1(1.4472 \mathrm{E}-1)^{\ddagger}$ & $1.3267 \mathrm{E}-2(1.1095 \mathrm{E}-3)$ \\
\hline & $(10,10)$ & $1.0136 \mathrm{E}-2(7.4361 \mathrm{E}-3)^{\ddagger}$ & $1.8316 \mathrm{E}-2(1.4011 \mathrm{E}-3)^{\ddagger}$ & $1.7072 \mathrm{E}-2(6.5312 \mathrm{E}-3)^{\ddagger}$ & $4.8939 \mathrm{E}-1(1.9408 \mathrm{E}-1)^{\ddagger}$ & 7.5411E-3(5.8178E-4) \\
\hline & $(20,10)$ & $6.7495 \mathrm{E}-3(7.3732 \mathrm{E}-4)^{\ddagger}$ & $8.9615 \mathrm{E}-3(7.8094 \mathrm{E}-4)^{\ddagger}$ & $5.7913 \mathrm{E}-2(1.6129 \mathrm{E}-2)^{\ddagger}$ & $3.5391 \mathrm{E}-1(1.6524 \mathrm{E}-1)^{\ddagger}$ & $3.9986 \mathrm{E}-3(2.5969 \mathrm{E}-4)$ \\
\hline \multirow{3}{*}{ FDA2 } & $(5,10)$ & $7.6448 \mathrm{E}-3(3.1834 \mathrm{E}-4)$ & $2.7693 \mathrm{E}-2(3.9466 \mathrm{E}-3)^{\mp}$ & $2.4594 \mathrm{E}-2(6.0101 \mathrm{E}-3)^{\ddagger}$ & $1.8142 \mathrm{E}-2(2.8950 \mathrm{E}-2)^{\ddagger}$ & 9.4054E-3(1.6736E-3) \\
\hline & $(10,10)$ & $5.3715 \mathrm{E}-3(3.3796 \mathrm{E}-4)$ & $1.5614 \mathrm{E}-2(2.8655 \mathrm{E}-3)^{\ddagger}$ & $1.7122 \mathrm{E}-2(3.9192 \mathrm{E}-3)^{\ddagger}$ & $1.5625 \mathrm{E}-2(2.4152 \mathrm{E}-2)^{\ddagger}$ & $6.5871 \mathrm{E}-3(8.7753 \mathrm{E}-4)$ \\
\hline & $(20,10)$ & $5.0340 \mathrm{E}-3(1.3246 \mathrm{E}-4)^{\dagger}$ & $8.0937 \mathrm{E}-3(2.0835 \mathrm{E}-3)^{\ddagger}$ & $1.8392 \mathrm{E}-2(4.0463 \mathrm{E}-3)^{\ddagger}$ & $1.0903 \mathrm{E}-2(4.8363 \mathrm{E}-3)^{\ddagger}$ & 4.9516E-3(4.9187E-4) \\
\hline \multirow{3}{*}{ FDA3 } & $(5,10)$ & $1.7052 \mathrm{E}-2(2.3120 \mathrm{E}-3)$ & $3.3698 \mathrm{E}-2(1.6310 \mathrm{E}-2)^{\dagger}$ & $5.2045 \mathrm{E}-2(9.7887 \mathrm{E}-3)^{\ddagger}$ & $8.3517 \mathrm{E}-2(4.6837 \mathrm{E}-2)^{\mp}$ & $3.1669 \mathrm{E}-2(4.1347 \mathrm{E}-3)$ \\
\hline & $(10,10)$ & 1.1167E-2(1.9011E-3) & $1.7698 \mathrm{E}-2(9.1874 \mathrm{E}-3)$ & $1.6536 \mathrm{E}-2(4.1971 \mathrm{E}-3)$ & $4.6011 \mathrm{E}-2(1.8288 \mathrm{E}-2)^{\ddagger}$ & $2.4160 \mathrm{E}-2(1.8298 \mathrm{E}-3)$ \\
\hline & $(20,10)$ & 8.2268E-3(1.7859E-3) & $1.2049 \mathrm{E}-2(6.1286 \mathrm{E}-3)$ & $9.0478 \mathrm{E}-3(2.0861 \mathrm{E}-3)$ & $2.9416 \mathrm{E}-2(8.6135 \mathrm{E}-3)^{\ddagger}$ & $2.2741 \mathrm{E}-2(9.9650 \mathrm{E}-4)$ \\
\hline \multirow{3}{*}{ FDA4 } & $(5,10)$ & $1.2706 \mathrm{E}-1(5.5003 \mathrm{E}-3)^{\ddagger}$ & $5.9217 \mathrm{E}-2(4.6346 \mathrm{E}-3)$ & $1.0232 \mathrm{E}-1(9.7961 \mathrm{E}-3)^{\dagger}$ & $1.8035 \mathrm{E}-1(3.2800 \mathrm{E}-2)^{\ddagger}$ & $8.7427 \mathrm{E}-2(7.6848 \mathrm{E}-3)$ \\
\hline & $(10,10)$ & $9.1659 \mathrm{E}-2(3.8467 \mathrm{E}-3)^{\ddagger}$ & 3.8658E-2(3.2771E-3) & $6.0989 \mathrm{E}-2(1.0643 \mathrm{E}-2)^{\ddagger}$ & $1.6494 \mathrm{E}-1(2.9433 \mathrm{E}-2)^{\ddagger}$ & 4.1252E-2(2.9737E-3) \\
\hline & $(20,10)$ & $5.5146 \mathrm{E}-2(2.1395 \mathrm{E}-3)^{\ddagger}$ & $2.7830 \mathrm{E}-2(1.5839 \mathrm{E}-3)^{\dagger}$ & $4.8519 \mathrm{E}-2(2.9057 \mathrm{E}-3)^{\ddagger}$ & $1.6572 \mathrm{E}-1(2.5986 \mathrm{E}-2)^{\ddagger}$ & $2.5354 \mathrm{E}-2(2.8502 \mathrm{E}-3)$ \\
\hline \multirow{3}{*}{ FDA5 } & $(5,10)$ & $1.5306 \mathrm{E}-1(5.0947 \mathrm{E}-3)^{\ddagger}$ & $9.9019 \mathrm{E}-2(8.8149 \mathrm{E}-3)^{\ddagger}$ & $1.4717 \mathrm{E}-1(1.1045 \mathrm{E}-2)^{\ddagger}$ & $1.5505 \mathrm{E}-1(1.4762 \mathrm{E}-2)^{\ddagger}$ & 8.2228E-2(4.2364E-3) \\
\hline & $(10,10)$ & $1.1245 \mathrm{E}-1(3.9588 \mathrm{E}-3)^{\ddagger}$ & $6.3211 \mathrm{E}-2(4.8740 \mathrm{E}-3)^{\ddagger}$ & $1.0820 \mathrm{E}-1(8.7265 \mathrm{E}-3)^{\ddagger}$ & $1.2839 \mathrm{E}-1(1.5067 \mathrm{E}-2)^{\ddagger}$ & $4.5009 \mathrm{E}-2(2.6441 \mathrm{E}-3)$ \\
\hline & $(20,10)$ & $8.0300 \mathrm{E}-2(2.3006 \mathrm{E}-3)^{\ddagger}$ & $4.9950 \mathrm{E}-2(3.1582 \mathrm{E}-3)^{\ddagger}$ & $8.6349 \mathrm{E}-2(4.1808 \mathrm{E}-3)^{\ddagger}$ & $1.0497 \mathrm{E}-1(7.8394 \mathrm{E}-3)^{\ddagger}$ & $3.0379 \mathrm{E}-2(6.7640 \mathrm{E}-4)$ \\
\hline \multirow{3}{*}{ dMOP1 } & $(5,10)$ & $5.3389 \mathrm{E}-3(7.8416 \mathrm{E}-4)^{\ddagger}$ & $8.4983 \mathrm{E}-2(5.2562 \mathrm{E}-3)^{\ddagger}$ & $1.0375 \mathrm{E}-1(7.8713 \mathrm{E}-2)^{\ddagger}$ & $4.1207 \mathrm{E}-2(1.1779 \mathrm{E}-1)^{\ddagger}$ & 3.4712E-3(5.4488E-4) \\
\hline & $(10,10)$ & $5.5311 \mathrm{E}-3(1.3101 \mathrm{E}-3)^{\ddagger}$ & $1.5696 \mathrm{E}-2(9.5712 \mathrm{E}-3)^{\ddagger}$ & $2.5068 \mathrm{E}-2(2.4719 \mathrm{E}-2)^{\ddagger}$ & $5.6413 \mathrm{E}-2(2.0924 \mathrm{E}-1)^{\ddagger}$ & 2.7029E-3(3.0835E-4) \\
\hline & $(20,10)$ & $5.2961 \mathrm{E}-3(2.7514 \mathrm{E}-4)^{\ddagger}$ & $6.3031 \mathrm{E}-3(6.6072 \mathrm{E}-4)^{\ddagger}$ & $1.4722 \mathrm{E}-2(2.0239 \mathrm{E}-2)^{\ddagger}$ & $2.6844 \mathrm{E}-2(8.1479 \mathrm{E}-2)^{\ddagger}$ & $2.5010 \mathrm{E}-3(2.5768 \mathrm{E}-4)$ \\
\hline \multirow{3}{*}{ dMOP2 } & $(5,10)$ & $1.6538 \mathrm{E}-2(1.7941 \mathrm{E}-3)^{\ddagger}$ & $6.0455 \mathrm{E}-2(2.1579 \mathrm{E}-3)^{\ddagger}$ & $2.7767 \mathrm{E}-2(4.5722 \mathrm{E}-3)^{\ddagger}$ & $1.4701 \mathrm{E}-1(5.3676 \mathrm{E}-2)^{\ddagger}$ & $1.3177 \mathrm{E}-2(1.4569 \mathrm{E}-3)$ \\
\hline & $(10,10)$ & $1.0690 \mathrm{E}-2(5.3335 \mathrm{E}-4)^{\ddagger}$ & $3.0587 \mathrm{E}-2(3.9867 \mathrm{E}-3)^{\ddagger}$ & $1.1608 \mathrm{E}-2(2.7373 \mathrm{E}-3)^{\ddagger}$ & $1.4459 \mathrm{E}-1(5.3516 \mathrm{E}-2)^{\ddagger}$ & $6.6710 \mathrm{E}-3(5.8584 \mathrm{E}-4)$ \\
\hline & $(20,10)$ & $6.2086 \mathrm{E}-3(1.9806 \mathrm{E}-4)^{\ddagger}$ & $1.4253 \mathrm{E}-2(1.7038 \mathrm{E}-3)^{\ddagger}$ & $6.2807 \mathrm{E}-3(1.1104 \mathrm{E}-3)^{\ddagger}$ & $1.4322 \mathrm{E}-1(6.6231 \mathrm{E}-2)^{\ddagger}$ & $3.9175 \mathrm{E}-3(2.9561 \mathrm{E}-4)$ \\
\hline \multirow{3}{*}{ dMOP3 } & $(5,10)$ & $1.4393 \mathrm{E}-2(1.2499 \mathrm{E}-3)^{\ddagger}$ & $3.3786 \mathrm{E}-2(5.5519 \mathrm{E}-3)^{\ddagger}$ & $2.7518 \mathrm{E}-2(4.8871 \mathrm{E}-3)^{\ddagger}$ & $2.7281 \mathrm{E}-2(2.2967 \mathrm{E}-2)^{\ddagger}$ & $9.5664 \mathrm{E}-3(9.9353 \mathrm{E}-4)$ \\
\hline & $(10,10)$ & $8.1655 \mathrm{E}-3(6.5231 \mathrm{E}-4)^{\ddagger}$ & $1.5418 \mathrm{E}-2(1.0978 \mathrm{E}-3)^{\ddagger}$ & $1.6453 \mathrm{E}-2(2.3904 \mathrm{E}-3)^{\ddagger}$ & $1.2555 \mathrm{E}-2(2.0652 \mathrm{E}-3)^{\ddagger}$ & $5.4336 \mathrm{E}-3(6.0751 \mathrm{E}-4)$ \\
\hline & $(20,10)$ & $5.3930 \mathrm{E}-3(5.5912 \mathrm{E}-4)^{\ddagger}$ & $7.3129 \mathrm{E}-3(3.9782 \mathrm{E}-4)^{\ddagger}$ & $1.1264 \mathrm{E}-2(1.7604 \mathrm{E}-3)^{\ddagger}$ & $9.9081 \mathrm{E}-3(1.4603 \mathrm{E}-3)^{\ddagger}$ & 4.2793E-3(5.3812E-4) \\
\hline
\end{tabular}

Specifically, the crossover probability was $p_{c}=1.0$ and its distribution index was $\eta_{c}=20$. The mutation probability was $p_{m}=1 / n$ and its distribution $\eta_{m}=20$. The archive size was the same as the population size.

3) Stopping criterion and the number of executions: Each algorithm terminates after a pre-specified number of generations and should cover all possible changes. To minimize the effect of static optimization, we gave 50 generations for each algorithm before the first change occurs. The total number of generations was set to $3 n_{t} \tau_{t}+50$, which ensures there are $3 n_{t}$ changes during the evolution. Additionally, each algorithm was executed 30 independent times on each test instance.

4) The neighbourhood size and the number $n_{r}$ of solutions allowed to replace in MOEA/D were set to 20 and 2, respectively.

5) For all the algorithms, the maximum $10 \%$ population members were chosen for change detection. For the steady-state MOEA/D, it used the same change detection mechanism as SGEA, and population re-evaluation for change response.

6) The number of uniformly sampled points on the true POF was set to 500 and 990 for the computation of IGD for bi- and three-objective problems, respectively.

\section{EXPERIMENTAl Results AND ANALYsis}

\section{A. Results on FDA and dMOP Problems}

To study the impact of change frequency on algorithms' ability in dynamic environments, the severity of change $\left(n_{t}\right)$ was fixed to 10 , and the frequency of change $\left(\tau_{t}\right)$ was set to 5,10 , and 20, respectively. The obtained average SP, MS, IGD, and HVD results over a series of time windows and their standard deviation values are presented in Tables I, II, III, and IV, respectively, where the best values obtained by one of five algorithms are highlighted in bold face. The Wilcoxon ranksum test [46] is carried out to indicate significance between different results at the 0.05 significance level.

It can be observed from Table I that SGEA obtains the best results on the majority of the tested FDA and dMOP instances, implying that it maintains better distribution of its approximations over changes than the other compared algorithms in most cases. However, it performs slightly worse than DNSGA-II for FDA2 and FDA3, and dCOEA for FDA4 with fast changes (i.e., $\tau_{t}=5$ and 10). For all the tested instances, both PPS and MOEA/D fail to show encouraging performance on the SP metric, and MOEA/D seems struggling for maintaining a uniform distribution of its obtained POF for dynamic optimization, as indicated by the large SP values in Table I.

As shown in Table II, the results on the MS metric are quite divergent. DNSGA-II and SGEA obtain a spread coverage for FDA2, FDA4, and FDA5, although DNSGA-II provides slightly better MS values than SGEA. For problems FDA1, FDA3, and dMOP2, SGEA significantly outperforms the other algorithms by a clear margin in terms of the MS metric. PPS and MOEA/D cover the POF very well for two threeobjective problems, i.e., FDA4 and FDA5, and all the algorithms perform similarly on dMOP1 except dCOEA, whose MS values are not very competitive in this case. To have a better understanding of how algorithms' MS performance can be affected by different dynamisms, we discuss a little bit more on FDA3 and dMOP3. FDA3 is a problem in which environmental changes shift the POS and affect the density of points on the POF whereas dMOP3 is a problem where 
TABLE II

MEAN AND STANDARD DEVIATION VALUES OF MS METRIC OBTAINED BY FIVE ALGORITHMS

\begin{tabular}{|c|c|c|c|c|c|c|}
\hline Prob. & $\left(\tau_{t}, n_{t}\right)$ & DNSGA-II & dCOEA & PPS & MOEA/D & SGEA \\
\hline \multirow{3}{*}{ FDA1 } & $(5,10)$ & $6.8875 \mathrm{E}-1(6.9604 \mathrm{E}-2)^{\ddagger}$ & $8.6361 \mathrm{E}-1(2.5899 \mathrm{E}-2)^{\ddagger}$ & $8.7571 \mathrm{E}-1(3.3122 \mathrm{E}-2)^{\ddagger}$ & $8.2378 \mathrm{E}-1(2.2483 \mathrm{E}-2)^{\ddagger}$ & $9.3411 \mathrm{E}-1(3.2794 \mathrm{E}-2)$ \\
\hline & $(10,10)$ & $9.2689 \mathrm{E}-1(1.9129 \mathrm{E}-2)^{\ddagger}$ & $8.9378 \mathrm{E}-1(2.2115 \mathrm{E}-2)^{\ddagger}$ & $9.6555 \mathrm{E}-1(1.2319 \mathrm{E}-2)^{\ddagger}$ & $9.2142 \mathrm{E}-1(1.6053 \mathrm{E}-2)^{\ddagger}$ & $9.7277 \mathrm{E}-1(1.0854 \mathrm{E}-2)$ \\
\hline & $(20,10)$ & $9.8453 \mathrm{E}-1(2.1657 \mathrm{E}-3)^{\dagger}$ & $9.2981 \mathrm{E}-1(1.2003 \mathrm{E}-2)^{\ddagger}$ & $9.8426 \mathrm{E}-1(4.8155 \mathrm{E}-3)^{\dagger}$ & $9.6140 \mathrm{E}-1(8.4959 \mathrm{E}-3)^{\ddagger}$ & $9.8810 \mathrm{E}-1(6.2816 \mathrm{E}-3)$ \\
\hline \multirow[t]{2}{*}{ FDA2 } & $(10,10)$ & $9.9730 \mathrm{E}-1(2.6637 \mathrm{E}-3)^{\dagger}$ & $8.7511 \mathrm{E}-1(2.9208 \mathrm{E}-2)^{\ddagger}$ & $9.3410 \mathrm{E}-1(1.2746 \mathrm{E}-2)^{\ddagger}$ & $9.6362 \mathrm{E}-1(2.5629 \mathrm{E}-2)^{\ddagger}$ & $9.9308 \mathrm{E}-1(3.3464 \mathrm{E}-3)$ \\
\hline & $(20,10)$ & $9.9786 \mathrm{E}-1(1.9825 \mathrm{E}-3)$ & $9.1688 \mathrm{E}-1(3.2152 \mathrm{E}-2)^{\ddagger}$ & $9.3897 \mathrm{E}-1(7.2423 \mathrm{E}-3)^{\ddagger}$ & $9.7535 \mathrm{E}-1(1.8048 \mathrm{E}-2)^{\ddagger}$ & 9.9342E-1(2.6409E-3) \\
\hline FDA3 & $(5,10)$ & $6.3387 \mathrm{E}-1(1.1045 \mathrm{E}-1)^{\ddagger}$ & $5.0510 \mathrm{E}-1(4.5498 \mathrm{E}-2)^{\mp}$ & $6.0036 \mathrm{E}-1(3.4102 \mathrm{E}-2)^{\ddagger}$ & $7.3593 \mathrm{E}-1(9.3637 \mathrm{E}-2)^{\ddagger}$ & 8.8834E-1(8.9085E-2) \\
\hline \multirow{3}{*}{ FDA4 } & $(5,10)$ & 9.9999E-1(3.2759E-6) ${ }^{\dagger}$ & $9.6390 \mathrm{E}-1(7.4777 \mathrm{E}-3)^{\ddagger}$ & $9.9823 \mathrm{E}-1(7.5711 \mathrm{E}-4)^{\ddagger}$ & $9.9999 \mathrm{E}-1(2.1721 \mathrm{E}-6)^{\dagger}$ & 9.9997E-1(1.9039E-5) \\
\hline & $(10,10)$ & $1.0000 \mathrm{E}+0(7.8284 \mathrm{E}-7)$ & $9.7421 \mathrm{E}-1(6.0289 \mathrm{E}-3)^{\ddagger}$ & $9.9903 \mathrm{E}-1(1.2185 \mathrm{E}-4)^{\ddagger}$ & $9.9999 \mathrm{E}-1(8.5330 \mathrm{E}-7)$ & 9.9995E-1(2.6230E-5) \\
\hline & $(20,10)$ & $1.0000 \mathrm{E}+0(3.0455 \mathrm{E}-7)$ & $9.8552 \mathrm{E}-1(2.3528 \mathrm{E}-3)^{\ddagger}$ & $9.9904 \mathrm{E}-1(9.8111 \mathrm{E}-5)^{\ddagger}$ & $1.0000 \mathrm{E}+0(2.6739 \mathrm{E}-7)$ & $9.9992 \mathrm{E}-1(2.5034 \mathrm{E}-5)$ \\
\hline \multirow{3}{*}{ FDA5 } & $(5,10)$ & 9.9999E-1(2.0403E-6) & $9.3043 \mathrm{E}-1(3.7021 \mathrm{E}-2)^{\ddagger}$ & $9.9758 \mathrm{E}-1(2.6961 \mathrm{E}-3)$ & $9.9866 \mathrm{E}-1(3.2365 \mathrm{E}-3)$ & $9.9442 \mathrm{E}-1(8.0786 \mathrm{E}-3)$ \\
\hline & $(10,10)$ & $1.0000 \mathrm{E}+0(4.3629 \mathrm{E}-7)$ & $9.5871 \mathrm{E}-1(3.5891 \mathrm{E}-2)^{\ddagger}$ & $9.9781 \mathrm{E}-1(3.8432 \mathrm{E}-3)^{\ddagger}$ & $9.9995 \mathrm{E}-1(1.4197 \mathrm{E}-4)$ & $9.9949 \mathrm{E}-1(7.9814 \mathrm{E}-4)$ \\
\hline & $(20,10)$ & $1.0000 \mathrm{E}+0(7.6916 \mathrm{E}-8)$ & $9.7908 \mathrm{E}-1(1.9611 \mathrm{E}-2)^{\ddagger}$ & $9.9955 \mathrm{E}-1(1.7863 \mathrm{E}-4)^{\dagger}$ & $9.9999 \mathrm{E}-1(7.9466 \mathrm{E}-7)$ & 9.9993E-1(5.9215E-5) \\
\hline dMOP2 & $(20,10)$ & $9.8039 \mathrm{E}-1(3.2935 \mathrm{E}-2)^{\ddagger}$ & $9.0203 \mathrm{E}-1(1.6144 \mathrm{E}-2)^{\ddagger}$ & $9.7464 \mathrm{E}-1(2.6993 \mathrm{E}-3)^{\ddagger}$ & $9.5552 \mathrm{E}-1(5.9188 \mathrm{E}-3)^{\ddagger}$ & $9.9251 \mathrm{E}-1(1.4628 \mathrm{E}-3)$ \\
\hline \multirow{3}{*}{ dMOP3 } & $(5,10)$ & $4.3016 \mathrm{E}-1(2.2614 \mathrm{E}-2)^{\ddagger}$ & 8.7837E-1(2.1444E-2) & $8.5479 \mathrm{E}-1(1.3831 \mathrm{E}-2)$ & $5.0950 \mathrm{E}-1(3.1263 \mathrm{E}-2)^{\dagger}$ & 4.9760E-1(2.2063E-2) \\
\hline & $(10,10)$ & 5.3193E-1(2.1894E-2 $)^{\dagger}$ & 9.1097E-1(1.1716E-2) & 8.8793E-1(9.6772E-3) & $6.3606 \mathrm{E}-1(1.8266 \mathrm{E}-2)$ & 5.7573E-1(2.9590E-2) \\
\hline & $(20,10)$ & $6.2492 \mathrm{E}-1(1.9883 \mathrm{E}-2)^{\ddagger}$ & 9.4844E-1(1.1052E-2) & $9.0666 \mathrm{E}-1(9.4326 \mathrm{E}-3)$ & 7.7993E-1(1.9421E-2) & 6.8486E-1(2.9571E-2) \\
\hline
\end{tabular}

TABLE III

MEAN AND STANDARD DEVIATION VALUES OF IGD METRIC OBTAINED B Y FIVE ALGORITHMS

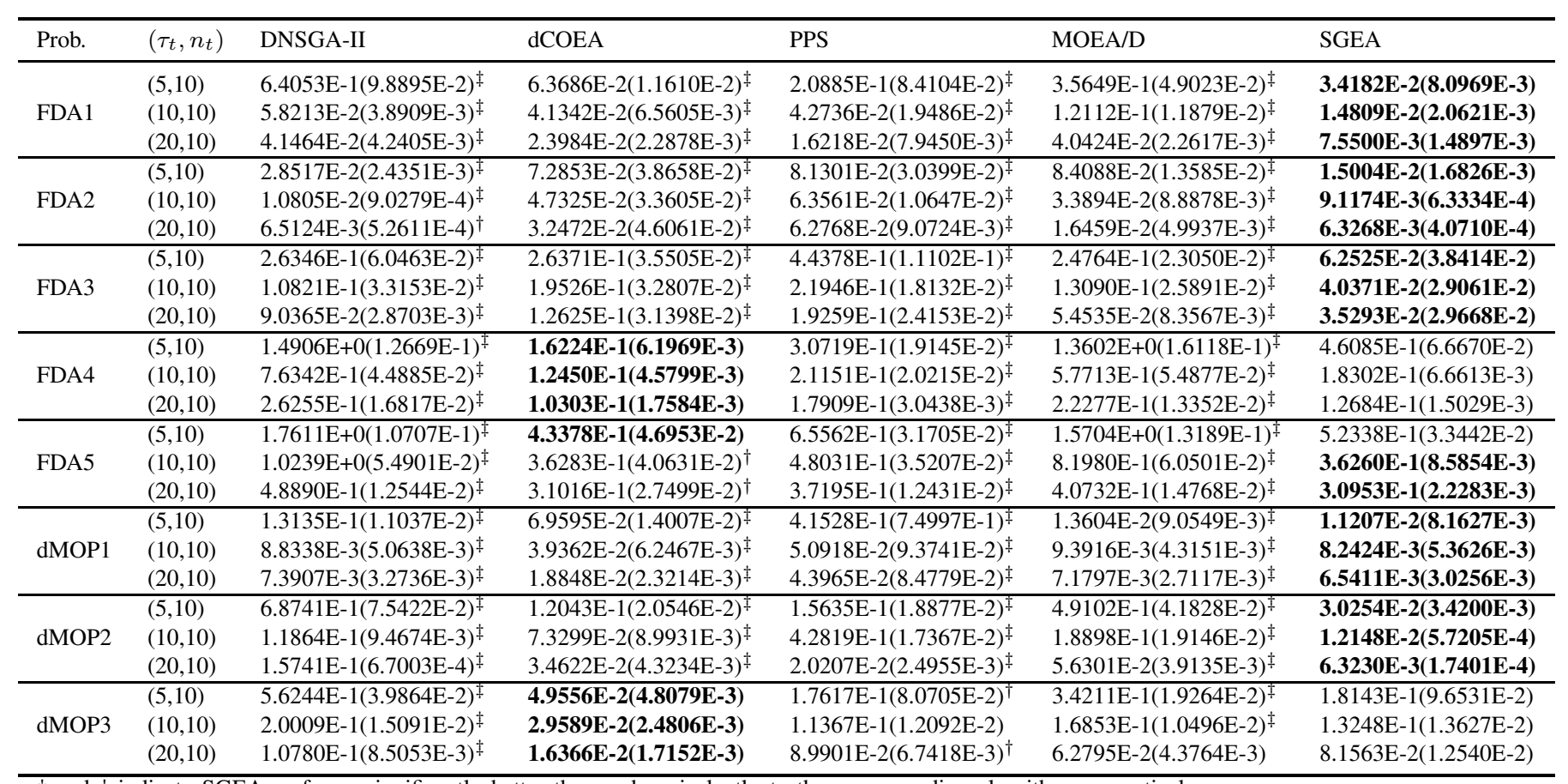

$\ddagger$ and $\dagger$ indicate SGEA performs significantly better than and equivalently to the corresponding algorithm, respectively.

the population diversity can decrease dramatically. The results of MS show that, for FDA3, SGEA can maintain a good coverage of the POF when the other algorithms perform poorly. However, this is not the case for $\mathrm{dMOP} 3$, where only dCOEA and PPS are able to distribute their obtained solutions widely on the POF. This means that the change response mechanisms in DNSGA-II, MOEA/D, and SGEA may face big challenges when dynamisms drastically aggravate population diversity.

Since the IGD metric mainly depends on the closeness, distribution, and coverage of an approximation to the true POF, we can use IGD together with SP and MS to deeply and extensively reveal the algorithms' performance on the test instances. Table III clearly shows that, SGEA performs the 
TABLE IV

MEAN AND STANDARD DEVIATION VALUES OF HVD METRIC OBTAINED BY FIVE ALGORITHMS

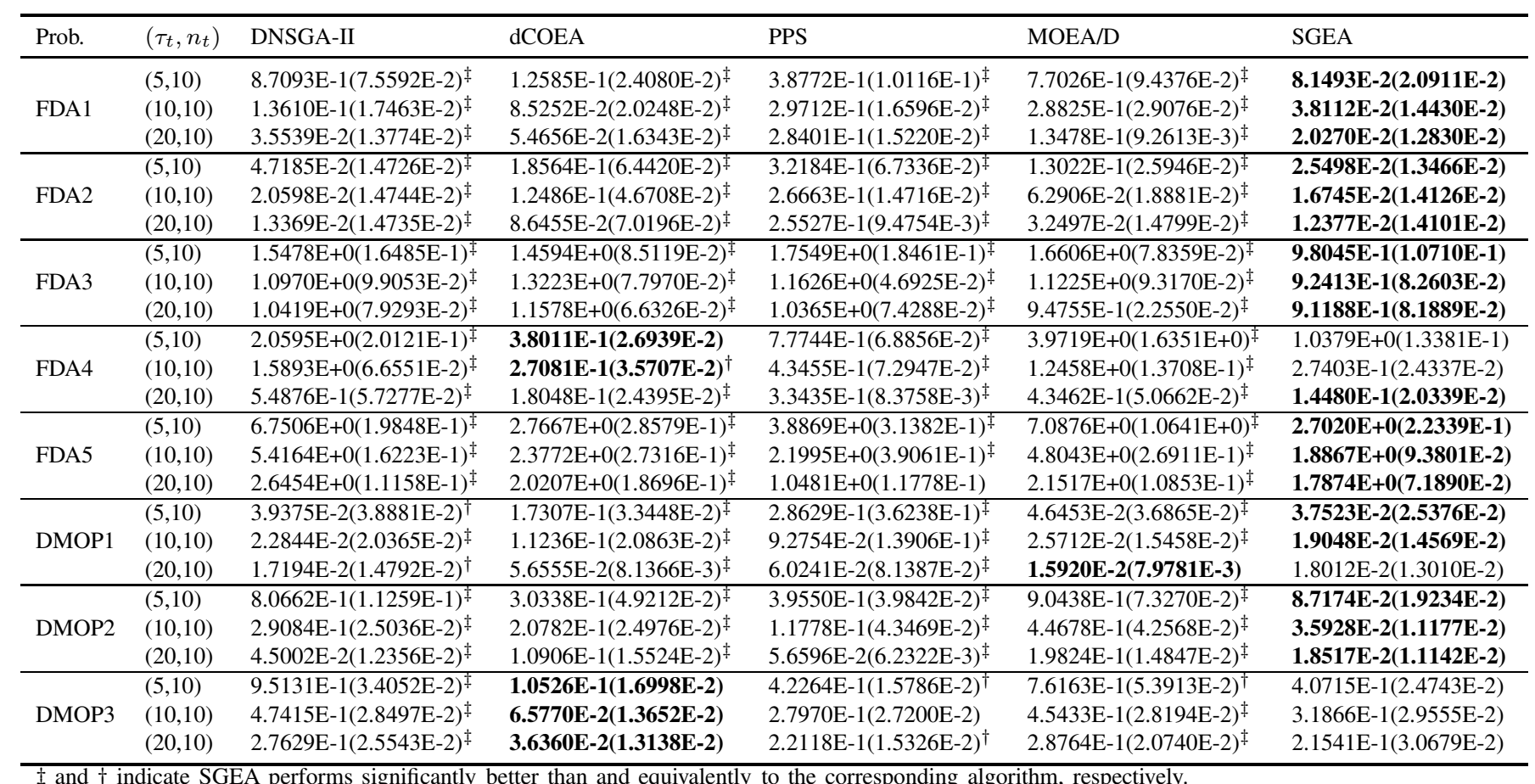

best on the majority of the test instances and mainly loses on FDA4 and dMOP3, where dCOEA is the best performer, in terms of the IGD metric. Clearly, the uncompetitive distribution (i.e., slightly large SP metric) and poor coverage (i.e., relatively small MS metric) of obtained approximations are the main reasons for the low performance of SGEA on FDA4 and dMOP3, respectively. However, good SP and MS values do not necessarily result in satisfying IGD metric, and this can be particularly observed from the case of DNSGA-II on FDA2, suggesting that DNSGA-II converges worse than SGEA although it provides the best SP and MS metrics on this problem. For PPS and MOEA/D, the IGD performance is not competitive in spite of their good spread performance for most of the test instances, and this may be caused by their poor solution distribution, as indicated by their large SP values.

Table IV presents the HVD metric obtained by five algorithms on the FDA and dMOP problems. The obtained HVD values are roughly consistent with the IGD ones illustrated in Table III. Clearly, SGEA is more promising than the other algorithms to solve most FDA and dMOP instances, but it is outperformed by dCOEA on FDA4 and DMOP3. Besides, the steady-state MOEA/D also shows some appealing results on FDA3 and DMOP1 when $\tau_{t}$ equals 20 , implying its steady-state update method may be helpful for handling slowchanging environments.

It can also be observed from the results of the three used metrics that, the frequency of change has a significant effect on algorithms' performance, and the effect decreases when environmental changes become slow. For two three-objective problems, i.e., FDA4 and FDA5, DNSGA-II and MOEA/D are most influenced by frequent changes and struggle to push their populations toward the POF, as indicated by their large IGD and HVD values in Tables III and IV, respectively. Overall, dCOEA and SGEA seems less sensitive to the frequency of change, as can be seen from their gradual improvement on three metrics when $\tau_{t}$ increases from 5 to 20 . On the other hand, with the variation of frequency, there are drastic improvements on DNSGA-II, PPS, and MOEA/D in most of the test instances.

Apart from tabular presentation, we provide evolution curves of the average IGD values on the test instances in Fig. 1. It can be clearly seen that, compared with the other algorithms, SGEA responds to changes more stably and recovers faster for most of the test problems, thereby obtaining higher convergence performance. The only exception is $\mathrm{dMOP} 3$, where dCOEA performs the best, and due to the lack of population diversity (indicated by poor MS values) when a change occurs, the IGD values obtained by SGEA fluctuate widely on this problem. Despite that, SGEA performs similarly to PPS and better than DNSGA-II and MOEA/D on dMOP3. For a graphical view of algorithms' tracking ability, we also plot their obtained POFs of FDA1, FDA2, FDA3 and dMOP3 over 31 time windows, which are shown in Fig. 2. Fig. 2 evidently shows that SGEA is very capable of tracking environmental changes, but may be of limited coverage if there is a significant diversity loss (e.g., on dMOP3) in dynamic environments.

\section{B. Results on ZJZ and UDF Problems}

Unlike the FDA and dMOP test suites, the ZJZ (F5-F10) [54] and UDF [4] test problems have nonlinear linkages between decision variables. Also, the ZJZ and UDF test suites introduces a number of new dynamic features which are not included in FDA and dMOP. Table V reports the HVD values obtained by five algorithms for these challenging problems 

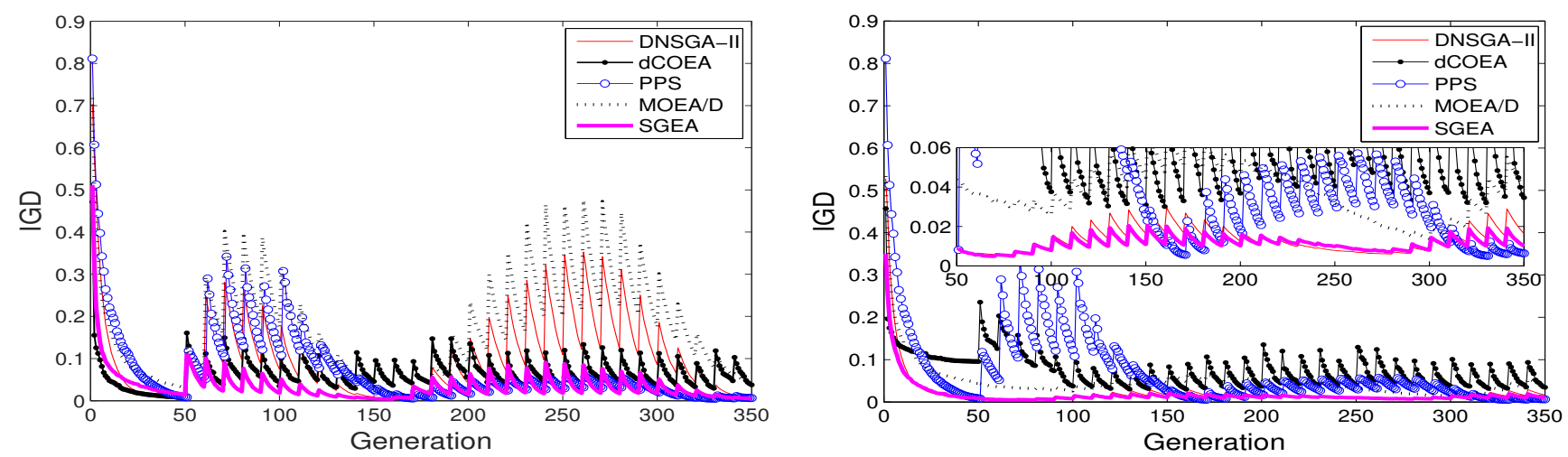

FDA1
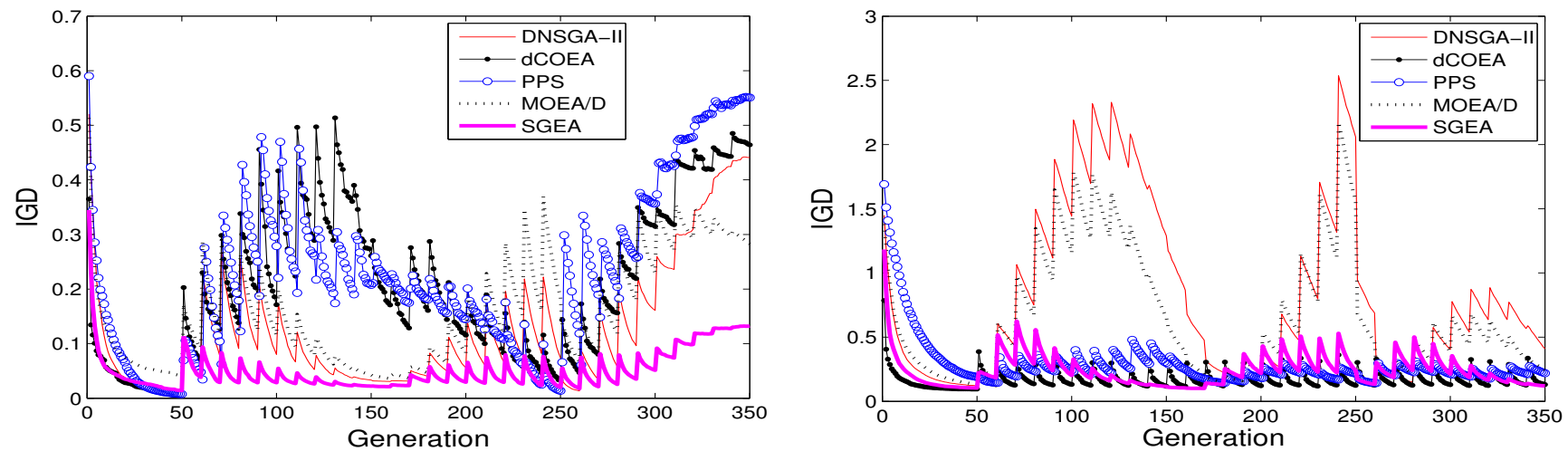

FDA3
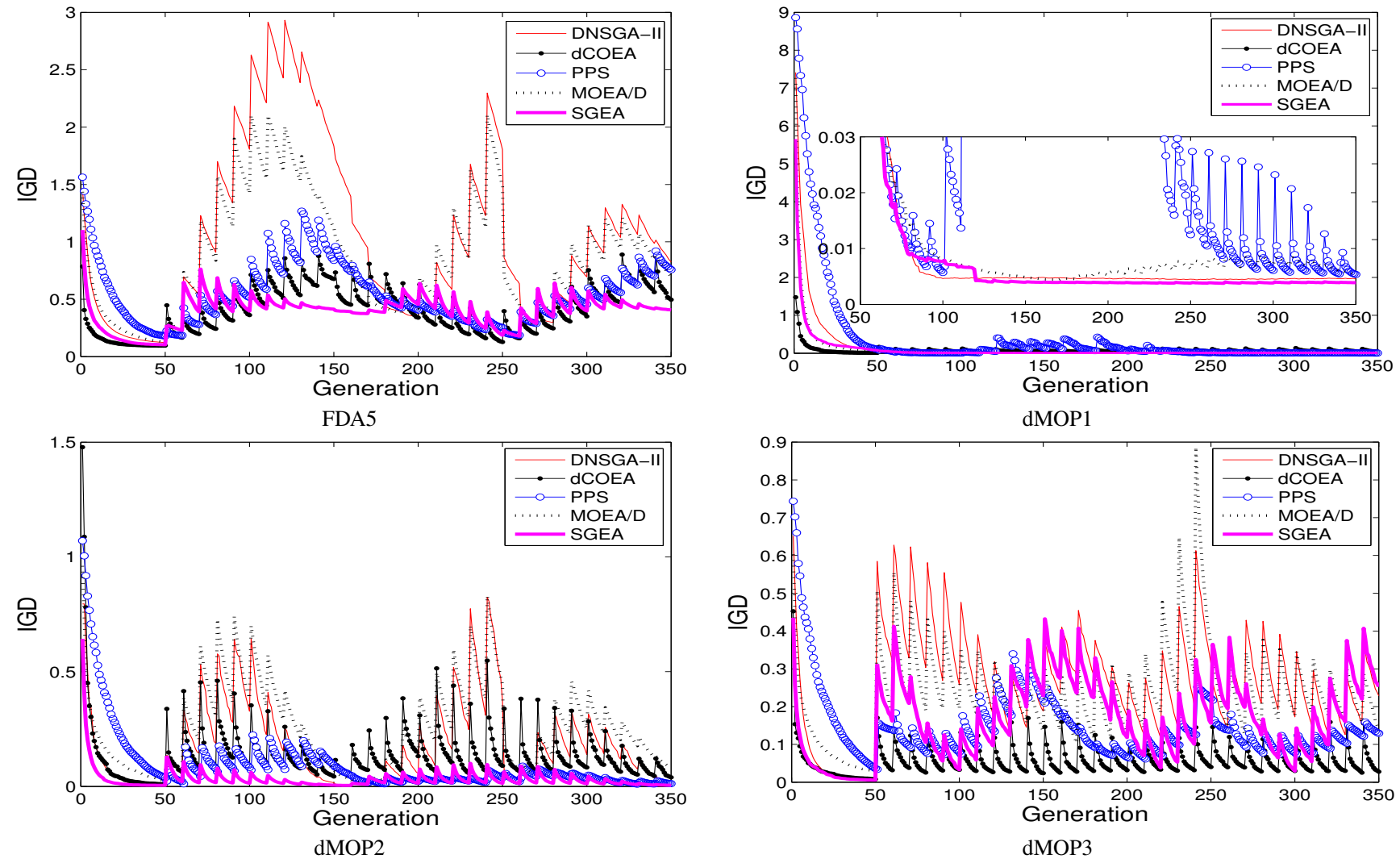

Fig. 1. Evolution curves of average $I G D$ values for eight problems with $\tau_{t}=10$ and $n_{t}=10$.

with $\left(\tau_{t}, n_{t}\right)=(10,10)$, and the obtained SP, MS, and IGD metric values can be found in the supplementary material.

Compared with the average HVD values on FDA and dMOP problems given in Section IV-A, the average HVD values obtained on ZJZ and UDF problems are generally much higher, implying that the optimization difficulties are increased in the ZJZ and UDF problems. Table V clearly shows that SGEA and PPS are top performers on these 

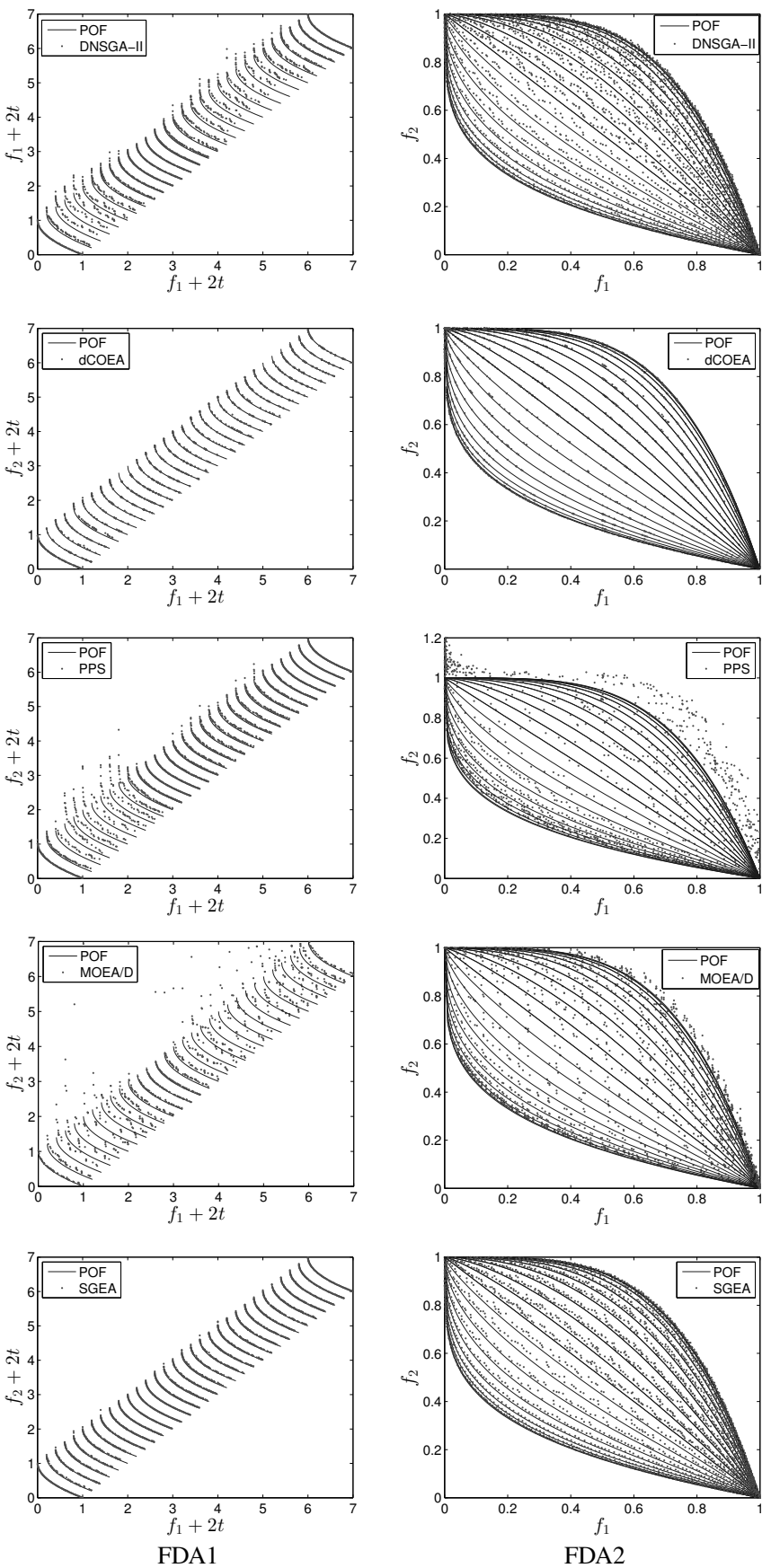

Fig. 2. Obtained POFs for four problems with $\tau_{t}=10$ and $n_{t}=10$.

difficult problems. SGEA obtains the best HVD values on some problems while PPS wins on others. SGEA performs significantly better than DNSGA-II on problems F5-F10, but this superiority disappears when they are compared on the UDF problems, and there is no much difference between them. This means SGEA has no much advantage in dealing with difficult variable-linkage UDF problems. PPS, which is not impressive for solving FDA and dMOP problems, shows very promising performance on some ZJZ and UDF problems. This is because PPS employs an estimation of distribution algorithm [53] as its reproduction operator. This operator can exploit problem specific knowledge, and hence is very helpful for solving variable-linkage problems. With the aid of such a
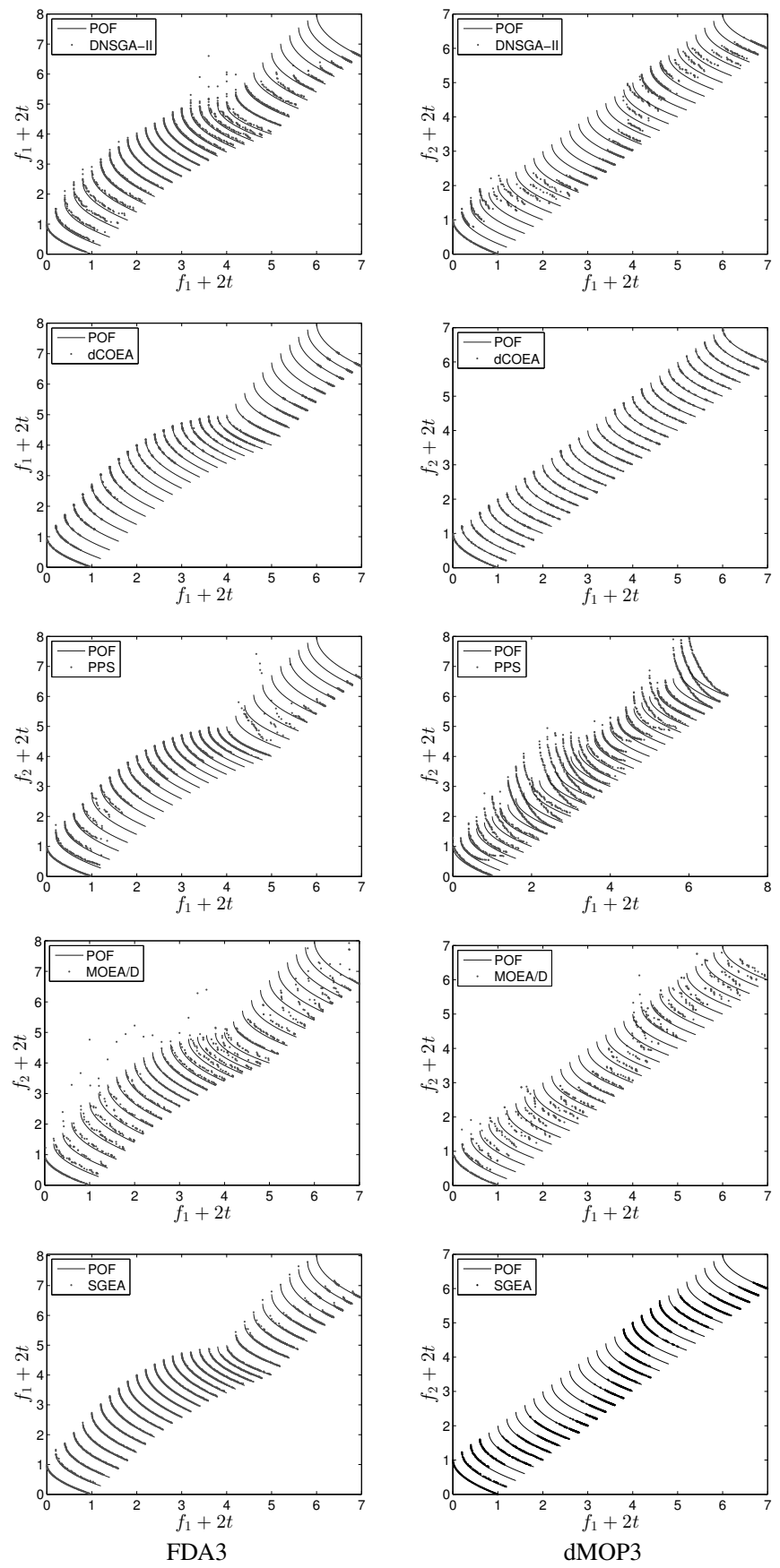

powerful operator, it is natural that PPS can obtain competitive results on these variable-linkage DMOPs. In contrast to PPS, dCOEA faces dramatic difficulties to handle the ZJZ and UDF problems, although it has previously shown good performance on FDA and dMOP problems.

Table $\mathrm{V}$ also shows that almost all the tested algorithms are struggling for three-objective problems, i.e., F8 and UDF7, and disconnected problems, i.e., UDF3 and UDF6, as indicated by their relatively high HVD values. This is understandable because the increase of the number of objectives and disconnectivity are themselves very challenging in static optimization, let alone in dynamic optimization.

To show the evolution performance, Fig. 3 plots the evo- 
TABLE V

MEAN AND STANDARD DEVIATION VALUES OF HVD METRIC OBTAINED BY FIVE ALGORITHMS ON ZJZ AND UDF PROBLEMS

\begin{tabular}{|c|c|c|c|c|c|}
\hline Prob. & DNSGA-II & dCOEA & PPS & MOEA/D & SGEA \\
\hline F5 & $1.2584 \mathrm{E}+0(2.5806 \mathrm{E}-2)^{\ddagger}$ & $1.1019 \mathrm{E}+0(1.6678 \mathrm{E}-1)^{\ddagger}$ & $4.0198 \mathrm{E}-1(9.9177 \mathrm{E}-2)$ & $1.1908 \mathrm{E}+0(2.9956 \mathrm{E}-2)^{\ddagger}$ & $7.1648 \mathrm{E}-1(8.2355 \mathrm{E}-2)$ \\
\hline F6 & $4.7654 \mathrm{E}-1(3.7611 \mathrm{E}-2)^{\ddagger}$ & $9.2223 \mathrm{E}-1(1.0246 \mathrm{E}-1)^{\ddagger}$ & $4.9294 \mathrm{E}-1(1.5074 \mathrm{E}-1)^{\ddagger}$ & $5.7587 \mathrm{E}-1(7.5659 \mathrm{E}-2)^{\ddagger}$ & $3.6068 \mathrm{E}-1(2.5674 \mathrm{E}-2)$ \\
\hline F7 & $6.4963 \mathrm{E}-1(1.0867 \mathrm{E}-2)^{\ddagger}$ & $1.2297 \mathrm{E}+0(1.5928 \mathrm{E}-1)^{\ddagger}$ & 4.4905E-1(1.4280E-1) & $6.5075 \mathrm{E}-1(2.8591 \mathrm{E}-2)^{\ddagger}$ & $6.0586 \mathrm{E}-1(1.5195 \mathrm{E}-2)$ \\
\hline F8 & $1.0626 \mathrm{E}+0(4.6244 \mathrm{E}-2)^{\ddagger}$ & $8.8580 \mathrm{E}-1(1.2482 \mathrm{E}-1)^{\ddagger}$ & $1.3462 \mathrm{E}+0(1.0652 \mathrm{E}-1)^{\ddagger}$ & $1.0615 \mathrm{E}+0(6.6784 \mathrm{E}-2)^{\ddagger}$ & 4.5728E-1 (3.2881E-2) \\
\hline F9 & $8.8751 \mathrm{E}-1(3.4535 \mathrm{E}-2)^{\ddagger}$ & $1.0741 \mathrm{E}+0(1.9861 \mathrm{E}-1)^{\ddagger}$ & $6.8857 \mathrm{E}-1(7.7943 \mathrm{E}-2)^{\ddagger}$ & $8.5809 \mathrm{E}-1(4.6913 \mathrm{E}-2)^{\ddagger}$ & $5.7634 \mathrm{E}-1(7.0349 \mathrm{E}-2)$ \\
\hline F10 & $1.2217 \mathrm{E}+0(5.0091 \mathrm{E}-2)^{\ddagger}$ & $8.5883 \mathrm{E}-1(8.8251 \mathrm{E}-2)^{\ddagger}$ & 5.3839E-1(1.2028E-1 $)^{\dagger}$ & $1.0590 \mathrm{E}+0(5.9197 \mathrm{E}-2)^{\ddagger}$ & 5.7721E-1(2.3204E-2) \\
\hline UDF1 & 5.1409E-1(3.2724E-2 $)^{\dagger}$ & $7.4761 \mathrm{E}-1(3.8905 \mathrm{E}-2)^{\ddagger}$ & $7.9775 \mathrm{E}-1(5.2094 \mathrm{E}-2)^{\ddagger}$ & $6.1209 \mathrm{E}-1(9.4226 \mathrm{E}-2)^{\ddagger}$ & $5.1825 \mathrm{E}-1(5.0120 \mathrm{E}-2)$ \\
\hline UDF2 & $5.5156 \mathrm{E}-1(2.4931 \mathrm{E}-2)^{\ddagger}$ & $6.1354 \mathrm{E}-1(2.8689 \mathrm{E}-2)^{\ddagger}$ & $4.3230 \mathrm{E}-1(1.9124 \mathrm{E}-2)$ & $5.4236 \mathrm{E}-1(1.7627 \mathrm{E}-2)^{\ddagger}$ & $5.1049 \mathrm{E}-1(2.5728 \mathrm{E}-2)$ \\
\hline UDF3 & $1.2217 \mathrm{E}+0(1.9063 \mathrm{E}-3)^{\dagger}$ & $1.2314 \mathrm{E}+0(7.0157 \mathrm{E}-2)^{\dagger}$ & $1.7374 \mathrm{E}+0(3.1733 \mathrm{E}-4)^{\ddagger}$ & $1.2266 \mathrm{E}+0(2.4696 \mathrm{E}-3)^{\dagger}$ & $1.2212 \mathrm{E}+0(2.4181 \mathrm{E}-3)$ \\
\hline UDF4 & $3.4766 \mathrm{E}-1(8.3674 \mathrm{E}-2)^{\dagger}$ & $5.0624 \mathrm{E}-1(3.7884 \mathrm{E}-2)^{\ddagger}$ & $3.7727 \mathrm{E}-1(2.1791 \mathrm{E}-2)^{\ddagger}$ & $6.4101 \mathrm{E}-1(1.9436 \mathrm{E}-1)^{\ddagger}$ & 3.3216E-1(7.1516E-2) \\
\hline UDF5 & $2.7870 \mathrm{E}-1(2.5461 \mathrm{E}-2)^{\dagger}$ & $3.9877 \mathrm{E}-1(3.3025 \mathrm{E}-2)^{\ddagger}$ & 2.7052E-1(1.5772E-2 $)^{\dagger}$ & $3.6585 \mathrm{E}-1(2.7331 \mathrm{E}-2)^{\ddagger}$ & $2.7251 \mathrm{E}-1(1.8914 \mathrm{E}-2)$ \\
\hline UDF6 & $9.3426 \mathrm{E}-1(1.5483 \mathrm{E}-1)$ & $1.2681 \mathrm{E}+0(7.2900 \mathrm{E}-2)^{\ddagger}$ & $1.8374 \mathrm{E}+0(1.0066 \mathrm{E}-2)^{\ddagger}$ & $1.2118 \mathrm{E}+0(1.4935 \mathrm{E}-1)$ & $9.7707 \mathrm{E}-1(2.0394 \mathrm{E}-1)$ \\
\hline UDF7 & $2.4041 \mathrm{E}+0(7.4722 \mathrm{E}-2)^{\ddagger}$ & $1.9125 \mathrm{E}+0(1.7349 \mathrm{E}-1)^{\dagger}$ & $2.0607 \mathrm{E}+0(5.4338 \mathrm{E}-2)^{\dagger}$ & $2.3287 \mathrm{E}+0(2.4253 \mathrm{E}-1)^{\ddagger}$ & $2.0625 \mathrm{E}+0(1.2304 \mathrm{E}-1)$ \\
\hline
\end{tabular}

$\ddagger$ and $\dagger$ indicate SGEA performs significantly better than and equivalently to the corresponding algorithm, respectively.

lution curve of the average IGD metric values over 30 independent runs. We can see from the figure that, SGEA is able to respond to environmental changes fast and stably in most cases. DNSGA-II and MOEA/D roughly have similar evolution curves on the majority of cases. PPS recovers from environmental changes fast on some problems, e.g., F6, F9, UDF2, and UDF5, but recovers slowly on other problems like F8 and UDF1. dCOEA seems struggling on these variablelinkage DMOPs.

It is worth noting that, the tested algorithms do not react to changes stably on a few problems, e.g., F5, F9, and F10. The IGD values vary widely on these problems because they involves more severe changes in POS than the other ZJZ problems. Clearly, the severe POS movement in F5 degrades the performance of SGEA, hence it is outperformed by PPS.

\section{Discussions}

\section{A. Influence of Severity of Change}

To examine the effect of severity levels on algorithms' performance, experiments were carried out on FDA and dMOP problems with $\tau_{t}$ fixed to 10 , and $n_{t}$ set to 5,10 , and 20, which represent severe, moderate, and slight environmental changes, respectively. Experimental results of five algorithms on the HVD metric are given in Table VI. For the inspection of the values of the SP, MS, and IGD metrics, the interested readers can be referred to the supplementary material.

It can be observed from the table that, all the algorithms are very sensitive to the severity of change, as can be seen from the improvement of the metrics when increasing the value of $n_{t}$. For different severity levels, SGEA is able to produce impressive performance and wins on the majority of the instances, and this algorithm is mainly exceeded by dCOEA on only two problems, i.e., FDA4 and dMOP3. However, for the problem dMOP3, the HVD metric of SGEA deteriorates with the decrease of the severity level. One possible explanation is that, on dMOP3, the degree of diversity loss is roughly the same for different severity levels, but for different severity levels, SGEA reacts to changes differently, with a large movement step-size for severe changes $\left(n_{t}=5\right)$ and a small movement step-size for slight ones $\left(n_{t}=20\right)$. A larger movement step-size is likely to increase more population diversity than a smaller one. Therefore, the increase of $n_{t}$ may negatively affect population diversity, which in turn leads to the deterioration of the HVD metric. Such impact suggests that SGEA may need diversity increase techniques to deal with problems like dMOP3.

\section{B. Study of Different Components of SGEA}

This subsection is devoted to studying the effect of different components of SGEA. SGEA has three key components, i.e., the "guided" reinitialization for change response, the steadystate population update, and the generational environmental selection. To deeply examine the role that each component plays in dynamic optimization, we adapt the original SGEA into three variants. The first variant (SGEA-S1) does not use the the part of "guided" change response. Instead, it re-evaluates all current population members in the event of environmental changes. The second variant (SGEA-S2) discards the steady-state upadate part of SGEA. In other words, SGEA-S2 generationally detects and reacts to changes, and reproduces offspring. SGEA-S3 is another modification of SGEA, in which environmental selection at the end of every generation is conducted by preserving a population of individuals with good fitness. This means, SGEA-S3 prefers well-converged solutions regardless of their diversity. These three variants are compared with the original SGEA on four problems with the setting of $\left(\tau_{t}, n_{t}\right)=(10,10)$. Table VII presents the average and standard deviation values of four metrics obtained by different SGEA variants. The Wilcoxon signed-rank test [46] is carried out at the 0.05 significance level to indicate statistically significant difference between SGEA and the other variants.

In Table VII, SGEA performs significantly better than the three variants on FDA1 in terms of four metrics, implying all the three key components are crucial to the high performance of SGEA on this problem. For dMOP1, SGEA-S1, SGEAS2, and SGEA obtain considerably small IGD and HVD values, indicating they can solve this problem very well. In contrast, SGEA-S3 seems incapable of solving dMOP1, as indicated by the inferior four metrics. The poor performance of SGEA-S3 on dMOP1 is mainly due to the lack of diversity 

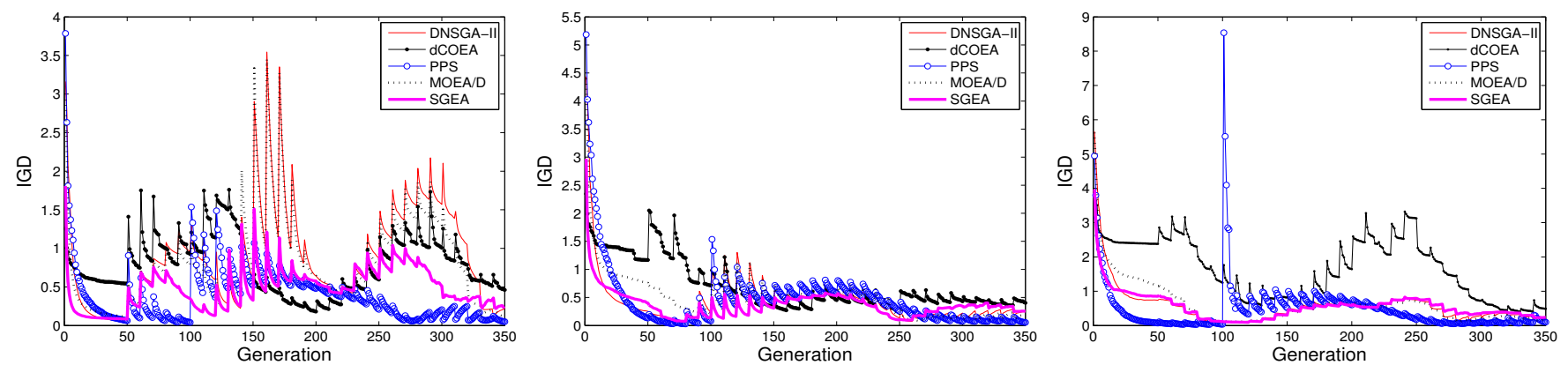

F5
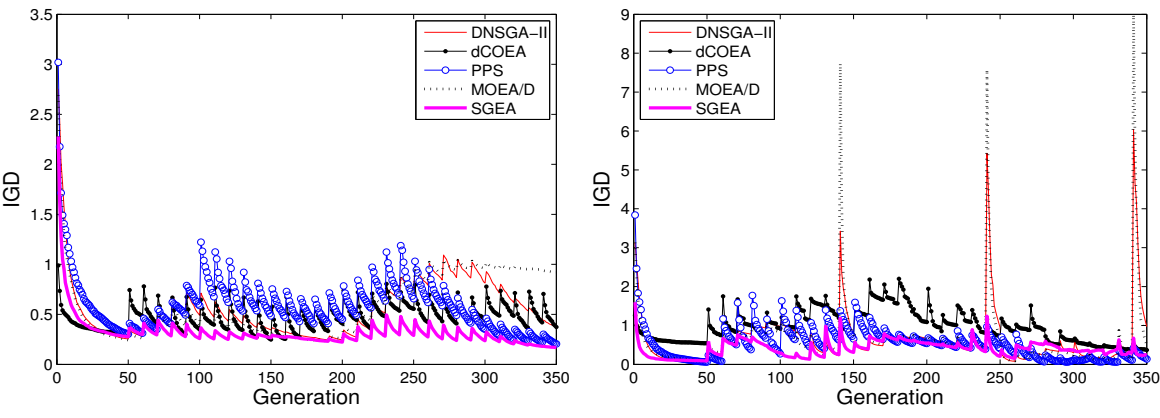

F7

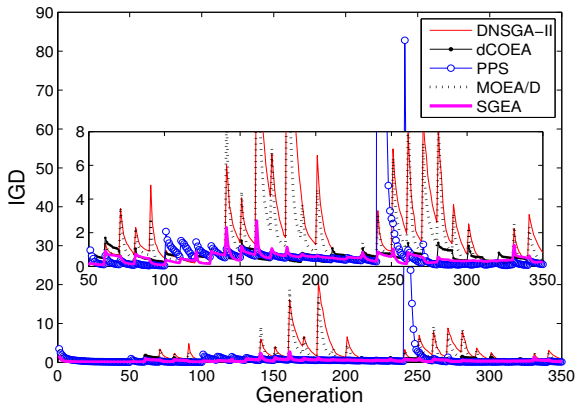

F9
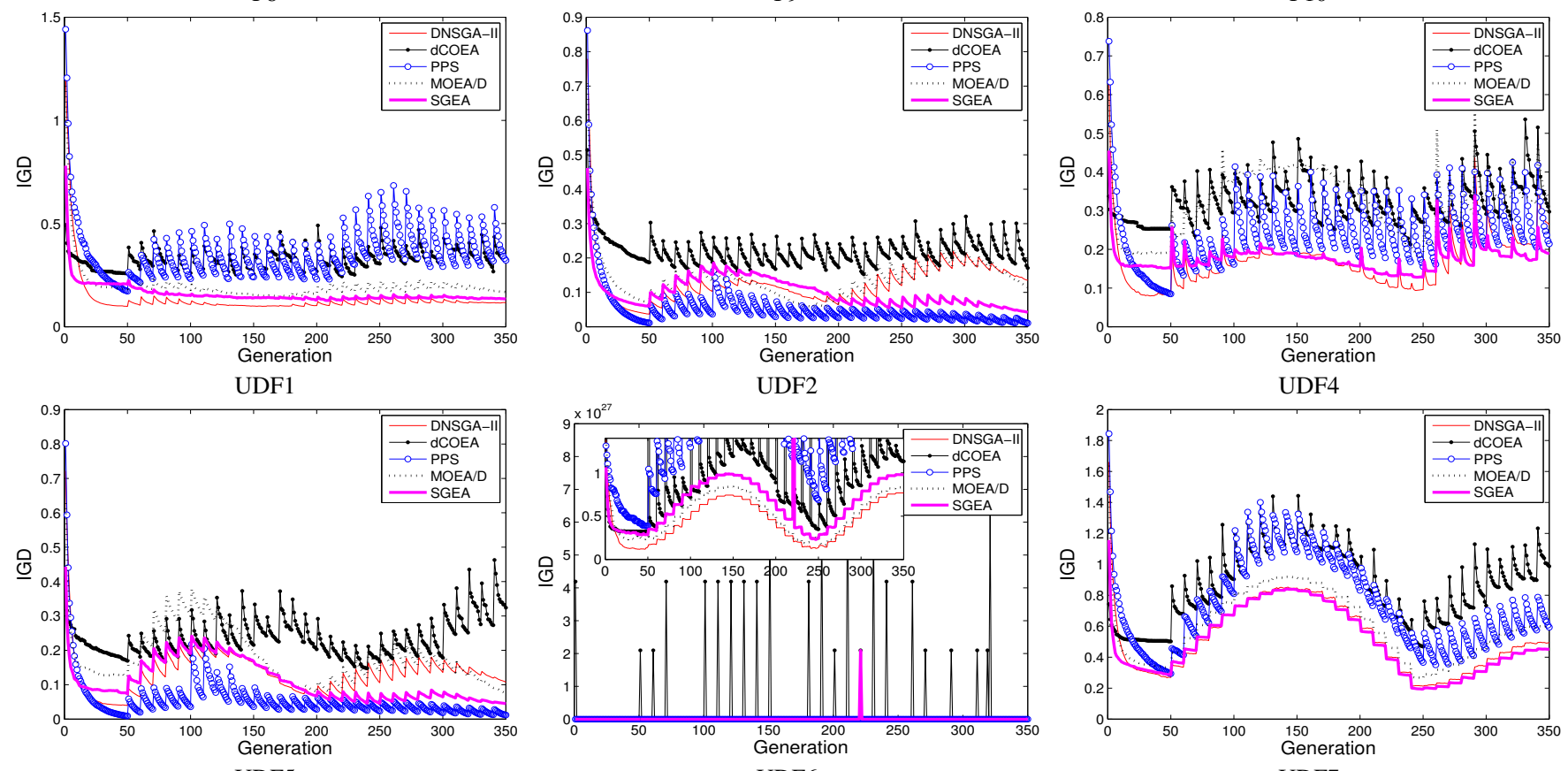

UDF6

UDF7

Fig. 3. Evolution curves of average $I G D$ values for eight variable-linkage problems with $\tau_{t}=10$ and $n_{t}=10$.

maintenance, particularly when excessive nondominated solutions are obtained. This case clearly illustrates the importance of generational environmental selection to SGEA. For F5, there is notable difference between SGEA-S2 and the other algorithms in terms of the metrics. SGEA-S2 obtains the worst SP, IGD, and HVD values, although it has better coverage (MS) than the others. The results of SGEA-S2 on F5 obviously suggest that the use of steady-state population update can significantly improve the performance of SGEA. Besides, the difference between SGEA-V1 and SGEA on F5, in terms of the IGD and HVD metrics, also validates the effectiveness of the proposed "guided" population reinitialization for handling environmental changes. The results of four algorithms on UDF1 show that SGEA is significantly better than SGEA-S1 and SGEA-S3. This observation further confirms the benefit of the "guided" population reinitialization and generational selection used in SGEA for dynamic optimization.

It is not difficult to understand that, as a combination of three key components, SGEA generally outperforms the other compared variants. The above observations clearly exhibit the importance of each component in dealing with dynamic environments. Here, we would like to give more explanations for the role of each component. The "guided" population reinitialization exploits the information of new environments 
TABLE VI

MEAN AND STANDARD DEVIATION VALUES OF HVD METRIC OBTAINED BY FIVE ALGORITHMS WITH DIFFERENT VALUES OF $n_{t}$

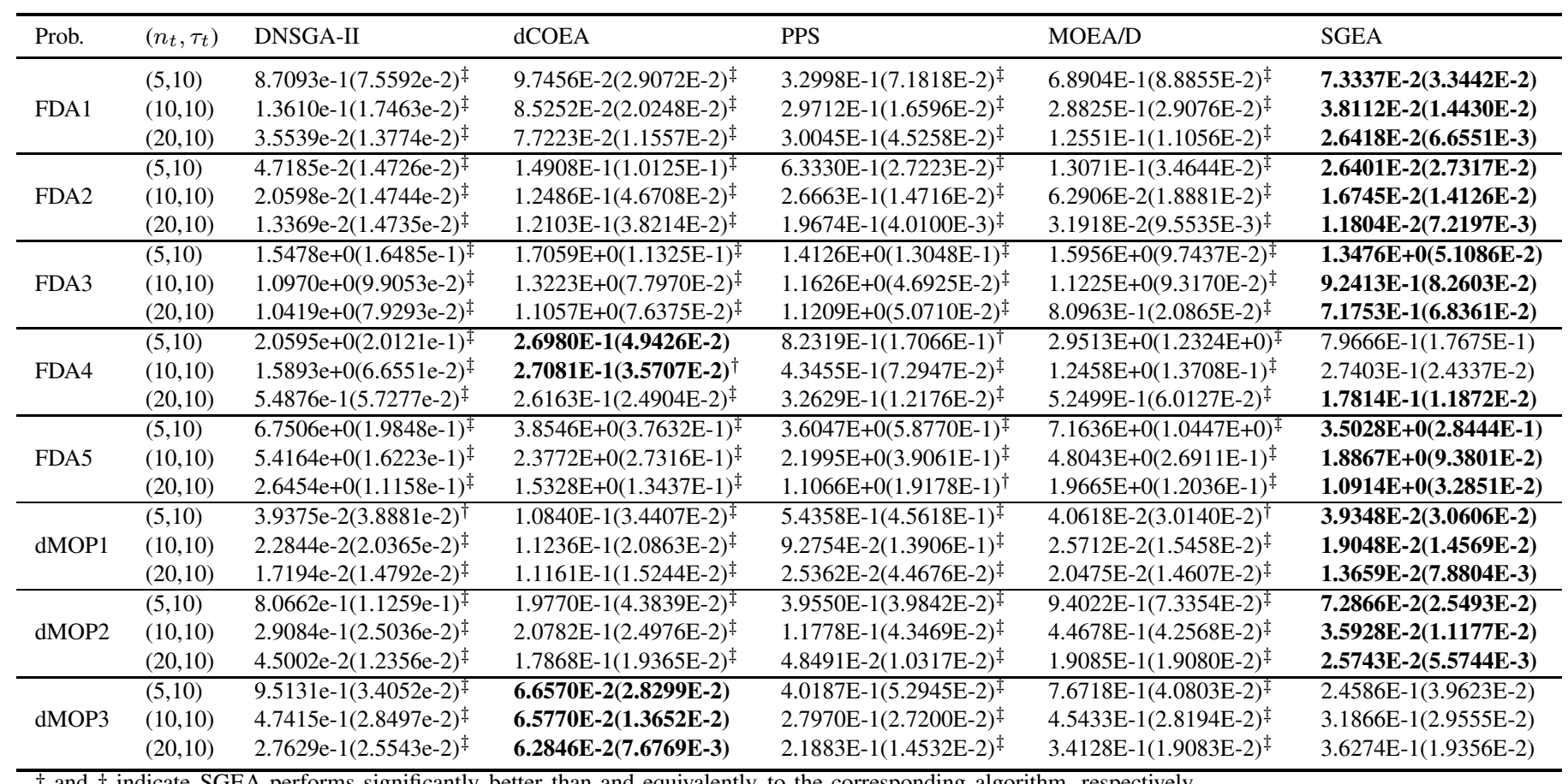

$\ddagger$ and $\dagger$ indicate SGEA performs significantly better than and equivalently to the corresponding algorithm, respectively.

TABLE VII

Performance Comparison OF SGEA VARiants

\begin{tabular}{|c|c|c|c|c|c|}
\hline Problem & Indicator & SGEA-S1 & SGEA-S2 & SGEA-S3 & SGEA \\
\hline \multirow{3}{*}{ FDA1 } & SP & $1.0573 \mathrm{E}-2(1.4425 \mathrm{E}-3)^{\ddagger}$ & $9.0396 \mathrm{E}-3(5.2292 \mathrm{E}-4)^{\ddagger}$ & $9.7488 \mathrm{E}-3(1.1191 \mathrm{E}-3)^{\ddagger}$ & $7.5411 \mathrm{E}-3(5.8178 \mathrm{E}-4)$ \\
\hline & MS & $9.6158 \mathrm{E}-1(1.0782 \mathrm{E}-2)^{\ddagger}$ & $9.6332 \mathrm{E}-1(1.2436 \mathrm{E}-2)^{\ddagger}$ & $9.6631 \mathrm{E}-1(9.1630 \mathrm{E}-3)^{\ddagger}$ & $9.7277 \mathrm{E}-1(1.0854 \mathrm{E}-2)$ \\
\hline & IGD & $1.9931 \mathrm{E}-2(1.6198 \mathrm{E}-3)^{\ddagger}$ & $2.6038 \mathrm{E}-2(2.9232 \mathrm{E}-3)^{\ddagger}$ & $1.6973 \mathrm{E}-2(1.8987 \mathrm{E}-3)^{\ddagger}$ & $1.4809 \mathrm{E}-2(2.0621 \mathrm{E}-3)$ \\
\hline \multirow{3}{*}{ dMOP1 } & $\mathrm{SP}$ & $2.4045 \mathrm{E}-3(1.3972 \mathrm{E}-4)$ & $2.7215 \mathrm{E}-3(3.0493 \mathrm{E}-4)^{\dagger}$ & $8.5790 \mathrm{E}-3(1.0189 \mathrm{E}-3)^{\ddagger}$ & $2.7029 \mathrm{E}-3(3.0835 \mathrm{E}-4)$ \\
\hline & MS & $9.8107 \mathrm{E}-1(1.8150 \mathrm{E}-2)^{\dagger}$ & $9.8097 \mathrm{E}-1(2.4778 \mathrm{E}-2)^{\ddagger}$ & $8.1045 \mathrm{E}-1(1.0711 \mathrm{E}-1)^{\ddagger}$ & $9.8351 \mathrm{E}-1(1.3118 \mathrm{E}-2)$ \\
\hline & IGD & $9.0188 \mathrm{E}-3(4.3106 \mathrm{E}-3)^{\ddagger}$ & $8.5146 \mathrm{E}-3(6.9219 \mathrm{E}-3)^{\ddagger}$ & $4.9847 \mathrm{E}-2(3.1290 \mathrm{E}-2)^{\ddagger}$ & $6.5411 \mathrm{E}-3(3.0256 \mathrm{E}-3)$ \\
\hline \multirow{3}{*}{ F5 } & MS & $4.0412 \mathrm{E}-1(4.2687 \mathrm{E}-2)^{\ddagger}$ & $5.5816 \mathrm{E}-1(4.4388 \mathrm{E}-2)$ & $4.7777 \mathrm{E}-1(4.8569 \mathrm{E}-2)^{\dagger}$ & $5.0748 \mathrm{E}-1(4.2309 \mathrm{E}-2)$ \\
\hline & IGD & $5.4434 \mathrm{E}-1(4.3308 \mathrm{E}-2)^{\ddagger}$ & $6.4214 \mathrm{E}-1(4.7136 \mathrm{E}-2)^{\ddagger}$ & $4.5958 \mathrm{E}-1(3.3362 \mathrm{E}-2)^{\dagger}$ & $4.4195 \mathrm{E}-1(4.5046 \mathrm{E}-2)$ \\
\hline & HVD & $9.2472 \mathrm{E}-1(6.3984 \mathrm{E}-2)^{\ddagger}$ & $1.1087 \mathrm{E}+0(4.2539 \mathrm{E}-2)^{\ddagger}$ & $7.8997 \mathrm{E}-1(5.9973 \mathrm{E}-2)^{\ddagger}$ & $7.1648 \mathrm{E}-1(8.2355 \mathrm{E}-2)$ \\
\hline \multirow{3}{*}{ UDF1 } & SP & $2.6490 \mathrm{E}-2(2.8379 \mathrm{E}-2)^{\mp}$ & $6.8987 \mathrm{E}-2(3.6611 \mathrm{E}-2)^{\ddagger}$ & $2.5998 \mathrm{E}-2(2.0151 \mathrm{E}-2)^{\mp}$ & $2.1084 \mathrm{E}-2(1.8674 \mathrm{E}-2)$ \\
\hline & MS & $6.5907 \mathrm{E}-1(1.8926 \mathrm{E}-1)^{\ddagger}$ & $8.5675 E-1(8.3575 E-2)$ & $7.1284 \mathrm{E}-1(1.7661 \mathrm{E}-1)^{\dagger}$ & $7.2501 \mathrm{E}-1(1.1595 \mathrm{E}-1)$ \\
\hline & IGD & $1.6684 \mathrm{E}-1(6.5977 \mathrm{E}-2)^{\ddagger}$ & 9.9619E-2(1.0661E-2 $)^{\dagger}$ & $1.4393 \mathrm{E}-1(4.6269 \mathrm{E}-2)^{\ddagger}$ & $1.2449 \mathrm{E}-1(3.3093 \mathrm{E}-2)$ \\
\hline
\end{tabular}

$\ddagger$ and $\dagger$ indicate SGEA performs significantly better than and equivalently to the corresponding algorithm, respectively.

to coarsely relocate some population members close to the new POS, which is beneficial to rapidly track the changing POS. The steady-state update strategy can speed up the convergence process of the population. This is because, within every generation, when an offspring is generated, it is immediately used to update the evolving population and the external archive. Thus, the offspring, if very promising, has opportunities to be chosen as a parent for producing new offspring. This way, The steadystate update strategy offers a fast convergence speed and a steady reaction to changes as well. Although the steady-state update strategy is helpful for convergence, it does not consider population diversity. For this reason, the generational selection strategy is introduced to mainly maintain population diversity.
One particular situation is that, when plenty of nondominated individuals are available, the generational selection can prune them so as to preserve a fixed-size population with good diversity for next generation. As a result, the balance between convergence and diversity can be properly struck during the evolution. In a nutshell, all these three components of SGEA play a important role in reacting steadily and adapting rapidly to environmental changes.

\section{Influence of Introducing Mutated Solutions}

In the previous section, empirical studies indicate that SGEA is very competitive for handling dynamic environments, 
TABLE VIII

SP, MS AND IGD VALUES OF SGEA-V1 FOR FDA1 AND FDA2

\begin{tabular}{c|ccc|ccc}
\hline & \multicolumn{3}{|c|}{ FDA1 } & & \multicolumn{2}{c}{ FDA2 } \\
\hline$\eta$ & SP & MS & HVD & SP & MS & HVD \\
\hline 0 & $\mathbf{7 . 5 4 1 1 E - 3 ( 5 . 8 1 7 8 E - 4 )}$ & $\mathbf{9 . 7 2 7 7 E - 1 ( 1 . 0 8 5 4 E - 2 )}$ & $\mathbf{3 . 8 1 1 2 E}-2(1.4430 E-2)$ & $\mathbf{6 . 5 8 7 1 E - 3 ( 8 . 7 7 5 3 E - 4 )}$ & $\mathbf{9 . 9 3 0 8 E - 1 ( 3 . 3 4 6 4 E - 3 )}$ & $\mathbf{1 . 6 7 4 5 E}-2(1.4126 E-2)$ \\
10 & $9.4194 \mathrm{E}-3(5.2569 \mathrm{E}-4)$ & $9.7253 \mathrm{E}-1(9.4358 \mathrm{E}-3)$ & $3.9221 \mathrm{E}-2(1.3781 \mathrm{E}-2)$ & $7.2513 \mathrm{E}-3(8.1050 \mathrm{E}-4)$ & $9.9302 \mathrm{E}-1(3.1580 \mathrm{E}-3)$ & $1.7192 \mathrm{E}-2(1.4852 \mathrm{E}-2)$ \\
20 & $9.4802 \mathrm{E}-3(4.1391 \mathrm{E}-4)$ & $9.7125 \mathrm{E}-1(9.1182 \mathrm{E}-3)$ & $4.0204 \mathrm{E}-2(1.6126 \mathrm{E}-2)$ & $7.1854 \mathrm{E}-3(8.2471 \mathrm{E}-4)$ & $9.9275 \mathrm{E}-1(3.9994 \mathrm{E}-3)$ & $1.7308 \mathrm{E}-2(1.4810 \mathrm{E}-2)$ \\
30 & $9.8393 \mathrm{E}-3(6.5970 \mathrm{E}-4)$ & $9.6881 \mathrm{E}-1(1.0522 \mathrm{E}-2)$ & $4.2156 \mathrm{E}-2(1.4579 \mathrm{E}-2)$ & $6.8743 \mathrm{E}-3(6.3021 \mathrm{E}-4)$ & $9.9268 \mathrm{E}-1(4.8573 \mathrm{E}-3)$ & $1.7439 \mathrm{E}-2(1.4599 \mathrm{E}-2)$ \\
40 & $9.9007 \mathrm{E}-3(4.8708 \mathrm{E}-4)$ & $9.6982 \mathrm{E}-1(7.8856 \mathrm{E}-3)$ & $4.2984 \mathrm{E}-2(1.3953 \mathrm{E}-2)$ & $7.0167 \mathrm{E}-3(1.9724 \mathrm{E}-4)$ & $9.9165 \mathrm{E}-1(5.3058 \mathrm{E}-3)$ & $1.7284 \mathrm{E}-2(1.4777 \mathrm{E}-2)$ \\
50 & $1.1850 \mathrm{E}-2(1.4381 \mathrm{E}-3)$ & $9.6134 \mathrm{E}-1(1.3593 \mathrm{E}-2)$ & $5.0541 \mathrm{E}-2(1.3661 \mathrm{E}-2)$ & $7.2156 \mathrm{E}-3(3.9059 \mathrm{E}-4)$ & $9.9175 \mathrm{E}-1(5.0043 \mathrm{E}-3)$ & $1.7209 \mathrm{E}-2(1.4652 \mathrm{E}-2)$ \\
\hline
\end{tabular}

but it does not work as well as DNSGA-II for a good distribution and coverage on problems like FDA2. Similar to DNSGAII, we can introduce $\eta \%$ mutated solutions of existing solutions into the new population after a change into SGEA, and we call this version of SGEA as SGEA-v1. This means, the new population consists of $50 \%$ of old solutions, $\eta \%(0 \leq \eta \leq 50)$ mutated solutions, and $(50-\eta) \%$ guided solutions. Unlike SGEA, SGEA-v1 computes the moving direction (as shown in Eq. (5)) in a different way. To be specific, the $50 \%$ old solutions and $\eta \%$ mutated solutions are regarded as the set $R$ in Eq. (5), and nondominated solutions from $R$ after reevaluation are copied to $A$. This way, $(50-\eta) \%$ of the new population to be re-initialized can benefit from the reused old solutions as well as the mutated solutions, especially when these solutions have a high level of diversity.

The effect of mutated solutions is studied on FDA1 and FDA2 with the setting of $\tau_{t}=10$ and $n_{t}=10$, and $\eta$ varied from 0 to 50 . In the case of $\eta=0$, SGEA-v1 is actually the original SGEA, and $\eta=50$ means there are no guided solutions in the new population. The mutation probability and the distribution index for making mutated solutions were set the same as in DNSGA-II [12].

Table VIII presents the results of SGEA-v1 for the two tested problems. For FDA1, the performance of SGEA-v1 on three metrics notably deteriorates with the increase in the number of mutation solutions in population. The similar trend can be observed from the results of FDA2, in which all the metric values are negatively influenced when $\eta$ increases. The negative effect of introducing mutated solutions can be explained by the fact that, mutated solutions are more random than well-planned guided solutions used in SGEA, and may take more time to be directed toward the true POF. In other words, such mechanism seems not suitable for SGEA when handling dynamic environments.

\section{Influence of Introducing Random Solutions}

As illustrated in the previous experimental study, SGEA is quite vulnerable to severe diversity loss and thus cannot compete with dCOEA on dMOP3. For this reason, we devise another version of SGEA, denoted SGEA-v2, which is inspired by the use of stochastic competitors for diversity increase in dCOEA. SGEA-v2 has the similar change response framework to SGEA-v1 except that it replaces $\eta \%$ of the population with randomly created solutions. The influence of introducing random solutions is studied on $\mathrm{dMOP} 3$, where $\eta$ varies from 0 to 50 .

The results of SGEA-v2 on dMOP3 with $\tau_{t}=10$ and $n_{t}=10$ are given in Table IX. Clearly, the introduction of
TABLE IX

SP, MS AND IGD VALUES OF SGEA-V2 FOR DMOP3

\begin{tabular}{cccc}
\hline$\eta$ & SP & MS & IGD \\
\hline 0 & $\mathbf{5 . 4 3 3 6 E - 3 ( 6 . 0 7 5 1 E - 4 )}$ & $5.7573 \mathrm{E}-1(2.9590 \mathrm{E}-2)$ & $1.3248 \mathrm{E}-1(1.3627 \mathrm{E}-2)$ \\
10 & $7.8473 \mathrm{E}-3(1.1449 \mathrm{E}-3)$ & $8.8779 \mathrm{E}-1(2.3199 \mathrm{E}-2)$ & $3.6223 \mathrm{E}-2(9.4230 \mathrm{E}-3)$ \\
20 & $8.7294 \mathrm{E}-3(3.0487 \mathrm{E}-3)$ & $9.1631 \mathrm{E}-1(1.1874 \mathrm{E}-2)$ & $3.0153 \mathrm{E}-2(4.1528 \mathrm{E}-3)$ \\
30 & $8.8099 \mathrm{E}-3(2.8361 \mathrm{E}-3)$ & $9.3661 \mathrm{E}-1(1.5004 \mathrm{E}-2)$ & $2.5424 \mathrm{E}-2(4.8542 \mathrm{E}-3)$ \\
40 & $9.3054 \mathrm{E}-3(2.6714 \mathrm{E}-3)$ & $\mathbf{9 . 4 7 5 9 E}-1(\mathbf{1 . 3 0 6 4 E}-2)$ & $\mathbf{2 . 2 1 9 9 E - 2 ( 4 . 1 1 5 0 E - 3 )}$ \\
50 & $9.4439 \mathrm{E}-3(2.8387 \mathrm{E}-3)$ & $9.4656 \mathrm{E}-1(1.2554 \mathrm{E}-2)$ & $2.4757 \mathrm{E}-2(3.3081 \mathrm{E}-3)$ \\
\hline
\end{tabular}

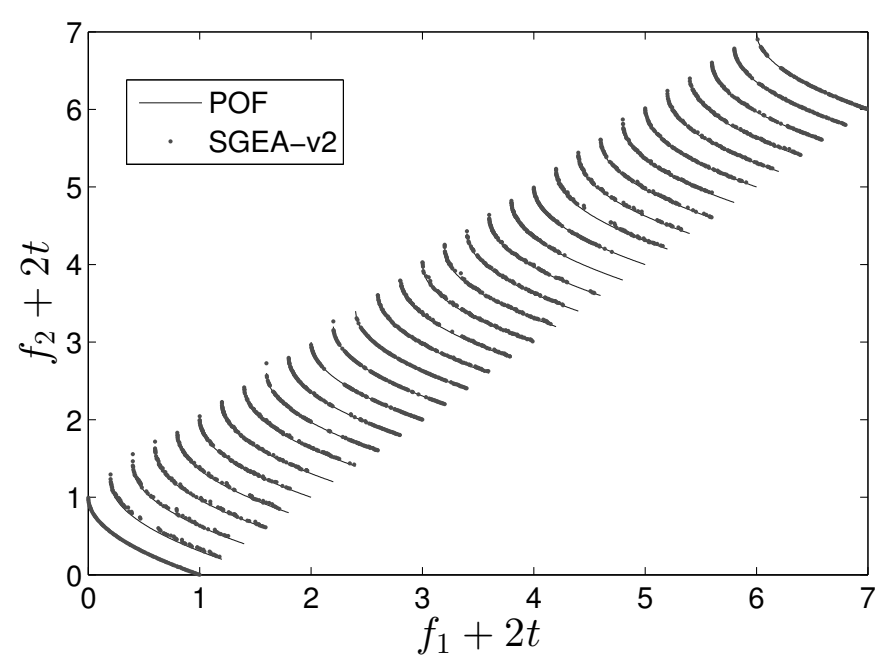

Fig. 4. POFs of dMOP3 $\left(\tau_{t}=10\right.$ and $\left.n_{t}=10\right)$ obtained by SGEA-v2 over 31 time steps.

random solutions significantly improves the coverage performance of SGEA, which in turn decreases the IGD values. Such benefit is maximized when $40 \%$ random solutions are adopted, and the corresponding approximations of 31 time steps are illustrated in Fig. 4, showing that SGEA with the use of random solutions is very capable of tracking the changing $\mathrm{POF}$ on dMOP3. On the other hand, the SP metric is negatively affected by random solutions, with a notable decline when $\eta$ increases. This is because the use of random solutions drastically increases population diversity, leading to a wide spread of the population along the POF so that the uniformity of the obtained approximation is not easy to keep. Thus, for dMOP3, the SP metric is inconsistent with MS and IGD.

Since the use of random solutions considerably help SGEA cope with the diversity loss, we wonder whether SGEA-v2 can win against the other compared algorithms on dMOP3. Hence, we compare SGEA-v2 with $\eta=40$ with the previous best performer, i.e., dCOEA, on different dynamic scenarios 
TABLE X

COMPARISON BETWEEN DCOEA AND SGEA-V2 ON DMOP3

\begin{tabular}{|c|c|c|c|c|c|c|}
\hline & \multicolumn{2}{|c|}{ SP } & \multicolumn{2}{|c|}{ MS } & \multicolumn{2}{|c|}{ IGD } \\
\hline$\left(\tau_{t}, n_{t}\right)$ & dCOEA & SGEA-v2 & dCOEA & SGEA-V2 & dCOEA & SGEA-v2 \\
\hline$(5,10)$ & $3786 \mathrm{E}-2(5.55$ & $1.9335 \mathrm{E}-2(4.50$ & 7837E-1(2.1444E- & $9.1029 \mathrm{E}-1(1.220$ & $.9556 \mathrm{E}-2(4.8079 \mathrm{E}-3)$ & $4.7222 \mathrm{E}-2(5.2525 \mathrm{E}-3)$ \\
\hline$(10,10)$ & $418 \mathrm{E}-2(1.0978 \mathrm{E}-3)$ & $9.3054 \mathrm{E}-3($ & $1716 \mathrm{E}-2)$ & $9.4759 \mathrm{E}-1$ & $2.9589 \mathrm{E}-2(2.4806 \mathrm{E}-3)$ & $2.2199 \mathrm{E}-2(4.1150 \mathrm{E}-3)$ \\
\hline$(20,10)$ & $.3129 \mathrm{E}-3(3.9782 \mathrm{E}-4)$ & $4.8211 \mathrm{E}-3(1.0737 \mathrm{E}-3)$ & $.4844 \mathrm{E}-1(1.1052 \mathrm{E}-2)$ & $9.6644 \mathrm{E}-1(8.0110 \mathrm{E}-3)$ & $1.6366 \mathrm{E}-2(1.7152 \mathrm{E}-3)$ & $1.1448 \mathrm{E}-2(2.5416 \mathrm{E}-3)$ \\
\hline$(10,5)$ & $1.6060 \mathrm{E}-2(1.9712 \mathrm{E}-3)$ & $1.0110 \mathrm{E}-2(2.6696 \mathrm{E}-3)$ & $9.1484 \mathrm{E}-1(1.4420 \mathrm{E}-2)$ & $9.3430 \mathrm{E}-1(1.4221 \mathrm{E}-2)$ & $2.9953 \mathrm{E}-2(3.5438 \mathrm{E}-3)$ & $2.5428 \mathrm{E}-2(4.8462 \mathrm{E}-3)$ \\
\hline$(10,20)$ & $.4903 \mathrm{E}-2(7.3451 \mathrm{E}-3)$ & $7.7303 \mathrm{E}-3(1.2510 \mathrm{E}-3)$ & $9.1736 \mathrm{E}-1(8.7132 \mathrm{E}-3)$ & $9.4923 \mathrm{E}-1(1.2537 \mathrm{E}-2)$ & $3.1686 \mathrm{E}-2(2.6402 \mathrm{E}-3)$ & $2.2085 \mathrm{E}-2(4.5406 \mathrm{E}-3)$ \\
\hline
\end{tabular}

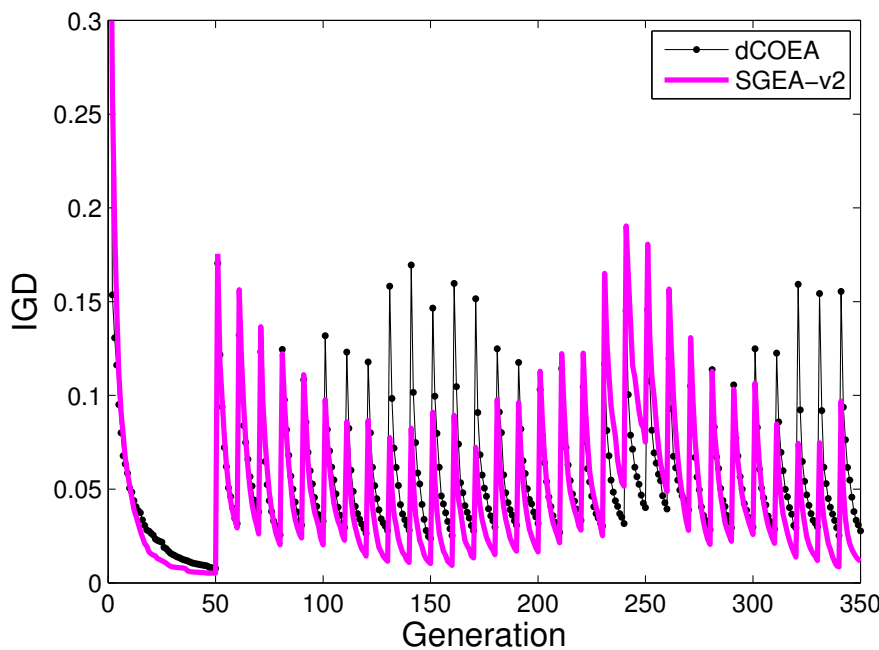

Fig. 5. Comparison of IGD curves between dCOEA and SGEA-v2 for dMOP3 with $\tau_{t}=10$ and $n_{t}=10$.

of dMOP3. Table $\mathrm{X}$ and Fig. 5 present the comparison results, clearly showing that SGEA-v2 significantly outperforms dCOEA in terms of the three performance metrics. This further confirms the potential of SGEA for handling dynamic environments if the population diversity is properly maintained.

\section{E. More Discussions}

The previous experimental comparison and analysis have shown that SGEA is capable of solving a wide range of DMOPs. Specifically, SGEA works well on simple DMOPs without strong variable linkages, like most of the FDA and dMOP problems. In some patterns of changes, such as, the geometric shapes of two consecutive POFs/POSs are similar, changes are slight or do not cause diversity loss, and changes are relatively smooth, SGEA is able to track the moving POFs/POSs effectively and efficiently. Therefore, SGEA provides better performance than the other compared algorithms in these cases. The fact that most of the test problems have periodical changes suggests SGEA is particularly applicable to periodical environments.

However, like other algorithms, SGEA has some drawbacks too. One drawback is that SGEA struggles to deal with changes that brings about severe diversity loss, which has been illustrated by dMOP3. In practice, SGEA does not increase diversity when changes occur, so it is vulnerable to the loss of diversity. However, as have shown in our study, this drawback can be alleviated by introducing some randomly created individuals when a change is detected. Another drawback comes from the inefficiency of SGEA for handling severe movements in POS. As verified by F5, such a severe change can significantly degrade the performance of SGEA. Besides, the dissimilar geometric shapes between two consecutive POFs/POSs (see results on F10) may challenge the performance of SGEA. In case that a change affects too much the relative positions between solutions in the POS, the guided reinitialization method of SGEA may not work well due to its linear property. affects too much the relative positions between solutions. On the other hand, SGEA also suffers from optimization difficulties caused by variable linkages. Experimental comparisons on the UDF problems evidently show that SGEA and the other algorithms all have difficulty in solving strong variable-linkage problems. A possible way to solve variable linkages may be borrowing similar idea from the optimizer of PPS or incorporating with new operators [42] to evolve the population.

\section{CONCLUSIONS}

In this paper, we have proposed a steady-state and generational evolutionary algorithm, i.e., SGEA, for handling multiobjective problems with time-varying characteristics. Different from existing dynamism handling approaches in the literature, SGEA detects and reacts to changes in a steady-state manner. If a change is detected, SGEA reuses a portion of old solutions with good diversity and re-evaluates them, providing the algorithm with some basic understanding of the landscape of the new environment. As a result, SGEA exploits useful information extracted from the new environment, i.e., the moving direction, to relocate the remaining portion of population to regions near the new POF. Otherwise, a generational cycle of static steady-state optimization is executed, in which the evolving population progressively interacts with an external archive, promoting the convergence speed of SGEA. At the end of each generation, the previous and current populations are combined, and the environmental selection is performed on the combined population to preserve elitists for the next generation.

SGEA has been compared with other several popular DMOEAs on a number of DMOPs, including bi- and threeobjective problems, with different dynamic characteristics and difficulties. Experimental studies have shown that, on the majority of the considered problems, SGEA is capable of tracking their changing POFs efficiently, but may struggle to recover if the problem has strong variable linkages or changes cause a significant diversity loss.

The main components of SGEA have been studied and their roles in handling dynamic environments have been deeply illustrated. Besides, the influence of the introduction of mutated and randomly created solutions for change reaction has 
been investigated, showing that mutated solutions may have a negative effect on the elaborated SGEA, and the use of random solutions can considerably alleviate the diversity loss caused by environmental changes, thereby offering significant improvement on the performance of SGEA.

Although SGEA has provided encouraging performance on the test problems considered in this paper, it needs to be examined on a wider range of dynamic environments, such as changes that are hard to be detected or do not vary regularly. Our future work includes the incorporation of new constraint handling techniques to deal with dynamic constrained problems, new operators like [42] to evolve population, new detectors and response mechanisms to handle environmental changes. Besides, new dynamic benchmarks and performance metrics are needed to facilitate the analysis of DMOEAs.

\section{REFERENCES}

[1] V. Aragón, S. Esquivel, and C. A. Coello Coello, "Evolutionary multiobjective optimization in non-stationary environments," Journal of Computer Science and Technology, vol. 5, no. 3, pp. 133-143, 2005.

[2] C. R. B. Azevedo and A. F. R. Araujo, "Generalized immigration schemes for dynamic evolutionary multiobjective optimization," in Proc. 2011 IEEE Congr. Evol. Comput. (CEC), 2011, pp. 2033-2040.

[3] S. Biswas, D. Bose, S. Das, and S. Kundu, "Decomposition-based evolutionary multi-objective optimization approach to the design of concentric circular antenna arrays," Progress In Electromagnetics Research $B$, vol. 52, pp.185-205, 2013.

[4] S. Biswas, S. Das, P. N. Suganthan, and C. A. Coello Coello, "Evolutionary multiobjective optimization in dynamic environments: A set of novel benchmark functions," in Proc. 2014 IEEE Congr. Evol. Comput. (CEC), 2014, pp. 3192-3199.

[5] S. Biswas, S. Kundu, and S. Das, "Inducing niching behavior in differential evolution through local information sharing," IEEE Trans. Evol. Comput., vol. 19, no. 2, pp. 246-263, 2014

[6] S. Biswas, and S. Das, "Utilizing time-linkage property in DOPs: An information sharing based artificial bee colony algorithm for tracking multiple optima in uncertain environments," Soft Computing, vol. 18, no. 6, pp. 1199-1212, 2014.

[7] J. Branke, "Memory enhanced evolutionary algorithms for changing optimization problems," in Proc. 1999 IEEE Congr. Evol. Comput. (CEC), vol. 3, 1999, pp. 1875-1882.

[8] L. T. Bui, M. Zbignew, P. Eddy, and B. A. Manuel, "Adaptation in dynamic environments: A case study in mission planning," IEEE Trans. Evol. Comput., vol. 16, no. 2, pp. 190-209, 2012.

[9] M. Cámara, J. Ortega, and F. de Toro, "A single front genetic algorithm for parallel multi-objective optimization in dynamic environments," $\mathrm{Neu}$ rocomputing, vol. 72, nos. 16-18, pp. 3570-3579, 2009.

[10] B. Chen, W. Zeng, Y. Lin, and D. Zhang, "A new local searchbased multiobjective optimization algorithm," IEEE Trans. Evol. Comput., vol. 19 , no. 1 , pp. 50-73, 2015.

[11] C. Chen and L. Y. Tseng, "An improved version of the multiple trajectory search for real value multiobjective optimization problems," Eng. Optim., vol. 46, no. 10, pp. 1430-1445, 2014.

[12] K. Deb and S. Karthik, "Dynamic multi-objective optimization and decision-making using modified NSGA-II: A case study on hydro-thermal power scheduling," in Proc. 4th Int. Conf. Evol. Multi-Criterion Optim., vol. 4403, 2007, pp. 803-817.

[13] K. Deb and A. Pratap, "A fast and elitist multiobjective genetic algorithm: NSGA-II," IEEE Trans. Evol. Comput., vol. 6, no. 2, pp. 182-197, 2002.

[14] E. U. Ergul and I. Eminoglu, "DOPGA: A new fitness assignment scheme for multi-objective evolutionary algorithms," Int. J. Syst. Sci., vol. 45, no. 3, pp. 407-426, 2014.

[15] M. Farina, K. Deb, and P. Amato, "Dynamic multiobjective optimization problems: Test cases, approximations, and applications," IEEE Trans. Evol. Comput., vol. 8, no. 5, pp. 425-442, 2004.

[16] H. Fu, B. Sendhoff, K. Tang, and X. Yao, "Finding robust solutions to dynamic optimization problems," in Applications of Evolutionary Computation, Lecture Notes in Computer Science, vol. 7835, 2013, pp. 616-625.
[17] C. Goh and K. C. Tan, "An investigation on noisy environments in evolutionary multiobjective optimization," IEEE Trans. Evol. Comput., vol. 11 , no. 3, pp. 354-381, 2007.

[18] C. Goh and K. C. Tan, "A competitive-cooperative coevolutionary paradigm for dynamic multiobjective optimization," IEEE Trans. Evol. Comput., vol. 13, no. 1, pp. 103-127, 2009.

[19] M. Helbig and A. P. Engelbrecht, "Performance measures for dynamic multi-objective optimisation algorithms," Inform. Sci., vol. 250, pp. 61$81,2013$.

[20] M. Helbig, A. P. Engelbrecht, "Benchmarks for dynamic multi-objective optimisation algorithms," ACM Comput. Surv., vol. 46, no. 3, Article No. 37, 2014.

[21] M. Helbig and A. P. Engelbrecht, "Population-based metaheuristics for continuous boundary-constrained dynamic multi-objective optimisation problems," Swarm Evol. Comput., vol. 14, pp. 31-47, 2014.

[22] I. Hatzakis and D. Wallace, "Dynamic multiobjective optimization with evolutionary algorithms: A forward-looking approach," in Proc. 8th Ann. Conf. Genetic Evol. Comput. (GECCO), 2006, pp. 1201-1208.

[23] S. Jiang and S. Yang, "A benchmark generator for dynamic multiobjective optimization problems," in Proc. 2014 UK Workshop Comput. Intell. (UKCI), 2014, pp. 1-8.

[24] S. Jiang and S. Yang, "A framework of scalable dynamic test problems for dynamic multi-objective optimization," in Proc. 2014 IEEE Symp. Comput. Intell. Dynamic and Uncertain Environments (CIDUE), 2014, pp. 32-39.

[25] S. Jiang and S. Yang, "Evolutionary dynamic multi-objective optimization: Benchmarks and algorithm comparisons," IEEE Trans. Cybern., 2016, in press.

[26] Y. Jin, B. Sendhoff, "Constructing dynamic optimization test problems using the multi-objective optimization concept," in Applications of Evolutionary Computing, Lecture Notes in Computer Science, vol. 3005, 2004, pp. 525-536.

[27] Y. Jin, K. Tang, X.Yu, B. Sendhoff, and X. Yao, "A framework for finding robust optimal solutions over time," Memetic Computing, vol. 5, no. 1, pp. 3-18, 2013.

[28] W. Koo, C. Goh, and K. C. Tan, "A predictive gradient strategy for multiobjective evolutionary algorithms in a fast changing environment," Memetic Computing, vol. 2, no. 2, pp. 87-110, 2010.

[29] S. Kundu, S. Biswas, S. Das, and P. N Suganthan, "Crowding-based local differential evolution with speciation-based memory archive for dynamic multimodal optimization," in Proc. 15th Ann. Conf. Genetic Evol. Comput. (GECCO), 2013, pp.33-40.

[30] M. Laumanns, E. Zitzler, and L. Thiele, "A unified model for multiobjective evolutionary algorithms with elitism," in Proc. 2000 IEEE Congr. Evol. Comput. (CEC), 2000, pp. 46-53.

[31] H. Li and Q. Zhang, "Multiobjective optimization problems with complicated Pareto sets, MOEA/D and NSGA-II," IEEE Trans. Evol. Comput., vol. 13 , no. 2, pp. 284-302, 2009.

[32] R. Liu, J. Fan, L. Jiao, "Integration of improved predictive model and adaptive differential evolution based dynamic multi-objective evolutionary optimization algorithm," Appl. Intell., vol. 43, no. 1, pp. 192-207, 2015.

[33] R. Liu, Y. Chen, W. Ma, C. Mu, and L. Jiao, "A novel cooperative coevolutionary dynamic multi-objective optimization algorithm using a new predictive model," Soft Computing, vol. 18, no. 10, pp. 1913-1929, 2014.

[34] H. Lu and G. G. Yen, "Rank-density-based multiobjective genetic algorithm and benchmark test function study," IEEE Trans. Evol. Comput., vol. 7, no. 4, pp. 325-343, 2003.

[35] S. Nguyen, M. Zhang, M. Johnston, and K. C. Tan, "Automatic design of scheduling policies for dynamic multi-objective job shop scheduling via cooperative coevolution genetic programming," IEEE Trans. Evol. Comput., vol. 18, no. 2, pp. 193-208, 2014.

[36] Z. Peng, J. Zheng, J. Zou, and M. Liu, "Novel prediction and memory strategies for dynamic multiobjective optimization," Soft Comput., vol. 19, no. 9, pp. 2633-2653, 2014.

[37] H. Richter, "Detecting change in dynamic fitness landscapes," in Proc. 2014 IEEE Congr. Evol. Comput. (CEC), 2009, pp. 1613-1620.

[38] S. Salomon, R. C. Purshouse, G. Avigad, and P. J. Fleming, "An evolutionary approach to active robust multiobjective optimisation," in Evolutionary Multi-Criterion Optimization, vol. 9019, Lecture Notes in Computer Science, 2015, pp. 141-155.

[39] J. Schott, "Fault tolerant design using single and multicriteria genetic algorithm optimization," M.S. thesis, Massachusetts of Technology, 1995.

[40] R. Shang, L. Jiao, Y. Ren, L. Li, and L. Wang, "Quantum immune clonal coevolutionary algorithm for dynamic multiobjective optimization," Soft Comput., vol. 18, no. 4, pp.743-756, 2014. 
[41] E. Tantar, A. Tantar, P. Bouvry, "On dynamic multi-objective optimization classification and performance measures," in Proc. 2011 IEEE Congr. Evol. Comput. (CEC), 2011, pp. 2759-2766.

[42] A. Trivedi, D. Srinivasan, S. Biswas, and T. Reindl, "Hybridizing genetic algorithm with different evolution for solving the unit commitment scheduling problem," Swarm Evol. Comput., vol. 23, pp.50-64, 2015

[43] L. Y. Tseng and C. Chen, "Multiple trajectory search for unconstrained/constrained multi-objective optimization," in Proc. 2014 IEEE Congr. Evol. Comput. (CEC), 2009, pp. 1951-1958.

[44] S. Tiwari, G. Fadel, and K. Deb, "AMGA2: Improving the performance of the archive-based micro-genetic algorithm for multi-objective optimization," Eng. Optim., vol. 43, no. 4, pp. 377-401, 2011.

[45] R. Wang, R. C. Purshouse, and P. J. Fleming, "Preference-inspired coevolutionary algorithms for many-objective optimization," IEEE Trans. Evol. Comput., vol. 17, no. 4, pp. 474-494, Aug. 2013.

[46] F. Wilcoxon, "Individual comparisons by ranking methods," Biometrics, vol. 1 , no. 6, pp. 80-83, 1945.

[47] Y. Wu, Y. Jin, and X. Liu, "A directed search strategy for evolutionary dynamic multiobjective optimization," Soft Computing, 2014.

[48] F. Vavak and T. C. Fogarty, "Comparison of steady-state and generational genetic algorithms for use in nonstationary environments," in Proc. 1996 IEEE Int. Conf. Evol. Comput., 1996, pp. 192-195.

[49] Y. Yuan, H. Xu, B. Zhang, and X. Yao, "Balancing convergence and diversity in decomposition-based many-objective optimizers," IEEE Trans. Evol. Comput., vol. 19, no. 5, pp. 694-716, 2015.

[50] Z. Zhang, "Multiobjective optimization immune algorithm in dynamic environments and its application to greenhouse control," Applied Soft Computing, vol. 8, no. 2, pp. 959-971, 2008.

[51] Q. Zhang and H. Li, "MOEA/D: A multiobjective evolutionary algorithm based on decomposition," IEEE Trans. Evol. Comput., vol. 11, no. 6, pp. 712-731, 2007.

[52] Z. Zhang and S. Qian, "Artificial immune system in dynamic environments solving time-varying non-linear constrained multi-objective problems," Soft Comput., vol. 15, no. 7, pp. 1333-1349, 2011.

[53] Q. Zhang, A. Zhou, and Y. Jin, "RM-MEDA: A regularity model-based multiobjective estimation of distribution algorithm," IEEE Trans. Evol. Comput., vol. 12, no. 1, pp. 41-63, 2008.

[54] A. Zhou, Y. Jin, and Q. Zhang, "A population prediction strategy for evolutionary dynamic multiobjective optimization," IEEE Trans. Cybern., vol. 44, no. 1, pp. 40-53, 2014.

[55] A. Zhou, Y. Jin, Q. Zhang, B. Sendhoff, and E. Tsang, "Prediction-based population re-initialization for evolutionary dynamic multi-objective optimization," in Proc. 4th Int. Conf. Evol. Multi-Criterion Optim., 2007, pp. 832-846.
[56] E. Zitzler, M. Laumanns, and L. Thiele, "SPEA2: Improving the strength Pareto evolutionary algorithm for multiobjective optimization," in Proc the EUROGEN Evol. Methods for Design, Optim. and Control with Appl. to Industry Problems, 2002, pp. 95-100.

[57] E. Zitzler and L. Thiele, "Multiobjective evolutionary algorithms: A comparative case study and the strength Pareto approach," IEEE Trans. Evol. Comput., vol. 3, no. 4, pp. 257-271, 1999.

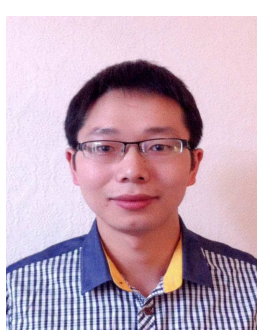

Shouyong Jiang received the B.Sc. degree in information and computation science and the M.Sc. degree in control theory and control engineering from Northeastern University, Shenyang, China in 2011 and 2013, respectively.

$\mathrm{He}$ is currently pursuing the Ph.D. degree in the School of Computer Science and Informatics, De Montfort University, Leicester, U.K. His current research interests include evolutionary computation, multi-objective optimization, and dynamic optimization

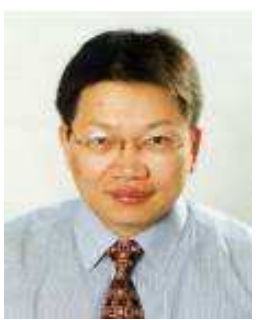

Shengxiang Yang (M'00-SM'14) received the B.Sc. and M.Sc. degrees in automatic control and the Ph.D. degree in systems engineering from Northeastern University, Shenyang, China in 1993, 1996, and 1999, respectively.

$\mathrm{He}$ is currently a Professor in Computational Intelligence and Director of the Centre for Computational Intelligence, School of Computer Science and Informatics, De Montfort University, Leicester, U.K. He has over 210 publications. His current research interests include evolutionary and genetic algorithms, swarm intelligence, computational intelligence in dynamic and uncertain environments, artificial neural networks for scheduling, and relevant real-world applications.

Prof. Yang is the Chair of the Task Force on Evolutionary Computation in Dynamic and Uncertain Environments, under the Evolutionary Computation Technical Committee of the IEEE Computational Intelligence Society and the Founding Chair of the Task Force on Intelligent Network Systems, under the Intelligent Systems Applications Technical Committee of the IEEE Computational Intelligence Society. 


\title{
A Steady-state and Generational Evolutionary Algorithm for Dynamic Multiobjective Optimization -Supplementary Material
}

\author{
Shouyong Jiang and Shengxiang Yang, Senior Member, IEEE
}

This is the supplementary material to the paper entitled "A Steady-state and Generational Evolutionary Algorithm for Dynamic Multiobjective Optimization", submitted to IEEE Transactions on Evolutionary Computation. This material provides the formulation of the test problems used in the paper, followed by some supplementary experimental results.

\section{TEST SUITES}

The test suites used for algorithm analysis are composed of both early- and newly-developed test problems, including biand three-objective instances. The FDA and dMOP test suites are the early ones whereas ZJZ and UDF are new variablelinkage test problems.

As shown in Table XI, the FDA test suite includes three bi-objective and five three-objective dynamic instances, which has often been employed to examine algorithms' performance for DMOPs. Note that, the POS of the original FDA2 does not change with time. To increase optimization difficulties, we have made some changes on FDA2, which is based on the study of Deb et al. in 2007. The dMOP test suite (see Table XII) is an extension of FDA, having three bi-objective instances. For dMOP3, its $G(t)$ function has been adapted to produce a problem with time-changing POS but static POF.

The ZJZ test suite (Table XIII) has four variable-linkage problems. Their dynamisms lie in that the boundary of the POS and/or the curvature of the POF change(s) with time. In F5-F8, the environment changes smoothly, and the geometric shapes of two consecutive POSs are similar to each other in some sense. In F9, the environment changes smoothly in most cases, and occasionally, the POS jumps from one area to another. In F10, the geometric shapes of two consecutive POFs are totally different from each other.

Table XIV lists seven deterministic test problems of the UDF test suite, where UDF8 and UDF9 are excluded due to their nature of randomness that drastically increases optimization difficulties. The UDF problems feature the strong dependency between variables, and in most cases the dependency is time-varying. Also, the UDF problems introduce new dynamisms like angular shift or slope change of the POF, shape change of both a polynomial POS and a trigonometric POS, change of curvature of a spherical POF resulting in different ellipsoids, etc. Note that, there is a basic misunderstanding

The authors are with the Centre for Computational Intelligence (CCI), School of Computer Science and Informatics, De Montfort University, The Gateway, Leicester LE1 9BH, U.K. (email: shouyong.jiang@email.dmu.ac.uk, syang@dmu.ac.uk). of the POF/POS of UDF3 and UDF6. That is, the POS and POF are inconsistent with each other. To make the resulting POS/POF exactly locate in the optimal regions suggested by the UDF developers, we have made very slightly changes in the objective formulation of UDF3 and UDF6.

\section{SUPPLEMENTARY RESULTS ON ZJZ AND UDF PROBLEMS}

Table XV presents the SP, MS, and IGD results of five algorithms on ZJZ and UDF test problems. Generally, SGEA obtains relatively better SP values than the other algorithms in most cases, indicating SGEA has an advantage in population distribution. The good distribution performance of SGEA might be due to the generational environmental selection, which is able to remove overcrowded individuals at the cost of a bit high computational complexity. Similarly, MOEA/D also achieves good distribution on several problems, due to its strength of diversity maintenance. dCOEA and PPS fail to provide good spacing metric on the majority of the test problems. However, when it comes to the spread of approximations, PPS turns the tables by obtaining considerably high MS values. This shows PPS is able to cover the whole region of the POF. In contrast, the other algorithms struggle to spread widely, indicating they face great challenges to solving most of these variable-linkage problems.

Due to good spread performance, it is not surprising that PPS solves most of ZJZ and UDF problems very well in terms of the IGD metric. SGEA obtains very competitive IGD values on F6, F8, F9, F10, UDF1, UDF3, UDF4, and UDF7, but it is outperformed by PPS or DNSGA-II on the rest of the problems. The IGD results also suggest that dCOEA performs the worst, thus it is not suitable for solving these variablelinkage problems. Interestingly, on two three-objective problems, i.e., F8 and UDF7, SGEA performs significantly better than the other algorithms in terms of IGD. This observation shows SGEA may have great potential to solving higherdimensional problems. On the other hand, it can be also seen from Table XV that, PPS and SGEA obtains relatively smaller IGD values on UDF2 and UDF5 than the other UDF instances. This is because UDF2 and UDF5 are two monotonic variablelinkage problems whereas the other UDF problems have non-monotonic dependencies between variables. Monotonic variable linkages are much easier to be cracked than nonmonotonic ones, so PPS and SGEA surely perform better on UDF2 and UDF5 than the other UDF problems. 
TABLE XI

FDA TESt Suite

\begin{tabular}{|c|c|c|c|c|}
\hline Instance & Description & Domain & $n$ & Remarks \\
\hline FDA1 & $\begin{array}{l}f_{1}(x)=x_{1} \\
f_{2}(x)=g(x)\left(1-\sqrt{f_{1} / g(x)}\right) \\
g(x)=1+\sum_{i=2}^{n}\left(x_{i}-G(t)\right)^{2} \\
G(t)=\sin (0.5 \pi t) \\
\operatorname{POS}(t): 0 \leq x_{1} \leq 1, x_{i}=G(t), i=2, \ldots, n \\
\operatorname{POF}(t): f_{2}=1-\sqrt{f_{1}}\end{array}$ & {$[0,1] \times[-1,1]^{n-1}$} & 11 & $\begin{array}{l}\text { POS shifts } \\
\text { POF is static }\end{array}$ \\
\hline FDA2 & $\begin{array}{l}f_{1}(x)=x_{1} \\
f_{2}(x)=g(x)\left(1-\left(f_{1} / g(x)\right)^{2}\left(H(t)+\sum_{j=n-8}^{n}\left(x_{j}-H(t) / 4\right)^{2}\right)\right. \\
g(x)=1+\sum_{i=2}^{n-7} x_{i}^{2} \\
H(t)=2 \sin (0.5 \pi(t-1)) \\
\operatorname{POS}(t): 0 \leq x_{1} \leq 1, x_{i}=0, i=2, \ldots, n-7 \\
x_{j}=H(t), j=n-8, \ldots, n \\
\operatorname{POF}(t): f_{2}=1-f_{1}^{2 H(t)}\end{array}$ & {$[0,1] \times[-1,1]^{n-1}$} & 13 & $\begin{array}{l}\text { POS shifts } \\
\text { POF shape changes }\end{array}$ \\
\hline FDA3 & $\begin{array}{l}f_{1}(x)=\left(x_{1}^{F(t)}+x_{2}^{F(t)}\right) / 2 \\
f_{2}(x)=g(x)\left(1-\sqrt{f_{1} / g(x)}\right) \\
g(x)=1+G(t)+\sum_{i=3}^{n}\left(x_{i}-G(t)\right)^{2} \\
G(t)=|\sin (0.5 \pi t)|, F(t)=10^{2} \sin (0.5 \pi t) \\
\operatorname{POS}(t): 0 \leq x_{1}, x_{2} \leq 1, x_{i}=G(t), i=3, \ldots, n \\
\operatorname{POF}(t): f_{2}=(1+G(t))\left(1-\sqrt{f_{1} /(1+G(t))}\right)\end{array}$ & {$[0,1]^{2} \times[-1,1]^{n-2}$} & 10 & $\begin{array}{l}\text { POS shifts } \\
\text { POF changes }\end{array}$ \\
\hline FDA4 & $\begin{array}{l}f_{1}(x)=\left((1+g(x)) \cos \left(0.5 \pi x_{1}\right) \cos \left(0.5 \pi x_{2}\right)\right) \\
f_{2}(x)=\left((1+g(x)) \cos \left(0.5 \pi x_{1}\right) \sin \left(0.5 \pi x_{2}\right)\right) \\
f_{3}(x)=\left((1+g(x)) \sin \left(0.5 \pi x_{1}\right)\right) \\
g(x)=\sum_{i=3}^{n}\left(x_{i}-G(t)\right)^{2} \\
G(t)=|\sin (0.5 \pi t)| \\
\text { POS }(t): 0 \leq x_{1} \leq 1, x_{i}=G(t) i=2, \ldots, n \\
\text { POF: } f_{1}^{2}+f_{2}^{2}+f_{3}^{2}=1\end{array}$ & {$[0,1]^{n}$} & 12 & $\begin{array}{l}\text { POS shifts } \\
\text { POF is static }\end{array}$ \\
\hline FDA5 & $\begin{array}{l}f_{1}(x)=\left((1+g(x)) \cos \left(0.5 \pi x_{1}^{F(t)}\right) \cos \left(0.5 \pi x_{2}^{F(t)}\right)\right) \\
f_{2}(x)=\left((1+g(x)) \cos \left(0.5 \pi x_{1}^{F(t)}\right) \sin \left(0.5 \pi x_{2}^{F(t)}\right)\right) \\
f_{3}(x)=\left((1+g(x)) \sin \left(0.5 \pi x_{1}^{F(t)}\right)\right) \\
g(x)=G(t)+\sum_{i=3}^{n}\left(x_{i}-G(t)\right)^{2} \\
G(t)=|\sin (0.5 \pi t)|, F(t)=1+100 \sin ^{4}(0.5 \pi t) \\
\text { POS }(t): 0 \leq x_{1}, x_{2} \leq 1, x_{i}=G(t) i=3, \ldots, n \\
\text { POF: } f_{1}^{2}+f_{2}^{2}+f_{3}^{2}=(1+G(t))^{2}\end{array}$ & {$[0,1]^{n}$} & 12 & $\begin{array}{l}\text { POS shifts } \\
\text { POF shifts }\end{array}$ \\
\hline
\end{tabular}

TABLE XII

DMOP TEST SUITE

\begin{tabular}{|c|c|c|c|c|}
\hline Instance & Description & Domain & $n$ & Remarks \\
\hline dMOP1 & $\begin{array}{l}f_{1}(x)=x_{1} \\
f_{2}(x)=g(x)\left(1-f_{1} / g(x)^{H(t)}\right) \\
g(x)=1+\frac{9}{n-1} \sum_{i=2}^{n} x_{i}^{2} \\
H(t)=0.75 * \sin (0.5 \pi t)+1.25 \\
\operatorname{POS}(t): 0 \leq x_{1} \leq 1, x_{i}=0, i=2, \ldots, n \\
\operatorname{POF}(t): f_{2}=1-f_{1} H(t)\end{array}$ & {$[0,1]^{n}$} & 10 & $\begin{array}{l}\text { POS is static } \\
\text { POF shape changes }\end{array}$ \\
\hline dMOP2 & $\begin{array}{l}f_{1}(x)=x_{1} \\
f_{2}(x)=g(x)\left(1-\left(x_{1} / g(x)\right)^{H(t)}\right) \\
g(x)=1+\sum_{i=2}^{n}\left(x_{i}-G(t)\right)^{2} \\
H(t)=0.75 \sin (0.5 \pi t)+1.25, G(t)=|\sin (0.5 \pi t)| \\
\operatorname{POS}(t): 0 \leq x_{1} \leq 1, x_{i}=G(t), i=2, \ldots, n \\
\operatorname{POF}(t): f_{2}=1-f_{1} H(t)\end{array}$ & {$[0,1]^{n}$} & 10 & $\begin{array}{l}\text { POS shifts } \\
\text { POF shape changes }\end{array}$ \\
\hline dMOP3 & $\begin{array}{l}f_{1}(x)=x_{r} \\
f_{2}(x)=g(x)\left(1-\sqrt{f_{1} / g}\right) \\
g(x)=1+\sum_{x_{i} \in x \backslash x_{r}}\left(x_{i}-G(t)\right)^{2} \\
G(t)=|\sin (0.5 \pi t)|, r=U(1, \ldots, n) \\
\operatorname{POS}(t): 0 \leq x_{r} \leq 1, x_{i} \in x \backslash x_{r}=G(t), i=1, \ldots, n \\
\operatorname{POF}(t): f_{2}=1-\sqrt{f_{1}}\end{array}$ & {$[0,1]^{n}$} & 10 & $\begin{array}{l}\text { POS changes } \\
\text { POF is static }\end{array}$ \\
\hline
\end{tabular}


TABLE XIII

ZJZ TEST SUITE

\begin{tabular}{|c|c|c|c|c|}
\hline Instance & Description & Domain & $n$ & Remarks \\
\hline F5 & $\begin{array}{l}f_{1}(x)=\left|x_{1}-a\right|^{H}+\sum_{i \in I_{1}} y_{i}^{2} \\
f_{2}(x)=\left|x_{1}-a-1\right|^{H}+\sum_{i \in I_{2}} y_{i}^{2} \\
y_{i}=x_{i}-b-1+\left|x_{1}-a\right|^{\left(H+\frac{i}{n}\right)}, H=0.75 \sin (\pi t)+1.25 \\
a=2 \cos (\pi t)+2, b=2 \sin (\pi t)+2 \\
I_{1}=\{i \mid 1 \leq i \leq n, i \text { is old }\}, I_{2}=\{i \mid 1 \leq i \leq n, i \text { is even }\} \\
\operatorname{POS}(t): a \leq x_{1} \leq a+1, x_{i}=b+1-\left|x_{1}-a\right|^{\left(H+\frac{i}{n}\right)}, i=2, \ldots, n \\
\operatorname{POF}(t): f_{2}=\left(1-f_{1} \frac{1}{H}\right)^{H}\end{array}$ & {$[0,5]^{n}$} & 11 & $\begin{array}{l}\text { POS changes } \\
\text { POF changes }\end{array}$ \\
\hline F6 & $\begin{array}{l}f_{1}(x)=\left|x_{1}-a\right|^{H}+\sum_{i \in I_{1}} y_{i}^{2} \\
f_{2}(x)=\left|x_{1}-a-1\right|^{H}+\sum_{i \in I_{2}} y_{i}^{2} \\
y_{i}=x_{i}-b-1+\left|x_{1}-a\right|^{\left(H+\frac{1}{n}\right)}, H=0.75 \sin (\pi t)+1.25 \\
a=2 \cos (1.5 \pi t) \sin (0.5 \pi t)+2, b=2 \cos (1.5 \pi t) \sin (0.5 \pi t)+2 \\
I_{1}=\{i \mid 1 \leq i \leq n, i \text { is old }\}, I_{2}=\{i \mid 1 \leq i \leq n, i \text { is even }\} \\
\operatorname{POS}(t): a \leq x_{1} \leq a+1, x_{i}=b+1-\left|x_{1}-a\right|^{\left(H+\frac{i}{n}\right)}, i=2, \ldots, n \\
\operatorname{POF}(t): f_{2}=\left(1-f_{1} \frac{1}{H}\right)^{H}\end{array}$ & {$[0,5]^{n}$} & 11 & $\begin{array}{l}\text { POS changes } \\
\text { POF changes }\end{array}$ \\
\hline F7 & $\begin{array}{l}f_{1}(x)=\left|x_{1}-a\right|^{H}+\sum_{i \in I_{1}} y_{i}^{2} \\
f_{2}(x)=\left|x_{1}-a-1\right|^{H}+\sum_{i \in I_{2}} y_{i}^{2} \\
y_{i}=x_{i}-b-1+\left|x_{1}-a\right|^{\left(H+\frac{1}{n}\right)}, H=0.75 \sin (\pi t)+1.25 \\
a=1.7(1-\sin (\pi t)) \sin (\pi t)+3.4, b=1.4(1-\sin (\pi t)) \cos (\pi t)+2.1 \\
I_{1}=\{i \mid 1 \leq i \leq n, i \text { is old }\}, I_{2}=\{i \mid 1 \leq i \leq n, i \text { is even }\} \\
\operatorname{POS}(t): a \leq x_{1} \leq a+1, x_{i}=b+1-\left|x_{1}-a\right|^{\left(H+\frac{i}{n}\right)}, i=2, \ldots, n \\
\operatorname{POF}(t): f_{2}=\left(1-f_{1} \frac{1}{H}\right)^{H}\end{array}$ & {$[0,5]^{n}$} & 11 & $\begin{array}{l}\text { POS changes } \\
\text { POF changes }\end{array}$ \\
\hline F8 & $\begin{array}{l}f_{1}(x)=\left((1+g(x)) \cos \left(0.5 \pi x_{1}\right) \cos \left(0.5 \pi x_{2}\right)\right) \\
f_{2}(x)=\left((1+g(x)) \cos \left(0.5 \pi x_{1}\right) \sin \left(0.5 \pi x_{2}\right)\right) \\
f_{3}(x)=\left((1+g(x)) \sin \left(0.5 \pi x_{1}\right)\right) \\
g(x) \sum_{i=3}^{n}\left(x_{i}-\left(\frac{x_{1}+x_{2}}{2}\right)^{H}-G\right)^{2} \\
G=\sin (0.5 \pi t) \mid, H=0.75 \sin (\pi t)+1.25 \\
\left.\text { POS }(t): 0 \leq x_{1}, x_{2} \leq 1, x_{i}=\frac{x_{1}+x_{2}}{2}\right)^{H}+G, i=3, \ldots, n \\
\text { POF: } f_{1}^{2}+f_{2}^{2}+f_{3}^{2}=1\end{array}$ & {$[0,1]^{2} \times[-1,2]^{n-2}$} & 12 & $\begin{array}{l}\text { POS changes } \\
\text { POF changes }\end{array}$ \\
\hline F9 & $\begin{array}{l}f_{1}(x)=\left|x_{1}-a\right|^{H}+\sum_{i \in I_{1}} y_{i}^{2} \\
f_{2}(x)=\left|x_{1}-a-1\right|^{H}+\sum_{i \in I_{2}} y_{i}^{2} \\
y_{i}=x_{i}-b-1+\left|x_{1}-a\right|^{\left(H+\frac{1}{n}\right)}, H=0.75 \sin (\pi t)+1.25 \\
a=2 \cos (\pi(t-\lfloor t\rfloor))+2, b=2 \sin (2 \pi(t-\lfloor t\rfloor))+2 \\
I_{1}=\{i \mid 1 \leq i \leq n, i \text { is old }\}, I_{2}=\{i \mid 1 \leq i \leq n, i \text { is even }\} \\
\operatorname{POS}(t): a \leq x_{1} \leq a+1, x_{i}=b+1-\left|x_{1}-a\right|^{\left(H+\frac{i}{n}\right)}, i=2, \ldots, n \\
\operatorname{POF}(t): f_{2}=\left(1-f_{1} \frac{1}{H}\right)^{H}\end{array}$ & {$[0,5]^{n}$} & 11 & $\begin{array}{l}\text { POS changes } \\
\text { POF changes }\end{array}$ \\
\hline F10 & $\begin{array}{l}f_{1}(x)=\left|x_{1}-a\right|^{H}+\sum_{i \in I_{1}} y_{i}^{2} \\
f_{2}(x)=\left|x_{1}-a-1\right|^{H}+\sum_{i \in I_{2}} y_{i}^{2} \\
y_{i}=x_{i}-b-\left|x_{1}-a\right|^{\left(H+\frac{1}{n}\right)}, \text { if }\left\lfloor\tau / \tau_{t}\right\rfloor \text { is odd } \\
y_{i}=x_{i}-b-1+\left|x_{1}-a\right|^{\left(H+\frac{1}{n}\right)}, \text { if }\left\lfloor\tau / \tau_{t}\right\rfloor \text { is even } \\
H=0.75 \sin (\pi t)+1.25 \\
a=2 \cos (\pi t)+2, b=2 \sin (2 \pi t)+2 \\
I_{1}=\{i \mid 1 \leq i \leq n, i \text { is old }\}, I_{2}=\{i \mid 1 \leq i \leq n, i \text { is even }\} \\
\operatorname{POS}(t): a \leq x_{1} \leq a+1, x_{i}=b+1-\left|x_{1}-a\right|^{\left(H+\frac{i}{n}\right)}, i=2, \ldots, n \\
\operatorname{POF}(t): f_{2}=\left(1-f_{1} \frac{1}{H}\right)^{H}\end{array}$ & {$[0,5]^{n}$} & 11 & $\begin{array}{l}\text { POS changes } \\
\text { POF changes }\end{array}$ \\
\hline
\end{tabular}

\section{Supplementary Results on Different SeVERity LEVELS}

This section presents supplementary results of five algorithms on the SP, MS, and IGD metrics, which are given in Tables XVI, XVII, XVIII, respectively.

We can observe from the tables that, both DNSGA-II and SGEA provide very promising SP values for most of the test instances, and DNSGA-II performs the best on FDA2 and FDA3 whereas SGEA significantly wins on FDA1, FDA5, and three dMOP problems with respect to the SP metric. dCOEA shows its good distribution on FDA4 when changes are not slight, meaning that it may be able to handle severe changes. For the MS metric, SGEA obtains highly competitive results on all the test instances except dMOP3, in which only dCOEA and PPS can make a spread coverage of approximation. The IGD performance of SGEA on the majority of the instances is quite impressive, and this algorithm is mainly exceeded by dCOEA on only two problems, i.e., FDA4 and dMOP3. The outperformance of SGEA over the other algorithms on the IGD metric is probably due to its good distribution and spread abilities. Nevertheless, the spread ability of SGEA may be challenged when solving problems like dMOP3, which can impose severe diversity loss in dynamic environments.

On the other hand, all the algorithms are very sensitive to the severity of change, as can be seen from the improvement of the metrics when increasing the value of $n_{t}$. For MS and IGD, dCOEA and SGEA seem to be least influenced by $n_{t}$, and the other algorithms experience significant changes for 
TABLE XIV

UDF TEST SUITE

\begin{tabular}{|c|c|c|c|c|}
\hline Instance & Description & Domain & $n$ & Remarks \\
\hline UDF1 & $\begin{array}{l}f_{1}(x)=x_{1}+|G|+\frac{2}{J_{1}} \sum_{j \in J_{1}} y_{j}^{2} \\
f_{2}(x)=1-x_{1}+|G|+\frac{2}{J_{2}} \sum_{j \in J_{2}} y_{j}^{2} \\
y_{j}=x_{j}-\sin \left(6 \pi x_{1}+j \frac{\pi}{n}\right)-G, G=\sin (0.5 \pi t) \\
J_{1}=\{j \mid 1 \leq j \leq n, j \text { is old }\}, J_{2}=\{j \mid 1 \leq i \leq n, j \text { is even }\} \\
\operatorname{POS}(t): 0 \leq x_{1} \leq 1, x_{i}=\sin \left(6 \pi x_{1}+j \frac{\pi}{n}\right)+G, i=2, \ldots, n \\
\operatorname{POF}(t): f_{1}+f_{2}=1+2|G|,|G| \leq f_{1} \leq 1+|G|\end{array}$ & {$[0,1] \times[-2,2]^{n-1}$} & 10 & $\begin{array}{l}\text { POS shifts } \\
\text { POF shifts }\end{array}$ \\
\hline UDF2 & $\begin{array}{l}f_{1}(x)=x_{1}+|G|+\frac{2}{J_{1}} \sum_{j \in J_{1}} y_{j}^{2} \\
f_{2}(x)=1-x_{1}+|G|+\frac{2}{J_{2}} \sum_{j \in J_{2}} y_{j}^{2} \\
y_{j}=x_{j}-x_{1} 0.5\left(2+3 \frac{j-2}{n-2}+G\right)-G, G=\sin (0.5 \pi t) \\
J_{1}=\{j \mid 1 \leq j \leq n, j \text { is old }\}, J_{2}=\{j \mid 1 \leq i \leq n, j \text { is even }\} \\
\operatorname{POS}(t): 0 \leq x_{1} \leq 1, x_{i}=x_{1} 1\left(2+3 \frac{j-2}{n-2}+G\right)+G, i=2, \ldots, n \\
\operatorname{POF}(t): f_{1}+f_{2}=1+2|G|,|G| \leq f_{1} \leq 1+|G|\end{array}$ & {$[0,1] \times[-1,2]^{n-1}$} & 10 & $\begin{array}{l}\text { POS changes } \\
\text { POF shifts }\end{array}$ \\
\hline UDF3 & $\begin{aligned} & f_{1}(x)= x_{1}+\max \left(0,\left(\frac{1}{2 N}+\epsilon\right) \sin \left(2 N \pi x_{1}\right)\right)+|G| \\
&+\frac{2}{J_{1}}\left(4 \sum_{j \in J_{1}} 2 y_{j}^{2}-2 \prod_{j \in J_{1}} \cos \left(\frac{20 \pi y_{j}}{\sqrt{3}}\right)+2\right) \\
& f_{2}(x)= 1-x_{1}+\max \left(0,\left(\frac{1}{2 N}+\epsilon\right) \sin (2 N \pi)\right)+|G| \\
&+\frac{2}{J_{2}}\left(4 \sum_{j \in J_{2}} 2 y_{j}^{2}-2 \prod_{j \in J_{2}} \cos \left(\frac{20 \pi y_{j}}{\sqrt{3}}\right)+2\right) \\
& y_{j}=x_{j}-\sin \left(6 \pi x_{1}+j \frac{\pi}{n}\right), G=\sin (0.5 \pi t), N=10, \epsilon=0.1 \\
& J_{1}=\{j \mid 1 \leq j \leq n, j \text { is old }\}, J_{2}=\{j \mid 1 \leq i \leq n, j \text { is even }\} \\
& \operatorname{POS}(t): 0 \leq x_{1} \leq 1, x_{i}=\sin \left(6 \pi x_{1}+j \frac{\pi}{n}\right), i=2, \ldots, n \\
& \operatorname{POF}(t):(0,1) \text { and } \bigcup_{i=1}^{N}\left[\frac{2 i-1}{2 N}+|G|, \frac{2 i}{2 N}+|G|\right], i=1, \ldots, N\end{aligned}$ & {$[0,1] \times[-1,1]^{n-1}$} & 10 & $\begin{array}{l}\text { POS is static } \\
\text { POF changes }\end{array}$ \\
\hline UDF4 & $\begin{array}{l}f_{1}(x)=x_{1}+\frac{2}{J_{1}} \sum_{j \in J_{1}} y_{j}^{2} \\
f_{2}(x)=1-H x_{1}^{H}+\frac{2}{J_{2}} \sum_{j \in J_{2}} y_{j}^{2} \\
y_{j}=x_{j}-\sin \left(6 \pi x_{1}+(j+K) \frac{\pi}{n}\right)-G \\
G=\sin (0.5 \pi t), H=0.5+|G|, K=\lceil n G\rceil \\
J_{1}=\{j \mid 1 \leq j \leq n, j \text { is old }\}, J_{2}=\{j \mid 1 \leq i \leq n, j \text { is even }\} \\
\operatorname{POS}(t): 0 \leq x_{1} \leq 1, x_{i}=\sin \left(6 \pi x_{1}+j \frac{\pi}{n}\right)+G, i=2, \ldots, n \\
\operatorname{POF}(t): f_{1}+f_{2}=1+2|G|,|G| \leq f_{1} \leq 1+|G|\end{array}$ & {$[0,1] \times[-1,1]^{n-1}$} & 10 & $\begin{array}{l}\text { POS is changes } \\
\text { POF changes }\end{array}$ \\
\hline UDF5 & $\begin{array}{l}f_{1}(x)=x_{1}+\frac{2}{J_{1}} \sum_{j \in J_{1}} y_{j}^{2} \\
f_{2}(x)=1-H x_{1}^{H}+\frac{2}{J_{2}} \sum_{j \in J_{2}} y_{j}^{2} \\
y_{j}=x_{j}-x_{1} 0.5\left(2+3 \frac{j-2}{n-2}+G\right)-G \\
G=\sin (0.5 \pi t), H=0.5+|G| \\
J_{1}=\{j \mid 1 \leq j \leq n, j \text { is old }\}, J_{2}=\{j \mid 1 \leq i \leq n, j \text { is even }\} \\
\operatorname{POS}(t): 0 \leq x_{1} \leq 1, x_{i}=x_{1} 0.5\left(2+3 \frac{j-2}{n-2}+G\right) \\
\operatorname{POF}(t): f_{1}+f_{2}=1+2|G|,|G| \leq f_{1} \leq 1+|G|\end{array}$ & {$[0,1] \times[-1,2]^{n-1}$} & 10 & $\begin{array}{l}\text { POS changes } \\
\text { POF changes }\end{array}$ \\
\hline UDF6 & $\begin{array}{l}f_{1}(x)=x_{1}+\left(\frac{1}{2 N}+\epsilon\right)\left|\sin \left(2 N \pi x_{1}\right)\right|+|G|+\frac{2}{J_{1}} \sum_{j \in J_{1}}\left(2 y_{j}^{2}-\cos \left(4 \pi y_{j}\right)+1\right)^{2} \\
f_{2}(x)=1-x_{1}+\left(\frac{1}{2 N}+\epsilon\right)\left|\sin \left(2 N \pi x_{1}\right)\right|+|G|+\frac{2}{J_{2}} \sum_{j \in J_{2}}\left(2 y_{j}^{2}-\cos \left(4 \pi y_{j}\right)+1\right)^{2} \\
y_{j}=x_{j}-\sin \left(6 \pi x_{1}+j \frac{\pi}{n}\right), G=\sin (0.5 \pi t), N=10, \epsilon=0.1 \\
J_{1}=\{j \mid 1 \leq j \leq n, j \text { is old }\}, J_{2}=\{j \mid 1 \leq i \leq n, j \text { is even }\} \\
\operatorname{POS}(t): 0 \leq x_{1} \leq 1, x_{i}=\sin \left(6 \pi x_{1}+j \frac{\pi}{n}\right), i=2, \ldots, n \\
\operatorname{POF}(t):(0,1) \text { and } \bigcup_{i=1}^{N}\left[\frac{2 i-1}{2 N}+|G|, \frac{2 i}{2 N}+|G|\right], i=1, \ldots, N \\
\end{array}$ & {$[0,1] \times[-1,1]^{n-1}$} & 10 & $\begin{array}{l}\text { POS is static } \\
\text { POF changes }\end{array}$ \\
\hline UDF7 & $\begin{array}{l}f_{1}(x)=\left(R \cos \left(0.5 \pi x_{1}\right) \cos \left(0.5 \pi x_{2}\right)\right)+G+\frac{2}{J_{1}} \sum_{j \in J_{1}} y_{j}^{2} \\
f_{2}(x)=\left(R \cos \left(0.5 \pi x_{1}\right) \sin \left(0.5 \pi x_{2}\right)\right)+G+\frac{2}{J_{2}} \sum_{j \in J_{2}} y_{j}^{2} \\
f_{3}(x)=\left(R \sin \left(0.5 \pi x_{1}\right)\right)+G+\frac{2}{J_{3}} \sum_{j \in J_{3}} y_{j}^{2} \\
y_{j}=x_{j}-2 x_{2} \sin \left(2 \pi x_{1}+j \frac{\pi}{n}\right), G=\sin (0.5 \pi t), R=1+|G| \\
J_{1}=\{j \mid \bmod (j, 3)=2\}, J_{2}=\{j \mid \bmod (j, 3)=0\}, J_{3}=\{j \mid \bmod (j, 3)=1\}, 1 \leq j \leq n \\
\text { POS }(t): 0 \leq x_{1}, x_{2} \leq 1, x_{i}=2 x_{2} \sin \left(2 \pi x_{1}+j \frac{\pi}{n}\right), i=3, \ldots, n \\
\text { POF: }\left(f_{1}-G\right)^{2}+\left(f_{2}-G\right)^{2}+\left(f_{3}-G\right)^{2}=R^{2}, 0 \leq f_{1}, f_{2}, f_{3} \leq 1\end{array}$ & {$[0,1]^{2} \times[-2,2]^{n-2}$} & 10 & $\begin{array}{l}\text { POS is static } \\
\text { POF changes }\end{array}$ \\
\hline
\end{tabular}

most of the problems on these metrics with the increase of the $n_{t}$ value. However, for the problem dMOP3, the MS and IGD metric of SGEA deteriorates with the decrease of the severity level. One possible explanation is that, on dMOP3, the degree of diversity loss is roughly the same for different severity levels, but for different severity levels, SGEA reacts to changes differently, with a large movement step-size for severe changes $\left(n_{t}=5\right)$ and a small movement step-size for slight ones $\left(n_{t}=20\right)$. A larger movement step-size is likely to increase population diversity more than a smaller one, and better population diversity tends to provide better coverage values. Thus, an increase of the value of $n_{t}$ leads to the deterioration of the MS metric, which in turn results in the decrease of the IGD metric. Such impact suggests that SGEA may need diversity increase techniques to deal with problems like dMOP3. 
TABLE XV

MEAN AND STANDARD DEVIATION VALUES OF THREE METRICS OBTAINED BY FIVE ALGORITHMS

\begin{tabular}{|c|c|c|c|c|c|c|}
\hline & & DNSGA-II & dCOEA & PPS & MOEAD & SGEA \\
\hline \multirow{3}{*}{ F5 } & SP & $4.1305 \mathrm{E}-2(5.1942 \mathrm{E}-3)^{\dagger}$ & $1.3326 \mathrm{E}-1(7.3645 \mathrm{E}-2)^{\ddagger}$ & $8.7543 \mathrm{E}-2(2.3159 \mathrm{E}-2)^{\ddagger}$ & 3.3350E-2(3.6146E-3) & 3.8765E-2(7.1231E-3) \\
\hline & MS & $6.0023 \mathrm{E}-1(2.7069 \mathrm{E}-2)$ & $3.0085 \mathrm{E}-1(6.8719 \mathrm{E}-2)^{\ddagger}$ & $9.2766 \mathrm{E}-1(1.7241 \mathrm{E}-2)$ & $6.1657 \mathrm{E}-1(1.8022 \mathrm{E}-2)$ & 5.0748E-1(4.2309E-2) \\
\hline & IGD & $7.8262 \mathrm{E}-1(3.9446 \mathrm{E}-2)^{\ddagger}$ & $8.0110 \mathrm{E}-1(2.2441 \mathrm{E}-1)^{\ddagger}$ & 2.6924E-1(4.3332E-2) & $6.8854 \mathrm{E}-1(4.1976 \mathrm{E}-2)^{\ddagger}$ & 4.4195E-1(4.5046E-2) \\
\hline \multirow{3}{*}{ F6 } & SP & $3.0175 \mathrm{E}-2(4.3517 \mathrm{E}-3)^{\ddagger}$ & $1.8272 \mathrm{E}-1(8.9110 \mathrm{E}-2)^{\ddagger}$ & $1.2104 \mathrm{E}-1(3.4235 \mathrm{E}-2)^{\ddagger}$ & $2.7848 \mathrm{E}-2(3.1905 \mathrm{E}-3)^{\dagger}$ & $2.5625 \mathrm{E}-2(4.2917 \mathrm{E}-3)$ \\
\hline & MS & 7.4874E-1(3.1144E-2) & $3.5806 \mathrm{E}-1(4.4452 \mathrm{E}-2)^{\ddagger}$ & $9.1340 \mathrm{E}-1(2.6124 \mathrm{E}-2)$ & $7.2733 \mathrm{E}-1(3.1594 \mathrm{E}-2)$ & $6.6810 \mathrm{E}-1(2.5050 \mathrm{E}-2)$ \\
\hline & IGD & $3.0203 \mathrm{E}-1(2.1309 \mathrm{E}-2)^{\dagger}$ & $6.5794 \mathrm{E}-1(1.3275 \mathrm{E}-1)^{\ddagger}$ & 2.6023E-1(6.5503E-2) $)^{\dagger}$ & $3.4491 \mathrm{E}-1(5.6149 \mathrm{E}-2)^{\ddagger}$ & 2.9035E-1(1.3498E-2) \\
\hline \multirow{3}{*}{ F7 } & SP & $2.0466 \mathrm{E}-2(4.1072 \mathrm{E}-3)^{\dagger}$ & $1.1142 \mathrm{E}-1(7.2215 \mathrm{E}-2)^{\ddagger}$ & $9.6713 \mathrm{E}-2(2.4803 \mathrm{E}-2)^{\mp}$ & $2.2152 \mathrm{E}-2(4.4633 \mathrm{E}-3)^{\ddagger}$ & $1.8485 \mathrm{E}-2(3.6509 \mathrm{E}-3)$ \\
\hline & MS & $5.2999 \mathrm{E}-1(2.0255 \mathrm{E}-2)$ & $2.2973 \mathrm{E}-1(4.9128 \mathrm{E}-2)^{\ddagger}$ & 9.1852E-1(2.7465E-2) & $6.2445 \mathrm{E}-1(1.7365 \mathrm{E}-2)$ & 4.5375E-1(2.5882E-2) \\
\hline & IGD & $4.1988 \mathrm{E}-1(6.9493 \mathrm{E}-3)^{\dagger}$ & $1.5695 \mathrm{E}+0(6.0322 \mathrm{E}-1)^{\ddagger}$ & 2.6369E-1(7.1414E-2) & $4.1863 \mathrm{E}-1(6.0017 \mathrm{E}-2)^{\dagger}$ & 4.4742E-1(1.0215E-2) \\
\hline \multirow{3}{*}{ F8 } & SP & $1.5246 \mathrm{E}-1(2.1465 \mathrm{E}-2)^{\ddagger}$ & $2.2866 \mathrm{E}-1(7.8455 \mathrm{E}-2)^{\ddagger}$ & $3.0005 \mathrm{E}-1(2.7912 \mathrm{E}-2)^{\ddagger}$ & $5.3405 \mathrm{E}-1(1.8994 \mathrm{E}-1)^{\ddagger}$ & $6.8969 \mathrm{E}-2(1.6541 \mathrm{E}-2)$ \\
\hline & MS & $1.0000 \mathrm{E}+0(4.8026 \mathrm{E}-9)$ & $8.9463 \mathrm{E}-1(7.9732 \mathrm{E}-2)^{\ddagger}$ & $9.9930 \mathrm{E}-1(1.4674 \mathrm{E}-4)^{\ddagger}$ & $9.9983 \mathrm{E}-1(7.6740 \mathrm{E}-4)^{\ddagger}$ & $9.9998 \mathrm{E}-1(1.6568 \mathrm{E}-5)$ \\
\hline & IGD & $4.8669 \mathrm{E}-1(1.3287 \mathrm{E}-2)^{\ddagger}$ & $4.0033 \mathrm{E}-1(6.7456 \mathrm{E}-2)^{\ddagger}$ & $4.5632 \mathrm{E}-1(3.1250 \mathrm{E}-2)^{\ddagger}$ & $5.4900 \mathrm{E}-1(2.3683 \mathrm{E}-2)^{\ddagger}$ & 2.5119E-1(1.4621E-2) \\
\hline \multirow{3}{*}{ F9 } & SP & $3.7039 \mathrm{E}-2(6.3222 \mathrm{E}-3)$ & $2.1175 \mathrm{E}-1(8.1020 \mathrm{E}-2)^{\ddagger}$ & $1.5146 \mathrm{E}-1(2.3296 \mathrm{E}-2)^{\ddagger}$ & $3.1090 \mathrm{E}-2(4.2792 \mathrm{E}-3)$ & $4.1831 \mathrm{E}-2(1.0482 \mathrm{E}-2)$ \\
\hline & MS & $6.6866 \mathrm{E}-1(2.3963 \mathrm{E}-2)$ & $3.1904 \mathrm{E}-1(7.6351 \mathrm{E}-2)^{\ddagger}$ & 8.7697E-1(1.4230E-2) & $6.8434 \mathrm{E}-1(1.5545 \mathrm{E}-2)$ & 5.7945E-1(4.7702E-2) \\
\hline & IGD & $4.7433 \mathrm{E}-1(2.1642 \mathrm{E}-2)^{\ddagger}$ & $8.8765 \mathrm{E}-1(3.3403 \mathrm{E}-1)^{\ddagger}$ & $3.5937 \mathrm{E}-1(4.4137 \mathrm{E}-2)^{\dagger}$ & $4.2973 \mathrm{E}-1(2.4350 \mathrm{E}-2)^{\ddagger}$ & 3.6562E-1(3.4308E-2) \\
\hline \multirow{3}{*}{$\mathrm{F} 10$} & SP & $7.2754 \mathrm{E}-2(9.3243 \mathrm{E}-3)^{\ddagger}$ & $1.4275 \mathrm{E}-1(9.5345 \mathrm{E}-2)^{\ddagger}$ & $1.1666 \mathrm{E}-1(2.3391 \mathrm{E}-2)^{\ddagger}$ & $3.9906 \mathrm{E}-2(5.8603 \mathrm{E}-3)^{\dagger}$ & $3.6406 \mathrm{E}-2(5.9213 \mathrm{E}-3)$ \\
\hline & MS & $5.0622 \mathrm{E}-1(2.4791 \mathrm{E}-2)$ & $3.7811 \mathrm{E}-1(3.7959 \mathrm{E}-2)^{\ddagger}$ & 8.8624E-1(2.3515E-2) & $5.7719 \mathrm{E}-1(3.4409 \mathrm{E}-2)^{\dagger}$ & $5.3786 \mathrm{E}-1(2.7667 \mathrm{E}-2)$ \\
\hline & IGD & $1.0577 \mathrm{E}+0(1.5624 \mathrm{E}-1)^{\ddagger}$ & $5.7658 \mathrm{E}-1(8.1792 \mathrm{E}-2)^{\ddagger}$ & 3.7984E-1(8.7978E-2) $)^{\dagger}$ & $6.3930 \mathrm{E}-1(8.6115 \mathrm{E}-2)^{\ddagger}$ & 3.8048E-1(1.3943E-2) \\
\hline \multirow{3}{*}{ UDF1 } & SP & $3.0505 \mathrm{E}-2(1.7040 \mathrm{E}-2)^{\ddagger}$ & $2.0796 \mathrm{E}-1(4.1717 \mathrm{E}-2)^{\mp}$ & $1.4525 \mathrm{E}-1(2.6404 \mathrm{E}-2)^{\ddagger}$ & $2.3242 \mathrm{E}-2(8.1812 \mathrm{E}-3)^{\dagger}$ & 2.1084 \\
\hline & MS & & & & $7.7672 \mathrm{E}-1(1.1789 \mathrm{E}-1)^{\dagger}$ & E-1) \\
\hline & IGD & $1.0773 \mathrm{E}-1(2.4143 \mathrm{E}-2)$ & $2.9132 \mathrm{E}-1(2.3521 \mathrm{E}-2)^{\ddagger}$ & $2.6784 \mathrm{E}-1(2.2828 \mathrm{E}-2)^{\ddagger}$ & $1.7021 \mathrm{E}-1(5.1960 \mathrm{E}-2)^{\ddagger}$ & $1.2449 \mathrm{E}-1(3.3093 \mathrm{E}-2)$ \\
\hline \multirow{3}{*}{ UDF2 } & SP & $2.0358 \mathrm{E}-2(5.5219 \mathrm{E}-3)^{\dagger}$ & $5.1134 \mathrm{E}-2(1.0858 \mathrm{E}-2)^{\ddagger}$ & $973 E-2(1.9316 E-3)$ & $9 \mathrm{E}-2(2.3432 \mathrm{E}-3)^{\mp}$ & $2.0023 \mathrm{E}-2(4.5013 \mathrm{E}-3)$ \\
\hline & MS & $8.1659 \mathrm{E}-1(3.0827 \mathrm{E}-2)^{\dagger}$ & $5.9608 \mathrm{E}-1(2.8683 \mathrm{E}-2)^{\ddagger}$ & $961 E$ & $15 \mathrm{E}-2)$ & 7.990 \\
\hline & IGD & $1.1212 \mathrm{E}-1(1.0639 \mathrm{E}-2)^{\ddagger}$ & $1.8355 \mathrm{E}-1(2.0799 \mathrm{E}-2)^{\ddagger}$ & $2.5432 \mathrm{E}-2(5.0224 \mathrm{E}-3)$ & $1.1651 \mathrm{E}-1(9.5585 \mathrm{E}-3)^{\ddagger}$ & $8.9530 \mathrm{E}-$ \\
\hline \multirow{3}{*}{ UDF3 } & SP & $7.0693 \mathrm{E}-3(5.4821 \mathrm{E}-4)^{\ddagger}$ & $9.0140 \mathrm{E}+0(5.6139 \mathrm{E}+0)^{\ddagger}$ & $2.0728 \mathrm{E}+1(1.0781 \mathrm{E}+1)^{\ddagger}$ & $8.6347 \mathrm{E}-3(1.7376 \mathrm{E}-4)^{\ddagger}$ & $6.4064 \mathrm{E}-3(6.5391 \mathrm{E}-4)$ \\
\hline & MS & $4.6688 \mathrm{E}-1(2.9685 \mathrm{E}-3)^{\dagger}$ & $1.3816 \mathrm{E}-1(4.7570 \mathrm{E}-2)^{\ddagger}$ & $9.3051 E-2(7.5817 \mathrm{E}-2)$ & $4.6585 \mathrm{E}-1(1.7802 \mathrm{E}-3)^{\dagger}$ & 4.6569E-1(2.9756E-3) \\
\hline & IGD & $6.0670 \mathrm{E}-1(3.3698 \mathrm{E}-6)^{\dagger}$ & $6.5168 \mathrm{E}-1(7.7269 \mathrm{E}-2)^{\ddagger}$ & $4.5537 \mathrm{E}+0(1.1182 \mathrm{E}+0)^{\ddagger}$ & $6.0682 \mathrm{E}-1(6.3837 \mathrm{E}-5)^{\dagger}$ & $6.0668 \mathrm{E}-1(7.4343 \mathrm{E}-6)$ \\
\hline \multirow{3}{*}{ UDF4 } & $\mathrm{SP}$ & $1.3901 \mathrm{E}-2(7.1488 \mathrm{E}-3)^{\dagger}$ & $1.8505 \mathrm{E}-1(3.4702 \mathrm{E}-2)^{\ddagger}$ & $6.9258 \mathrm{E}-2(6.1038 \mathrm{E}-3)^{\ddagger}$ & 8.3353E-3(7.0013E-3) & $1.3755 \mathrm{E}-2(9.3584 \mathrm{E}-3)$ \\
\hline & MS & $6.7204 \mathrm{E}-1(1.0776 \mathrm{E}-1)^{\dagger}$ & $4.9713 \mathrm{E}-1(4.6596 \mathrm{E}-2)^{\ddagger}$ & 8.8494E-1(7.7262E-3) & $3.8658 \mathrm{E}-1(2.3906 \mathrm{E}-1)^{\ddagger}$ & 6.3916E-1(1.0243E-1) \\
\hline & IGD & $1.7068 \mathrm{E}-1(4.7922 \mathrm{E}-2)^{\dagger}$ & $2.8767 \mathrm{E}-1(2.8653 \mathrm{E}-2)^{\ddagger}$ & $1.8534 \mathrm{E}-1(8.2515 \mathrm{E}-3)^{\ddagger}$ & $3.1914 \mathrm{E}-1(1.3012 \mathrm{E}-1)^{\ddagger}$ & $1.6898 \mathrm{E}-1(4.4846 \mathrm{E}-2)$ \\
\hline \multirow{3}{*}{ UDF5 } & SP & $2.0649 \mathrm{E}-2(3.7285 \mathrm{E}-3)^{\dagger}$ & $4.9643 \mathrm{E}-2(9.1119 \mathrm{E}-3)^{\mp}$ & $1.5136 \mathrm{E}-2(7.2818 \mathrm{E}-3)$ & $1.8149 \mathrm{E}-2(2.1542 \mathrm{E}-3)^{\dagger}$ & $1.9872 \mathrm{E}-2(4.9098 \mathrm{E}-3)$ \\
\hline & MS & $8.2595 \mathrm{E}-1(3.5301 \mathrm{E}-2)^{\dagger}$ & $6.0877 \mathrm{E}-1(3.4923 \mathrm{E}-2)^{\ddagger}$ & $9.7851 E-1(6.2395 E-3)$ & $7.8208 \mathrm{E}-1(2.8993 \mathrm{E}-2)^{\dagger}$ & 7.9127E-1(3.9154E-2) \\
\hline & IGD & $1.1855 \mathrm{E}-1(1.2702 \mathrm{E}-2)^{\ddagger}$ & $2.0550 \mathrm{E}-1(3.5590 \mathrm{E}-2)^{\ddagger}$ & $2.8919 \mathrm{E}-2(1.3147 \mathrm{E}-2)$ & $1.6145 \mathrm{E}-1(1.4778 \mathrm{E}-2)^{\ddagger}$ & $1.0060 \mathrm{E}-1(1.1665 \mathrm{E}-2)$ \\
\hline \multirow{3}{*}{ UDF6 } & SP & $7.2716 \mathrm{E}-2(3.0720 \mathrm{E}-2)$ & 7.5137E-2(5.9636E-2) & $1.9746 \mathrm{E}-1(2.0849 \mathrm{E}-2)^{\ddagger}$ & 3.7043E-2(9.2546E-3) & $9.1724 \mathrm{E}-2(2.6126 \mathrm{E}-2)$ \\
\hline & MS & $2.8465 \mathrm{E}-1(7.2939 \mathrm{E}-2)$ & $2.5459 \mathrm{E}-2(1.6907 \mathrm{E}-2)^{\ddagger}$ & $1.1087 \mathrm{E}-1(4.9999 \mathrm{E}-2)^{\ddagger}$ & $1.6277 \mathrm{E}-1(3.4706 \mathrm{E}-2)$ & $1.4911 \mathrm{E}-1(1.1118 \mathrm{E}-1)$ \\
\hline & IGD & 4.5779E-1(8.7098E-2) & $8.0414 \mathrm{E}-1(1.0972 \mathrm{E}-1)^{\ddagger}$ & $1.3401 \mathrm{E}+0(7.1751 \mathrm{E}-2)^{\ddagger}$ & $5.3159 \mathrm{E}-1(1.6401 \mathrm{E}-1)$ & $6.6801 \mathrm{E}-1(2.0177 \mathrm{E}-1)$ \\
\hline \multirow{3}{*}{ UDF7 } & SP & $1.8419 \mathrm{E}-1(4.0273 \mathrm{E}-2)^{\ddagger}$ & $1.4078 \mathrm{E}-1(4.9032 \mathrm{E}-2)^{\ddagger}$ & $2.8369 \mathrm{E}-1(4.7337 \mathrm{E}-2)^{\ddagger}$ & $9.6489 \mathrm{E}-2(2.0613 \mathrm{E}-2)$ & 1.2889E-1(5.0211E-2) \\
\hline & MS & 9.9934E-1(7.3516E-4) ${ }^{\dagger}$ & $7.6178 \mathrm{E}-1(5.9074 \mathrm{E}-2)^{\ddagger}$ & $9.5487 \mathrm{E}-1(6.8474 \mathrm{E}-3)^{\ddagger}$ & $9.6654 \mathrm{E}-1(6.6230 \mathrm{E}-2)^{\ddagger}$ & $9.9581 \mathrm{E}-1(5.5058 \mathrm{E}-3)$ \\
\hline & IGD & $5.2447 \mathrm{E}-1(2.2852 \mathrm{E}-2)^{\ddagger}$ & $8.4026 \mathrm{E}-1(6.4416 \mathrm{E}-2)^{\ddagger}$ & $6.6895 \mathrm{E}-1(4.4901 \mathrm{E}-2)^{\ddagger}$ & $6.0373 \mathrm{E}-1(1.4375 \mathrm{E}-1)^{\ddagger}$ & $5.0877 \mathrm{E}-1(4.2250 \mathrm{E}-2)$ \\
\hline
\end{tabular}

$\dagger$ indicates SGEA performs equivalently to the corresponding algorithm.

$\ddagger$ indicates SGEA performs significantly better than the corresponding algorithm. 
TABLE XVI

MEAN AND STANDARD DEVIATION VALUES OF SP METRIC OBTAINED BY FIVE ALGORITHMS

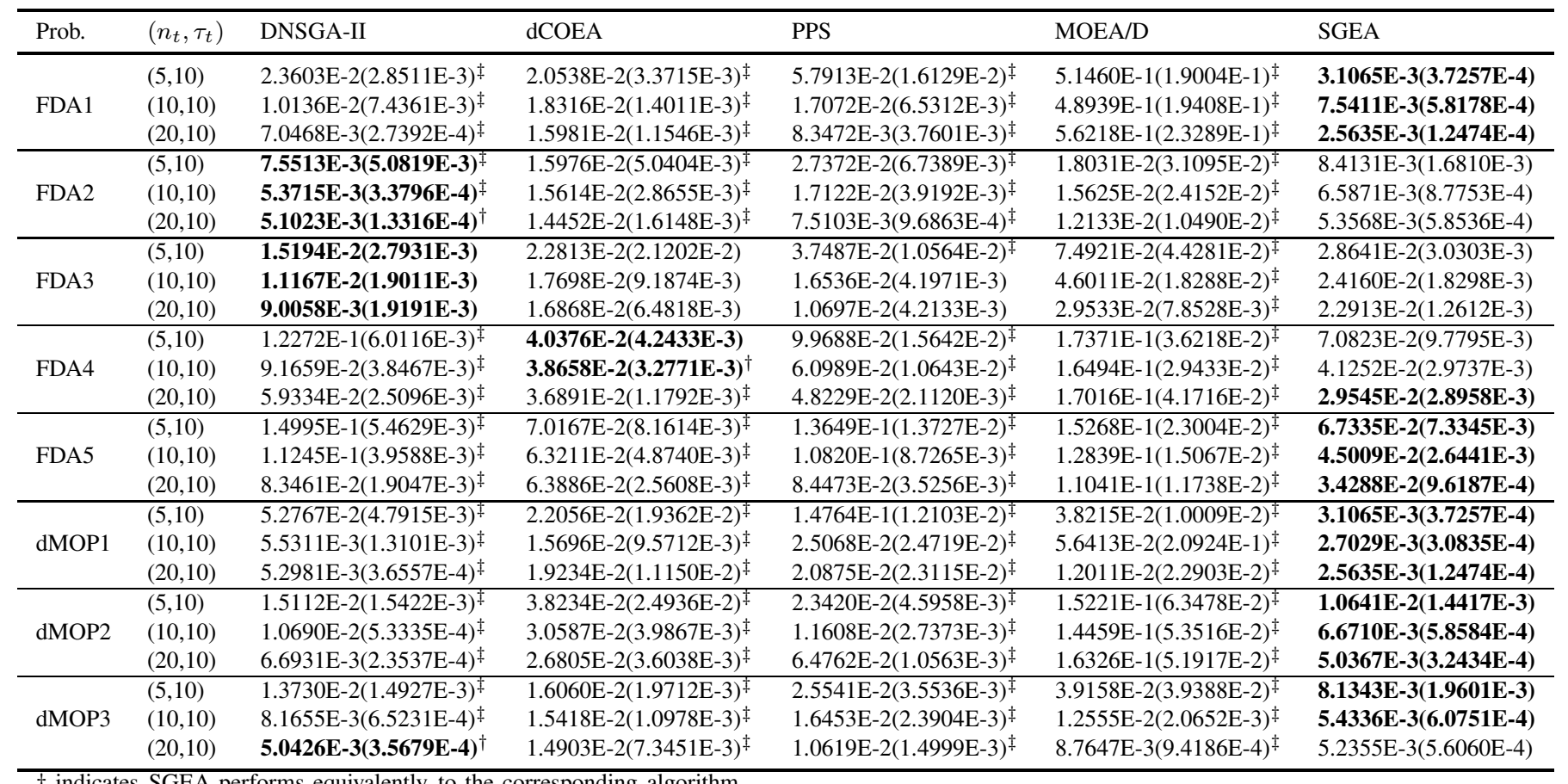

$\dagger$ indicates SGEA performs equivalently to the corresponding algorithm.

$\ddagger$ indicates SGEA performs significantly better than the corresponding algorithm.

TABLE XVII

MEAN AND STANDARD DEVIATION VALUES OF MS METRIC OBTAINED BY FIVE ALGORITHMS

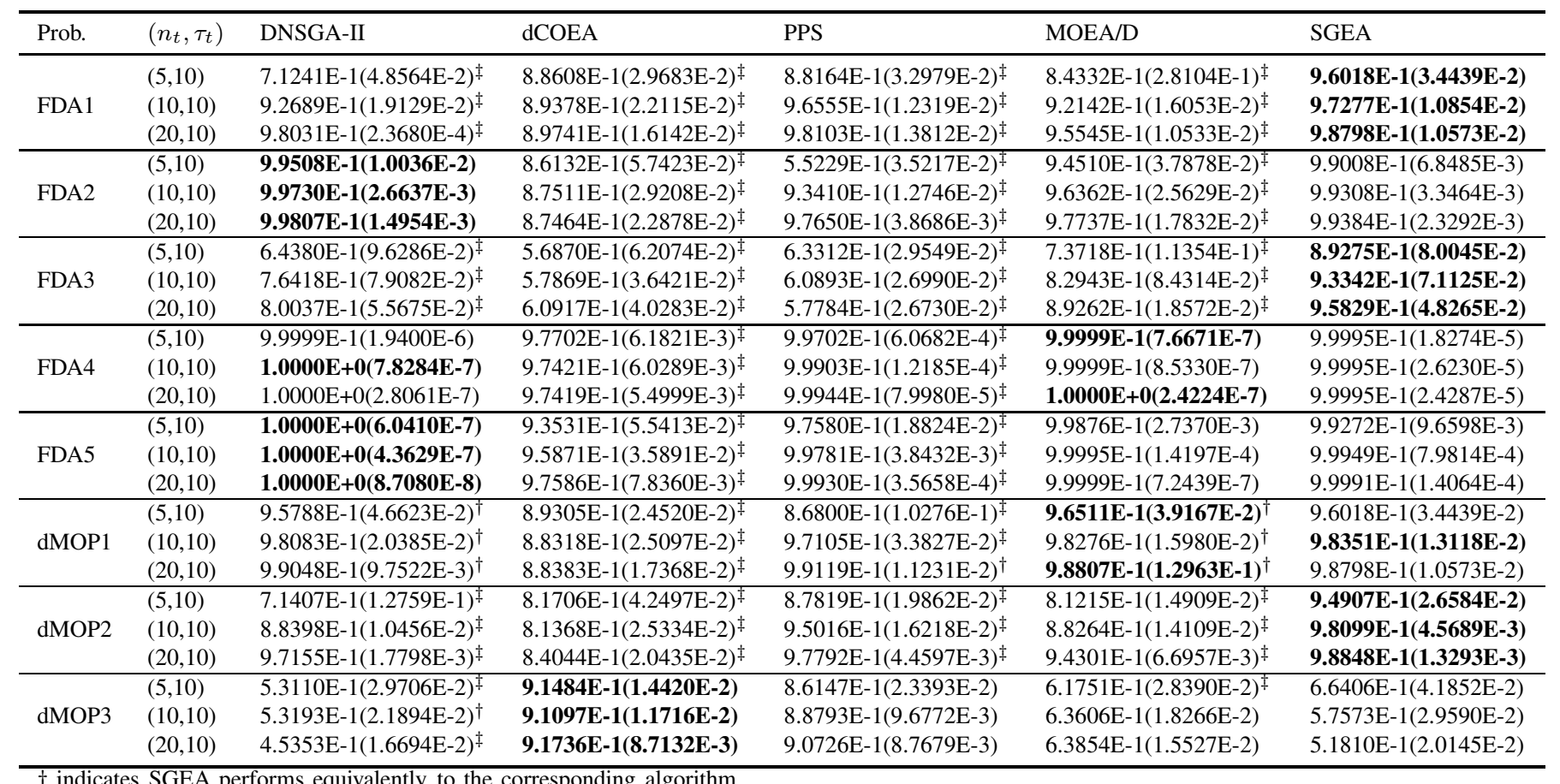

$\dagger$ indicates SGEA performs equivalently to the corresponding algorithm.

$\ddagger$ indicates SGEA performs significantly better than the corresponding algorithm. 
TABLE XVIII

MEAN AND STANDARD DEVIATION VALUES OF IGD METRIC OBTAINED B Y FIVE ALGORITHMS

\begin{tabular}{|c|c|c|c|c|c|c|}
\hline Prob. & $\left(n_{t}, \tau_{t}\right)$ & DNSGA-II & dCOEA & PPS & MOEA/D & SGEA \\
\hline \multirow{3}{*}{ FDA1 } & $(5,10)$ & $5.4897 \mathrm{E}-1(1.0686 \mathrm{E}-1)^{\ddagger}$ & $4.6477 \mathrm{E}-2(1.0304 \mathrm{E}-2)^{\ddagger}$ & $1.8417 \mathrm{E}-1(7.3672 \mathrm{E}-2)^{\ddagger}$ & $3.0228 \mathrm{E}-1(5.1321 \mathrm{E}-2)^{\ddagger}$ & $1.1789 \mathrm{E}-2(8.5757 \mathrm{E}-3)$ \\
\hline & $(10,10)$ & $5.8213 \mathrm{E}-2(3.8909 \mathrm{E}-3)^{\ddagger}$ & $4.1342 \mathrm{E}-2(6.5605 \mathrm{E}-3)^{\ddagger}$ & $4.2736 \mathrm{E}-2(1.9486 \mathrm{E}-2)^{\ddagger}$ & $1.2112 \mathrm{E}-1(1.1879 \mathrm{E}-2)^{\ddagger}$ & $1.4809 \mathrm{E}-2(2.0621 \mathrm{E}-3)$ \\
\hline & $(20,10)$ & $2.0064 \mathrm{E}-2(4.8584 \mathrm{E}-4)^{\ddagger}$ & $3.9106 \mathrm{E}-2(4.6821 \mathrm{E}-3)^{\ddagger}$ & $2.6966 \mathrm{E}-2(3.2638 \mathrm{E}-2)^{\ddagger}$ & $5.2317 \mathrm{E}-2(3.0543 \mathrm{E}-3)^{\ddagger}$ & $6.1478 \mathrm{E}-3(2.7057 \mathrm{E}-3)$ \\
\hline \multirow{3}{*}{ FDA2 } & $(5,10)$ & $2.4801 \mathrm{E}-2(3.4246 \mathrm{E}-3)^{\ddagger}$ & $5.6324 \mathrm{E}-2(6.0436 \mathrm{E}-2)^{\ddagger}$ & $2.9452 \mathrm{E}-1(2.0496 \mathrm{E}-2)^{\mp}$ & $8.3039 \mathrm{E}-2(1.7388 \mathrm{E}-2)^{\ddagger}$ & $1.3540 \mathrm{E}-2(1.4827 \mathrm{E}-3)$ \\
\hline & $(10,10)$ & $1.0805 \mathrm{E}-2(9.0279 \mathrm{E}-4)^{\ddagger}$ & $4.7325 \mathrm{E}-2(3.3605 \mathrm{E}-2)^{\ddagger}$ & $6.3561 \mathrm{E}-2(1.0647 \mathrm{E}-2)^{\ddagger}$ & $3.3894 \mathrm{E}-2(8.8878 \mathrm{E}-3)^{\ddagger}$ & $9.1174 E-3(6.3334 E-4)$ \\
\hline & $(20,10)$ & $7.0108 \mathrm{E}-3(3.6493 \mathrm{E}-4)^{\ddagger}$ & $4.5156 \mathrm{E}-2(2.5766 \mathrm{E}-2)^{\ddagger}$ & $2.4352 \mathrm{E}-2(5.0433 \mathrm{E}-3)^{\ddagger}$ & $1.6503 \mathrm{E}-2(4.0957 \mathrm{E}-3)^{\ddagger}$ & $6.9199 \mathrm{E}-3(3.6482 \mathrm{E}-4)$ \\
\hline \multirow{3}{*}{ FDA3 } & $(5,10)$ & $2.3102 \mathrm{E}-1(4.7984 \mathrm{E}-2)^{\ddagger}$ & $2.1511 \mathrm{E}-1(5.3849 \mathrm{E}-2)^{\ddagger}$ & $2.9905 \mathrm{E}-1(4.7499 \mathrm{E}-2)^{\ddagger}$ & $2.1691 \mathrm{E}-1(2.6667 \mathrm{E}-2)^{\ddagger}$ & $5.5370 \mathrm{E}-2(3.5390 \mathrm{E}-2)$ \\
\hline & $(10,10)$ & $1.0821 \mathrm{E}-1(3.3153 \mathrm{E}-2)^{\ddagger}$ & $1.9526 \mathrm{E}-1(3.2807 \mathrm{E}-2)^{\ddagger}$ & $2.1946 \mathrm{E}-1(1.8132 \mathrm{E}-2)^{\ddagger}$ & $1.3090 \mathrm{E}-1(2.5891 \mathrm{E}-2)^{\ddagger}$ & 4.0371E-2(2.9061E-2) \\
\hline & $(20,10)$ & $8.7141 \mathrm{E}-2(2.3225 \mathrm{E}-2)^{\ddagger}$ & $1.7092 \mathrm{E}-1(2.9548 \mathrm{E}-2)^{\ddagger}$ & $2.1572 \mathrm{E}-1(1.6693 \mathrm{E}-2)^{\ddagger}$ & $6.4143 \mathrm{E}-2(5.9047 \mathrm{E}-3)^{\ddagger}$ & $3.2264 \mathrm{E}-2(2.0559 \mathrm{E}-2)$ \\
\hline \multirow{3}{*}{ FDA4 } & $(5,10)$ & $1.4121 \mathrm{E}+0(1.3105 \mathrm{E}-1)^{\ddagger}$ & 1.2435E-1(5.3278E-3) & $3.1747 \mathrm{E}-1(4.9315 \mathrm{E}-2)$ & $1.2436 \mathrm{E}+0(1.4598 \mathrm{E}-1)^{\ddagger}$ & 3.7517E-1(6.7244E-2) \\
\hline & $(10,10)$ & $7.6342 \mathrm{E}-1(4.4885 \mathrm{E}-2)^{\ddagger}$ & $1.2450 \mathrm{E}-1(4.5799 \mathrm{E}-3)$ & $2.1151 \mathrm{E}-1(2.0215 \mathrm{E}-2)^{\ddagger}$ & $5.7713 \mathrm{E}-1(5.4877 \mathrm{E}-2)^{\ddagger}$ & $1.8302 \mathrm{E}-1(6.6613 \mathrm{E}-3)$ \\
\hline & $(20,10)$ & $2.9918 \mathrm{E}-1(1.8309 \mathrm{E}-1)^{\ddagger}$ & $1.2169 \mathrm{E}-1(2.8761 \mathrm{E}-3)$ & $1.7864 \mathrm{E}-1(4.3912 \mathrm{E}-3)^{\ddagger}$ & $2.4916 \mathrm{E}-1(1.5594 \mathrm{E}-2)^{\ddagger}$ & $1.4241 \mathrm{E}-1(2.5387 \mathrm{E}-3)$ \\
\hline \multirow{3}{*}{ FDA5 } & $(5,10)$ & $1.7221 \mathrm{E}+0(9.3446 \mathrm{E}-2)^{\ddagger}$ & 3.8319E-1(7.0915E-2) & $6.2954 \mathrm{E}-1(7.5622 \mathrm{E}-2)^{\ddagger}$ & $1.4674 \mathrm{E}+0(1.1638 \mathrm{E}-1)^{\ddagger}$ & 4.7733E-1(4.3702E-2) \\
\hline & $(10,10)$ & $1.0239 \mathrm{E}+0(5.4901 \mathrm{E}-2)^{\ddagger}$ & $3.6283 \mathrm{E}-1(4.0631 \mathrm{E}-2)^{\dagger}$ & $4.8031 \mathrm{E}-1(3.5207 \mathrm{E}-2)^{\ddagger}$ & $8.1980 \mathrm{E}-1(6.0501 \mathrm{E}-2)^{\ddagger}$ & $3.6260 \mathrm{E}-1(8.5854 \mathrm{E}-3)$ \\
\hline & $(20,10)$ & $5.4101 \mathrm{E}-1(1.7738 \mathrm{E}-2)^{\ddagger}$ & $3.3554 \mathrm{E}-1(1.5279 \mathrm{E}-2)^{\dagger}$ & $3.8012 \mathrm{E}-1(1.7546 \mathrm{E}-2)^{\ddagger}$ & $4.4964 \mathrm{E}-1(1.3514 \mathrm{E}-2)^{\ddagger}$ & $3.2537 \mathrm{E}-1(2.5246 \mathrm{E}-3)$ \\
\hline \multirow{3}{*}{ dMOP1 } & $(5,10)$ & $2.0159 \mathrm{E}-2(2.3252 \mathrm{E}-2)^{\ddagger}$ & $3.7094 \mathrm{E}-2(7.2991 \mathrm{E}-3)^{\ddagger}$ & $1.0484 \mathrm{E}+0(1.0767 \mathrm{E}+0)^{\ddagger}$ & $1.4129 \mathrm{E}-2(9.1741 \mathrm{E}-3)^{\ddagger}$ & $1.1789 \mathrm{E}-2(8.5757 \mathrm{E}-3)$ \\
\hline & $(10,10)$ & $8.8338 \mathrm{E}-3(5.0638 \mathrm{E}-3)^{\ddagger}$ & $3.9362 \mathrm{E}-2(6.2467 \mathrm{E}-3)^{\ddagger}$ & $5.0918 \mathrm{E}-2(9.3741 \mathrm{E}-2)^{\ddagger}$ & $9.3916 \mathrm{E}-3(4.3151 \mathrm{E}-3)^{\ddagger}$ & $6.5411 \mathrm{E}-3(3.0256 \mathrm{E}-3)$ \\
\hline & $(20,10)$ & $6.6614 \mathrm{E}-3(2.3015 \mathrm{E}-3)^{\ddagger}$ & $3.9089 \mathrm{E}-2(4.1774 \mathrm{E}-3)^{\ddagger}$ & $1.8599 \mathrm{E}-2(4.8021 \mathrm{E}-2)^{\ddagger}$ & $7.2666 \mathrm{E}-3(3.1716 \mathrm{E}-3)^{\ddagger}$ & $6.1478 \mathrm{E}-3(2.7057 \mathrm{E}-3)$ \\
\hline \multirow{3}{*}{ dMOP2 } & $(5,10)$ & $6.3388 \mathrm{E}-1(8.4149 \mathrm{E}-2)^{\ddagger}$ & $6.8629 \mathrm{E}-2(1.4197 \mathrm{E}-2)^{\ddagger}$ & $1.4011 \mathrm{E}-1(4.8219 \mathrm{E}-2)^{\ddagger}$ & $4.2265 \mathrm{E}-1(3.7463 \mathrm{E}-2)^{\ddagger}$ & $2.4477 \mathrm{E}-2(7.2375 \mathrm{E}-3)$ \\
\hline & $(10,10)$ & $1.1864 \mathrm{E}-1(9.4674 \mathrm{E}-3)^{\ddagger}$ & $7.3299 \mathrm{E}-2(8.9931 \mathrm{E}-3)^{\ddagger}$ & $4.2819 \mathrm{E}-1(1.7367 \mathrm{E}-2)^{\ddagger}$ & $1.8898 \mathrm{E}-1(1.9146 \mathrm{E}-2)^{\ddagger}$ & $1.2148 \mathrm{E}-2(5.7205 \mathrm{E}-4)$ \\
\hline & $(20,10)$ & $2.3878 \mathrm{E}-2(7.8330 \mathrm{E}-4)^{\ddagger}$ & $6.1763 \mathrm{E}-2(6.0134 \mathrm{E}-3)^{\ddagger}$ & $1.7442 \mathrm{E}-2(3.6816 \mathrm{E}-3)^{\ddagger}$ & $7.5743 \mathrm{E}-2(4.8974 \mathrm{E}-3)^{\ddagger}$ & $9.2375 \mathrm{E}-3(2.5852 \mathrm{E}-4)$ \\
\hline \multirow{3}{*}{ dMOP3 } & $(5,10)$ & $4.9094 \mathrm{E}-1(4.2572 \mathrm{E}-2)^{\ddagger}$ & 2.9953E-2(3.5438E-3) & $1.6803 \mathrm{E}-1(2.5591 \mathrm{E}-2)^{\ddagger}$ & $2.8448 \mathrm{E}-1(2.4158 \mathrm{E}-2)^{\ddagger}$ & $1.0476 \mathrm{E}-1(1.6017 \mathrm{E}-2)$ \\
\hline & $(10,10)$ & $2.0009 \mathrm{E}-1(1.5091 \mathrm{E}-2)^{\ddagger}$ & $2.9589 \mathrm{E}-2(2.4806 \mathrm{E}-3)$ & $1.1367 \mathrm{E}-1(1.2092 \mathrm{E}-2)$ & $1.6853 \mathrm{E}-1(1.0496 \mathrm{E}-2)^{\ddagger}$ & $1.3248 \mathrm{E}-1(1.3627 \mathrm{E}-2)$ \\
\hline & $(20,10)$ & $1.9094 \mathrm{E}-1(9.8024 \mathrm{E}-2)^{\ddagger}$ & $3.1686 \mathrm{E}-2(2.6402 \mathrm{E}-3)$ & $8.8415 \mathrm{E}-2(6.1998 \mathrm{E}-3)$ & $1.1595 \mathrm{E}-1(3.9111 \mathrm{E}-3)$ & $1.5072 \mathrm{E}-1(9.1480 \mathrm{E}-3)$ \\
\hline
\end{tabular}

$\dagger$ indicates SGEA performs equivalently to the corresponding algorithm.

$\ddagger$ indicates SGEA performs significantly better than the corresponding algorithm. 